Science and Mathematics Education Centre

\title{
An Investigation into the Learning Environments of Blended Delivery (e-learning and classroom) in a Tertiary Environment
}

David J. E. Skelton

This thesis is presented as part of the requirements for the

Degree of Doctor of Science Education

of

Curtin University of Technology

November 2007 


\section{DECLARATION}

To the best of my knowledge and belief this thesis contains no material previously published by any other person except where due acknowledgment has been made. This thesis contains no material which has been accepted for the award of any other degree or diploma in any university.

Date 


\begin{abstract}
This thesis describes research investigating the learning environment of tertiary students undertaking their studies through a mixture of online learning management systems and traditional tertiary classroom delivery. A review of the literature examined traditional learning environments, pure online virtual environments and more recent literature pertaining to a blended environment. The examination of student and staff perceptions of learning environments in different contexts served to generate recommendations to help tertiary teachers optimise online and traditional teaching practices within a mixed-mode environment. Students' experiences of their learning environment were discovered through quantitative and qualitative methods. Quantitative data on students' experiences were gathered by using an adapted version of the Web-based Learning Environment Instrument (WEBLEI). Qualitative data on students' experiences were collected by discussion questions added to the WEBLEI survey. Qualitative data on the use of online and blended learning environment experiences by tertiary staff were gathered by email and supplementary interviews. The study synthesised results from these multiple sources within a tertiary institute environment and made recommendations and gave insight into optimal blended learning environments within the tertiary sector. Overall, the study provided a perspective on the psychology and strategic view of the learning environment for the future tertiary institute.
\end{abstract}




\section{ACKNOWLEDGEMENTS}

This thesis represents the end of a long journey of study that started in 1992 with my beginning study in a graduate information systems diploma, then in 2002 completing a Masters degree in information systems. Working through the science education doctorate at the Science and Mathematics Education Centre at Curtin University of Technology has allowed me to learn professional insight into my role as a tertiary lecturer in information technology as well as guide me through a major research study within the tertiary sector. This thesis has allowed me to explore and combine my teaching specialist area of information technology and the emerging online environment combined with the psychological and organisational viewpoint of the learning environment.

I would like to extend my thanks to my supervisor Dr. Darrell Fisher for his support and communication throughout this thesis. As a distance student located in Napier, New Zealand the block courses (institutes) delivered by the Curtin SMEC team were very helpful. The personal contact at the New Zealand courses was very motivating for a distance student. 


\section{TABLE OF CONTENTS}

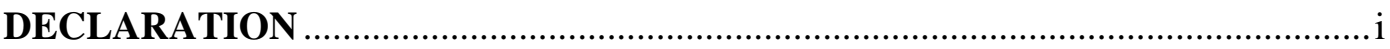

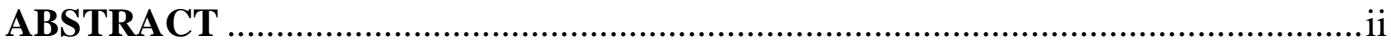

ACKNOWLEDGEMENTS .............................................................................ii

LIST OF TABLES................................................................................................ viii

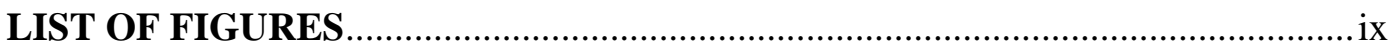

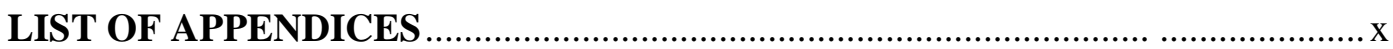

\section{CHAPTER 1: INTRODUCTION}

1.1. ORIGIN OF THIS THESIS.............................................................................

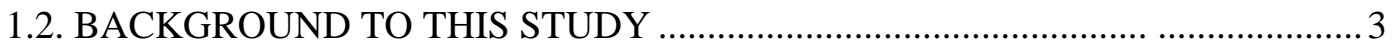

1.3. GENERAL AIM AND OBJECTIVES .........................................................

1.4. SIGNIFICANCE OF THIS STUDY …………………………................... 6

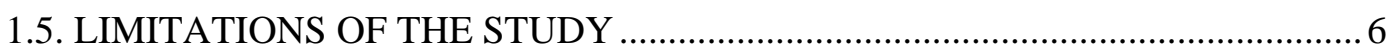

1.6. OVERVIEW OF THE METHODOLOGY ........................................................

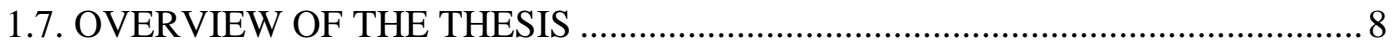

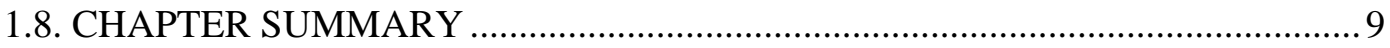

\section{CHAPTER 2: LITERATURE REVIEW}

2.1. INTRODUCTION AND OVERVIEW ………………………………………..... 10

2.2. THEORETICAL FRAMEWORK …………………………………………..... 11

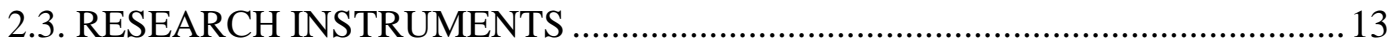

2.4. THE ONLINE LEARNING ENVIRONMENT...................................................14

2.4.1. Concerns about online learning .................................................................... 22

2.4.2. What constitutes a course? Pedagogical and delivery changes ....................23

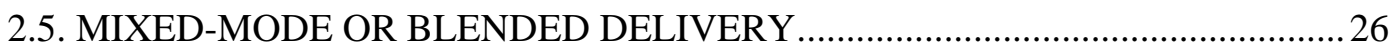

2.5.1. The influence of pedagogy on the blended environment................................33

2.6. LIMITATIONS OF IDEAL LEARNING ENVIRONMENTS: CONTEXT OF THE MODERN MEDIA ENVIRONMENT …………………………………........ 35

2.7. HISTORIC AND TECHNOLOGY ISSUES ......................................................... 38

2.8. CONCEPTUAL FRAMEWORK FOR EVALUATION OF THE ONLINE

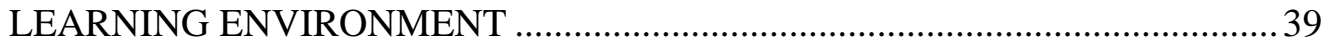


2.9. RELATING TO THEORIES IN THE FIELD OF LEARNING ENVIRONMENTS, E-LEARNING AND MIXED-MODE DELIVERY .......... 40

2.10. OTHER STUDIES EVALUATING LEARNING ENVIRONMENTS 41

2.11. THE EFFECT OF EMERGING TECHNOLOGIES ON THE ONLINE ENVIRONMENT 45

2.12 NEW ZEALAND E-LEARNING PROJECTS ................................................. 48

2.13. BLENDED EXAMPLES FROM E-BUSINESS …............................................ 49

2.14. LITERATURE REVIEW SUMMARY .50

\section{CHAPTER 3: METHODOLOGY}

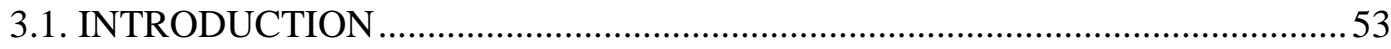

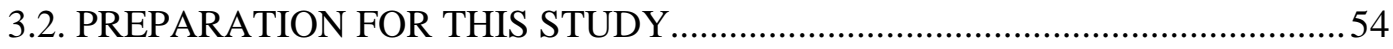

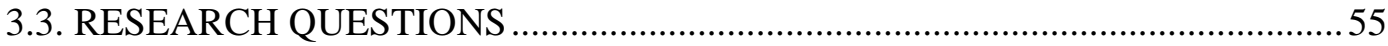

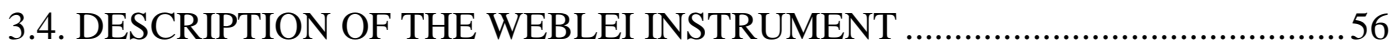

3.5. SELECTION AND DESCRIPTION OF THE SAMPLE ......................................... 58

3.6. JUSTIFICATION OF THE ADAPTED WEBLEI FOR THE EIT

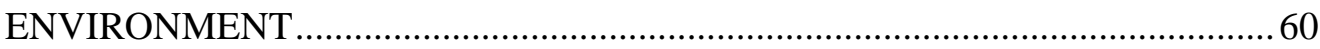

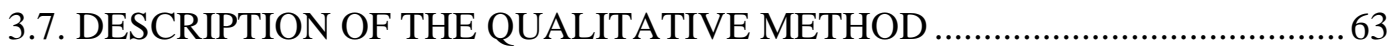

3.7.1. Justification of including supplementary qualitative approaches ................63

3.7.2. Collection of student qualitative data .....................................................63

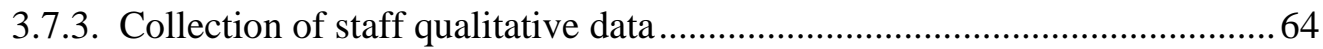

3.8. DATA COLLECTION FOR WEBLEI QUANTITATIVE DATA .........................65

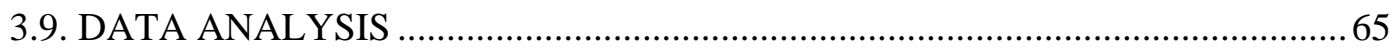

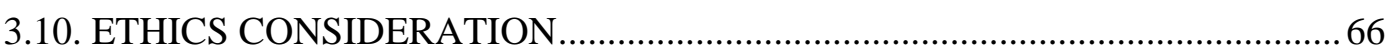

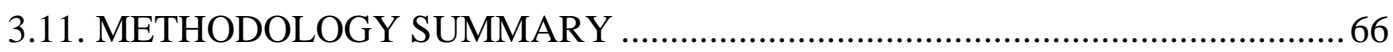

\section{CHAPTER 4: VALIDATION AND APPLICATION OF THE WEBLEI}

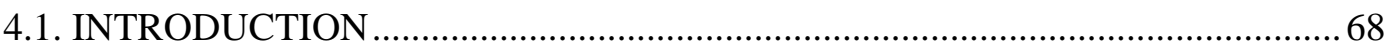

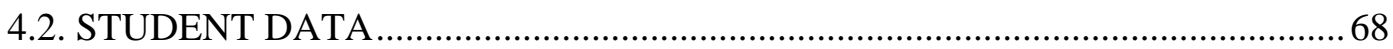

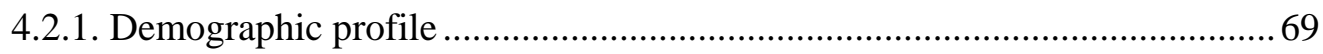

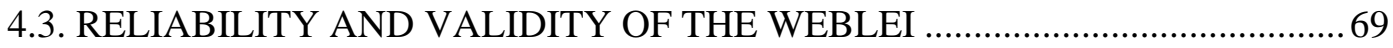

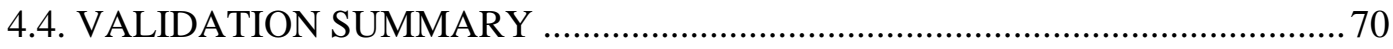




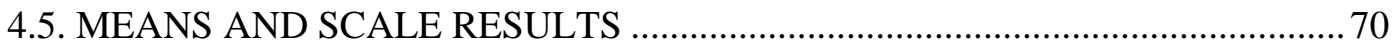

4.6. GENDER DIFFERENCES IN THE WEBLEI RESPONSES .............................. 72

4.7. YEAR DIFFERENCES IN WEBLEI RESULTS .............................................. 74

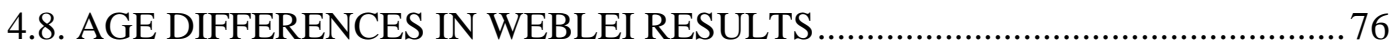

4.9. OVERALL RESULTS FOR ALL WEBLEI QUESTIONS .................................. 78

4.9.1. Access Scale - discussion on individual questions .................................. 79

4.9.2. Interaction Scale - discussion on individual statements............................ 79

4.9.3. Response Scale - discussion on individual statements .............................. 81

4.9.4. Results Scale - discussion on individual statements ................................82

4.9.5. General comments on the overall WEBLEI results .................................... 83

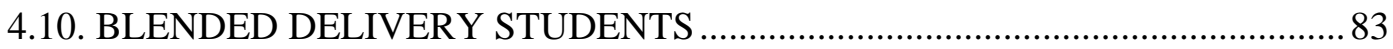

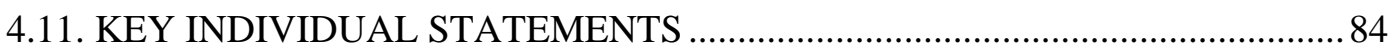

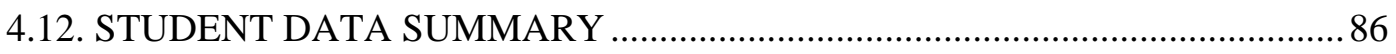

\section{CHAPTER 5: QUALITATIVE DATA FROM STUDENTS}

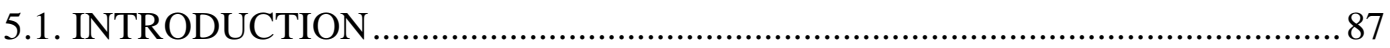

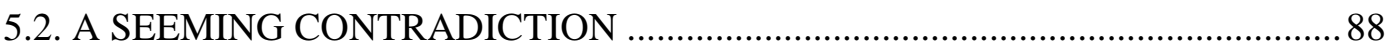

5.3. FIVE DISCUSSION QUESTIONS ATTACHED TO THE WEBLEI................... 88

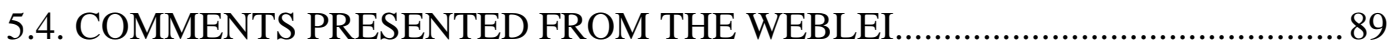

5.4.1. Group 1: Blended Preference.................................................................... 89

5.4.2. Group 2: Online Preference …………......................................................... 94

5.4.3. Group 3: Traditional Classes Preference .................................................... 98

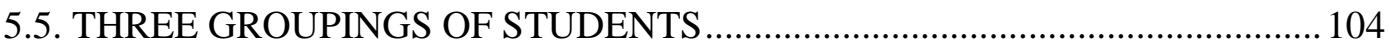

5.6. SUMMARY OF STUDENT COMMENTS …..................................................... 104

\section{CHAPTER 6: TERTIARY STAFF VIEW OF THE BLENDED ENVIRONMENT}

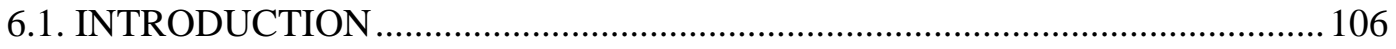

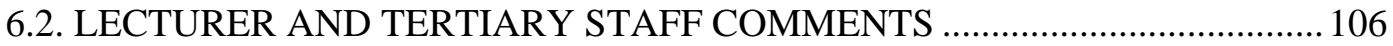

6.3. RESULTS OF INTERVIEW WITH ACADEMIC MANAGER AND

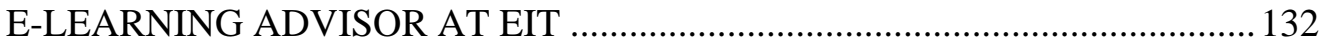

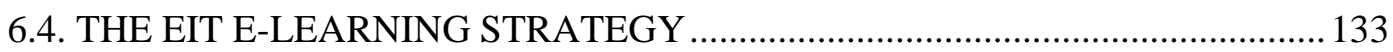

6.4.1. Gradients of utilisation of the LMS by staff .......................................... 135 
6.4.2. The disintermediation of the teaching and provision role

\section{CHAPTER 7: CONCLUSIONS}

7.1. INTRODUCTION

7.2. MAIN FINDINGS OF THE STUDY

7.2.1. Research Question 1: Are modern tertiary students experiencing a sense of being in a positive, encouraging learning environment?

7.2.2. Research Question 2: Has the recent addition of the LMS really enhanced the overall learning environment from the students’ perspective? 143

7.2.3. Research Question 3: What elements help construct an ideal or optimal blended learning environment in a tertiary setting?

7.2.4. Research Question 4: How can the best components of online e-learning be combined with the best components of the traditional 'bricks and mortar' classroom learning environments? Is there an ideal mix of the two types of environments?

7.2.5. Research Question 5: Does e-learning in some forms or implementations actually damage the 'real-world' learning environment? 146

7.2.6. Research Question 6: Are we simply forced by the trends and rise of Internet activity to 'jump on board' regardless of the cost to academic quality and sense of community? 147

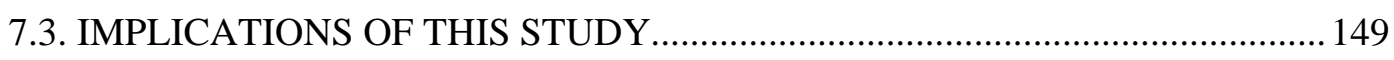

7.3.1. Optimal blended learning environments ................................................ 151

7.4. FUTURE PROSPECTS FOR THIS RESEARCH ........................................... 154

7.5. SUMMARY AND CONCLUDING REMARKS ................................................ 156

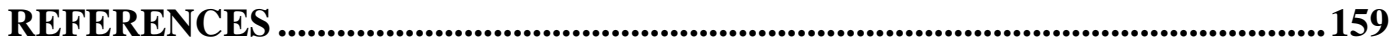




\section{LIST OF TABLES}

Table

Page

Table 3.1 Composition of Student Data Sample

.59

Table 3.2 Adapted Blended-mode WEBLEI Scales and Items

61

Table 4.1 Cronbach Alpha Reliability and Discriminant Validity

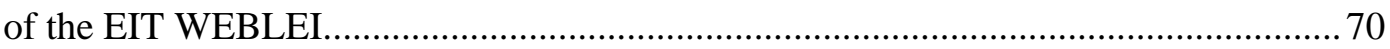

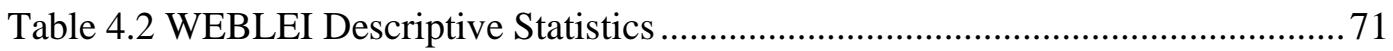

Table 4.3 Scale Means for Male and Female EIT Students’ scores on WEBLEI...........73

Table 4.4 WEBLEI Results for Year Levels of EIT Students........................................74

Table 4.5 WEBLEI Results for Age Ranges of EIT Students.................................... 77

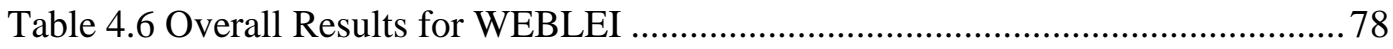

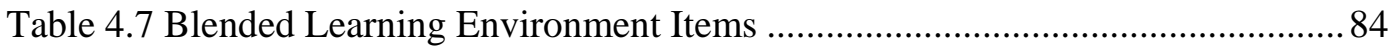

Table 6.1 Translation of Traditional Teaching Processes ......................................... 135

Table 7.1 Elements of a desirable Blended/Flexible learning environment for the New Zealand ITP sector.................................................................................... 150 


\section{LIST OF FIGURES}

Figure

Page

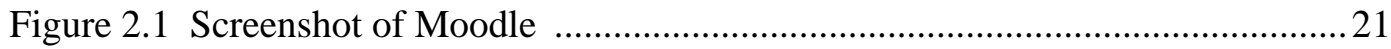

Figure 3.1 WEBLEI scales (Chang \& Fisher, 2003) .....................................................57

Figure 7.1 Blended Learning on-campus (Seely-Brown, 2007)................................153 


\section{LIST OF APPENDICES}

Appendix Page

Appendix A. Web-based Learning Environment Instrument …............................ 170

Appendix B. Staff Email Discussion Questions...................................................175

Appendix C. The Eastern Institute of Technology E-learning Strategy ......................177 


\section{CHAPTER 1}

\section{INTRODUCTION}

“Alone we can do so little; together we can do so much.” Helen Keller

\subsection{ORIGIN OF THIS THESIS}

This thesis has allowed me to explore the ideas, motivation and effectiveness of various modes of teaching and learning environments currently in effect in the tertiary sector. As an information technology lecturer at the Eastern Institute of Technology (EIT) in New Zealand, I observed the advancing tide of online learning mechanisms alongside the strength of local classroom environments particularly for technology programmes. I questioned whether the environment of classroom interaction and positive atmosphere could be more effectively 'mixed' with online features and e-learning presence as a deliberate strategy. Much of the current use of learning management systems, such as Moodle and Blackboard, seemed to be as a repository for documents and lecture notes with little thought as to the integration with what was happening in the timetabled lectures, tutorials and laboratories.

For a medium sized institute of technology and polytechnic (ITP) in New Zealand with a local monopoly in a population base of 150,000 within a defined geographic region such as EIT, too strong a move towards placing entire courses online may have a negative impact with a loss of geographical uniqueness. At the centre of this argument is the ideal learning environment. Viewing the overall learning environments that are currently being experienced by typical tertiary students in all aspects was thought to offer insight into the concept of the ideal learning environment. Universities and polytechnics currently have an outlined strategy for e-learning but may be losing sight of the overall learning environment and may not be taking all the effects into account. Students spend 
many hours within their learning environments, for example, a computing student at EIT may spend three years involving at least 3,600 hours studying in physical classrooms, laboratories, computer rooms, online and at home. Are these students experiencing a sense of being in a positive, encouraging learning environment?

Has the recent addition of the learning management systems (LMS) such as Moodle, Blackboard, and WebCT within most tertiary courses and programmes really enhanced the overall learning environments from the students' perspective? Fraser (2001) points out that much assessment of academic achievement does not provide a full overview of the educational process and effectiveness of the learning environments that the student has experienced. The purpose of any educational experience should be more than delivering content and achieving formal assessment outcomes (Fraser, 2001). The experience in reality today includes places (virtual and physical), laboratories, lecture theatres, tutorial rooms, offices, libraries, learning assistance centres, computer-based systems and many varieties of Internet-based learning content systems. “Teachers often speak of a classroom's climate, environment, atmosphere or ambience. They consider it to be both important in its own right and influential in terms of student learning” (Fraser, 2001, p. 3). The teacher can affect the entire atmosphere of any classroom in a positive or negative manner. One special challenge for online teachers is the degree of influence they can have, within a learning management system, on the 'atmosphere' of the virtual meeting place. An additional complexity for the teacher in the blended environment is to balance the mix of timetabled campus classes and the activity online including the choice and quantity of e-learning material available on the Internet. Lecturers aim "to create a learning atmosphere that sustains motivation, promotes self-initiation and encourages collaboration” (Fetaji, 2006, p. 4). A possible danger of pure online elearning and fully flexible delivery programmes is a diminishing of the influence of the teacher or lecturer over the informal atmosphere of the learning environment. The inclusion of partially-qualified and lower-paid staff assisting in the delivery of flexible or online programmes also raises the issue of the qualified teacher being kept at arms length from the essential daily process of the learning 
environment. This relates to the efficiency and cost reduction business reasons at least partially driving the move to e-learning.

There are also unofficial opportunities for lecturers and staff to interact with tertiary students and these interactions also contribute to the overall learning environment atmosphere. Responding to a student email with a warm friendly tone, speaking briefly to students on campus or in the halls outside the lecture rooms and taking students to seminars or industry events to meet industry representatives all contribute to the atmosphere of the student's experience of the institute's learning environment. These lecturer-student interactions may also hold some clues about student behaviour and response to the environment which we seek to create. Within this context, lecturers at EIT report that more time can be spent on emailing and instructing individual students on flexible programmes than to manage a traditional campus based course. Hence, the efficiency arguments, although valid for overcoming geographical constraints, are not necessarily valid for time management aspects when comparing online and traditional programmes for local students.

This study outlined an investigation into the learning environments of blended delivery (e-learning and classroom) in an information technology tertiary environment. The study is unique in that it does not focus solely on pure online learning or purely on the physical learning environment but sought to evaluate student preferences and experiences from aspects of both of these environment types. This study used a sample of 151 tertiary students at the Eastern Institute of Technology and incorporated discussion responses from a range of EIT staff.

\subsection{BACKGROUND TO THIS STUDY}

The New Zealand ITP sector has evolved from the 1970s as community colleges providing purely vocational training, particularly in the trades area, through to the current situation of being degree-granting institutions with multiple programmes. The Eastern Institute of Technology is representative of a wide spectrum of the tertiary education environment in New Zealand as it is involved in programmes from community computing through to Masters Degrees. 
The online e-learning revolution has affected most universities, colleges and polytechnics world-wide. Most tertiary degree and diploma programmes are supported at some level by learning management systems which provide learning materials and interaction accessed via the Internet or other media.

The forces driving this change are multiple, from administrators seeking early competitive advantages, IT-literate teachers experimenting with available technology, emerging Internet technologies, online software development (for example, Moodle, Blackboard, and WebCT), student demands for flexibility including distance education, and governmental demands for economic rationalisation, student flexibility, and general upskilling of all citizens.

Fraser (2002) warns that although the integration of ICT into the learning environment is becoming a major part of teaching institutions, it is important that integration is accompanied by careful research and evaluation of the effectiveness of ICT-enabled diverse learning environments.

EIT is attempting to set out aims and goals for implementing e-learning where possible in any given programme. Recently, EIT participated in an assessment of its' "eCapability” which attempted to assess four areas; leadership, organisational culture, technology infrastructure, and staff capability within the context of eleaning capability. This survey combined with an in-house e-learning specialist advisor and other e-learning initiatives has raised awareness across all staff at EIT. This study of the optimal blended environment may be of some use in setting an institutional vision of the future blended learning environment and broaden the reception of newer flexible delivery initiatives.

\subsection{GENERAL AIM AND OBJECTIVES}

The general aim of this thesis and overall study was to analyse tertiary students' experiences and satisfaction with various aspects of the online learning environments together with their experience of the campus learning environment features. This general aim was thought to be able to produce some guidelines and blueprints for an ideal combination of newly emerging learning environments 
blended with traditional environments based on this analysis. It was also thought that synthesising the student survey data, with discussion comments from tertiary students and from tertiary staff, would further refine the research foundation for the proposed blended learning environment model.

The work of Walberg (1976) and Moos (1974) led to the development of a variety of learning environment instruments. The various types of learning environment instruments have similar design principles, with broad scales measuring student perceptions in each broad area. The Web-based Learning Environment Instrument (WEBLEI) (Chang \& Fisher, 1998) was developed to gather quantitative data on students' experience of e-learning systems in tertiary environments (Chandra \& Fisher, 2006).

As part of this evaluation, an adapted Web-Based Learning Environment Instrument (WEBLEI) survey was administered to a sample of tertiary business and information technology students at a New Zealand institute of technology (Eastern Institute of Technology).

The objectives of the research were to:

1. provide further confirmation of the WEBLEI in terms of its appropriateness within the tertiary environment and usefulness for evaluation of online and physical learning environments;

2. investigate student experiences and perceptions of learning environment factors within the online environment;

3. investigate student experiences and perceptions of learning environment features within the traditional environment;

4. investigate associations between gender, age, level of study, IT and student learning environment preferences; and

5. background the quantitative data with descriptive comments from the students and tertiary staff to provide a further qualitative foundation for a recommended mix for the blended learning environment. 


\subsection{SIGNIFICANCE OF THE STUDY}

In order for tertiary institutes to create warm, friendly learning environments and to effectively utilise the online learning environment more consideration will need to be given to the ideal blended situation. Strategically, a pure online environment may undermine the geographical uniqueness of many small to midsized institutes of technology and polytechnics and universities in New Zealand. Any serious consideration of the learning environment for the future must attempt to reconcile the rapid growth of the online e-learning environment and the strong history of real-world environments.

Tertiary institutes and universities that fully embrace online e-learning without due regard to the effects on the traditional learning environments which students still appreciate and rely on, may risk imbalance in their overall learning environment. Little data have yet been gathered or examined as to the flow-on effect on more traditional courses at higher levels of the increasing flexible delivery programmes at the lower levels in the tertiary sector. Therefore, this study takes a unique look at the cross-channel effects of different learning environments.

\subsection{LIMITATIONS OF THE STUDY}

The sample for this study comprised approximately $50 \%$ of full-time students in the Business and IT Faculty at EIT. The sample size, and the fact that only one institution was sampled, limits to some degree what can be extrapolated to the New Zealand or Australian tertiary sector. Comments from the students and staff that were recorded were reasonably open-ended and these opinions may not be fully representative across other Faculties or other tertiary institutions. The students involved with the study were primarily campus-based traditional students who were not totally dependant on the e-learning systems at EIT, however they all had access to the EIT online learning management system called Moodle. 
EIT is still in a pioneering phase of implementing new e-learning, online and flexible delivery programmes so staff may not have a full awareness of all the technical features and elements that could be utilised in an ideal blended environment.

A reasonable balance of gender and age differences was achieved; however no analysis was undertaken of Maori or Pacific Island students within the student respondents. A small number of WEBLEI surveys were only partially completed by the respondents so these were removed from the SPSS analysis data to increase the reliability of the statistics.

Although this study was limited to one tertiary institute, the study techniques and general case study approach for investigating blended learning environment approaches could in future be undertaken on a multiple case study basis including several tertiary institutes in New Zealand and Australia.

\subsection{OVERVIEW OF THE METHODOLOGY}

While the initial research component of this study involved a quantitative survey instrument, the adapted WEBLEI, this research also utilised case study techniques to combine qualitative and quantitative methods of data collection and analysis.

The WEBLEI included some discussion questions for the student respondents in addition to the quantitative questions. Teaching staff were also invited to comment on the idealised blended learning environment concept and various EIT initiatives in teaching and learning as well as e-learning committees were recorded and discussed.

The main survey instrument was administered with the cooperation of several lecturers within the Faculty of Business and Computing at EIT. The surveys were distributed to students within classes and were collected by lecturers. Some explanation about the study was given to the students to ensure the students were aware that the surveys were not part of the EIT academic evaluation process. 
Approximately $50 \%$ of the available Faculty students attending campus courses at EIT responded to the survey.

Data collection included 151 completed and returned surveys which were manually entered into the SPSS statistical software. Data analysis was undertaken within SPSS reporting data on the four main scales of the survey instrument, and analysing differences within the student sample group.

\subsection{OVERVIEW OF THE THESIS}

This thesis consists of seven chapters and three appendices. This first chapter has introduced and overviewed the origin and concepts leading to the study, and provides a brief description of the methodology along with the significance of the study.

Chapter 1, the origin of this thesis, explores the concept of the blended learning environment as experienced by the author in the tertiary sector in New Zealand. The study is set in the background of the Eastern Institute of Technology, New Zealand, and in the general state of tertiary education learning environments globally.

Chapter 2 reviews a wide range of literature pertaining to general learning environment research, online learning and the WEBLEI questionnaire evolution. The evolution of the learning environment preceded the advent of online elearning and still has an overall influence on the blended teaching delivery mechanisms. The influence of emerging technology and e-business development in industry is also discussed.

Chapter 3 describes the methodology used in the study including the research questions, sample and measures used. A justification is shown for the adaptation of the WEBLEI survey instrument. The additional qualitative methods involving students and staff were also described. 
Chapter 4 completes the validation for the WEBLEI then presents the student data with the preferences within the e-learning environment. Key indicators are drawn from the data which will form the basis of the optimal model proposed for the blended environment. The chapter also examines the student outcome variables and attempts to draw some statistical understandings from the WEBLEI data. Explanations for differences between student groups are suggested along with explanations of preferences within the blended learning environment.

Chapter 5 groups together comments from the student surveys and summarises these qualitative data. Students express clear preferences for their ideal mode of learning with three distinct groups of students emerging from these data.

Chapter 6 allows reflections from lecturers and teaching staff at EIT to influence the optimal blended learning environment recommendations. Academic staff along with administrative staff reflected on their experiences so far with elearning and blended initiatives together with their opinions on ideal future directions.

Chapter 7 draws the quantitative findings and the qualitative findings together and outlines conclusions and recommendations for an optimal blended learning environment for the future tertiary institute.

\subsection{CHAPTER SUMMARY}

This first chapter has described the motivations of the author for the study. The thesis is set in the context of tertiary education, learning environments and the notion of the ideal mixed learning environment with both online e-learning and traditional classroom-type learning environments. An overview of the contents of each chapter in this thesis has also been presented. The following chapter presents an in-depth literature review of learning environment evaluation, elearning paradigms and blended environment issues. 


\section{CHAPTER 2}

\section{LITERATURE REVIEW}

"Write them on the doorframes of your houses" Deuteronomy 6:9 (NIV).

\subsection{INTRODUCTION AND OVERVIEW}

This review attempts to combine the challenges and opportunities of the online learning environment with the traditional classroom environment and how this mixed-mode environment could be discussed and measured in terms of the learning environment. The literature combines e-learning articles and the pioneering work of many in the general learning environment evaluation field. This literature review also serves as a background to the study of contemporary learning environments which includes online e-learning components as well as traditional classroom environments in the tertiary sector. Fraser (1998) cites Murray (1938) who introduced the concept of 'alpha press' where a detached observer is assessing a classroom, and 'beta press' to describe the environment through the eyes of a class participant. Students themselves are in an excellent position to judge and evaluate what is really happening in a classroom, in terms of atmosphere, tone, openness and other psychological factors. This research attempts to reflect viewpoints of tertiary students who are exposed to mixedmode or blended learning environments. Sims, Dobbs, and Hand (2002) advise careful planning when implementing online learning within existing teaching frameworks as a holistic approach is needed for optimal learning environments and learning outcomes.

The Internet online community is of increasing importance to learning environments and in some cases has replaced the traditional bricks and mortar classroom. Thornburg (2000) discusses how the use of the Internet is having some interesting effects on the disintermediation of the teacher as the 
"middleman" and also the disintermediation of the institution (school, university) as the sole evaluator of what is happening in the classroom or in academic matters. For example, the Internet has forced some democratization of feedback and evaluation by students in discussion boards and chat rooms. In July 2006, a website was launched in New Zealand named 'ratemyteachers.co.nz' which allows students to rate their teachers and give anonymous comments on their classroom effectiveness. "Many institutions are hurrying to get a foothold in the distance learning marketplace, both locally and globally” (Muirhead, 2003, p. 246). There are many examples of genuine reasons for providing distance education such as marine education for maritime workers, rural citizens, and fulltime workers. Salmon (2004) acknowledges the tension between tertiary educators excited by the opportunities afforded by technology but also uncomfortable with the possibility of losing aspects of social contact in physical teaching spaces.

In a similar fashion to secondary schools, tertiary institutes are now heavily influenced both by the daily use of the Internet by students and in the implementing of formal online web-based learning systems. "In the Internet era, the teacher and the school do not comprise the only source of information. Surfing the Internet and information and communication facilities are now an integral part of our daily life” (Kesner, Frailich, \& Hofstein, 2003, p. 209).

\subsection{THEORETICAL FRAMEWORK}

The acknowledgement of the 'learning environment' has been documented from the 1930s (Goh \& Fraser, 1998). In more recent decades, investigations have been focused on the traditional classroom environment (Tobin \& Fraser, 1998) and this research has highlighted the importance and impact of the psychological and social factors within physical classrooms. A number of questionnaires have been developed for the science and mathematics traditional classroom environments within primary and secondary schools (Fraser, 1998).

There are various instruments that have been used in studies of learning environments and these are often related to the theoretical framework for human 
environments developed originally by Moos (1974) and Walberg (1976). The WEBLEI is one of the key instruments used in this study which has been used in many recent studies of learning environments (Chang \& Fisher, 2003).

The idea of the learning environment has evolved from the 1930s (Fraser, 1994) and over the last three decades, learning environment research has been grounded in the physical classroom environment especially in science and mathematics education (Chang \& Fisher, 2003). This research has shown that "students' perceptions are important social and psychological factors in classrooms” (Chang \& Fisher, 2003, p. 2). These perceptions are often assessed using surveys and a wide variety of instruments have been developed for the traditional classroom and, more recently, for the ICT-enabled and online learning environments.

Students are always interacting with a number of variables including teachers, peers, subject materials, physical settings, and a number of other factors (Chandra \& Fisher, 2006). In order to measure the impact of all these factors on the learning environment, a number of research instruments have been developed within this field of learning environments.

The use of various learning environment research instruments and techniques have provided a way of evaluating and investigating the effects of new technology impacting classrooms, laboratories and online environments. Learning environment research recently undertaken has also included the psychosocial factors in association with technical innovations such as e-learning and computerized classrooms (Zandvliet, 2003).

Blended learning environments can also be seen in the context of three interfaces, the social sphere, the technical sphere, and the natural world (Gardiner, 1989). As Kerr, Fisher, Yaxley, and Fraser (2006) discuss; the advantages of a holistic approach to the evaluation of learning environments include examining the psycho social aspect in balance with any technology involved in the learning environment. 


\subsection{RESEARCH INSTRUMENTS: MEASURING THE LEARNING ENVIRONMENT}

Fraser (1998) discusses the Classroom Environment Scale (CES) developed by Moos (1979) and a wide variety of other instruments designed to measure the classroom environment. These instruments include; the Individualized Classroom Environment Questionnaire (ICEQ) which attempts to separate individualized classrooms from normal ones, the College and University Classroom Environment Inventory (CUCEI) aimed at tertiary level classrooms, the Questionnaire on Teacher Interaction (QTI) which looks more closely at the quality of interpersonal relationships between teachers and students, the Science Laboratory Environment Inventory (SLEI), the Constructivist Learning Environment Survey (CLEs) and the What Is Happening In this Class (WIHIC) questionnaire which brings many of the questions and features from a range of instruments to gain a comprehensive picture of classroom realities.

The history of the first two decades of learning environments research in Western countries shows a strong emphasis on the use of a variety of validated and robust questionnaires that assess students' perceptions of their classroom learning environment.

(Fraser, 2002, p. 17)

Chang and Fisher (2003) in developing the Web-based Learning Environment Instrument (WEBLEI) built upon the work of Tobin and Fraser (1998) who outlined an evaluation framework for interactive and web environments. The online learning environment should be seen more holistically than merely a vehicle for desired distance education.

Chang and Fisher (2003) outline how web-based or online learning in tertiary education is increasing its influence and proposed a web-based learning environment instrument (WEBLEI) with four main scales to measure this new environment. The teacher has a changing role in the online environment and needs to foster a sense of community amongst learners. "This may mean that teachers need to pursue the role of a facilitator or a guide, rather than being an 
instructor where stringent instructions were usually given to students in a face-toface setting” (Chang \& Fisher, 2003, p. 4). The online learning environment also invites different types of students with different motivations. "Many students see web-based learning as an opportunity for them to gain higher education without having to physically attend classes and academics worldwide have realized the attraction of this new learning mode” (Chang \& Fisher, 2003, p. 3). The teaching and learning in this online environment is quite different from the traditional environment. An adapted version of the WEBLEI was used in this thesis research slightly changing the focus onto issues relating to experiences of online learning compared to traditional settings, rather than trying to evaluate individual lecturer's success in presenting web-based content. Changes to the WEBLEI were focused mainly around general use of online resources and traditional classrooms across several courses at the Eastern Institution of Technology, New Zealand.

Waxman and Chang (2006) observe that learning environment research has recently expanded its use of research methods from surveys alone to more mixed methods. This study combines quantitative and qualitative techniques in the use of the WEBLEI instrument with tertiary students, the associated discussion questions added to the WEBLEI, and use of the actual research questions with tertiary staff.

\subsection{THE ONLINE LEARNING ENVIRONMENT}

As the online learning environment has evolved, it has become obvious that it has not been used solely to overcome the problem of geographical distance (Picciano, 2006). Many universities and institutes with little history in traditional distance learning programs have provided online opportunities for local residents, many of whom combined work, family, and education activities into their lives. For many modern students, the problem or barrier is not geography but time. As online learning matures, more institutes offer online courses and typically students enrol regardless of their physical distance or time constraints. "Many stories are told of 
full-time students who live on campus in dormitories enrolling in online courses” (Picciano, 2006, p. 2).

Clayton (2003, p. 158) provides a simple definition of online learning as "the use by learners and tutors of connected (online) computers to participate in educational activities (learning)”. However, most commentators would include the use of the Internet as an essential prerequisite for modern online learning. Zhu and McKnight (2001, p. 1) define online learning as "any formal educational process in which the instruction occurs when the learner and the instructor are not in the same place and Internet technology is used to provide a communication link among the instructor and students.”

Downes (2006) explains the modern online learning environment in the context of tertiary organizations.

The dominant learning technology employed today is a type of system that organizes and delivers online courses-the learning management system (LMS). This piece of software has become almost ubiquitous in the learning environment; companies such as WebCT, Blackboard, and Desire2Learn have installed products at thousands of universities and colleges that are used by tens of thousands of instructors and students.

Downes (2006, p. 1)

This learning management software stores learning content and allows the content to be standardised, as a course populated with modules and lessons, supported with slides, tests and discussion forums, and in many systems today, integrated into the tertiary institute's student information system. The online environment allows students to modify material and facilitate discussions through the use of tools like wikis and blogs. Rather than discussing pre-assigned topics with their classmates, students can discuss a wide range of topics with peers worldwide (Downes, 2006). 
Wikipedia (2007, p. 1) outlines a comprehensive list of the many technologies that can be used in e-learning:

\author{
Screencasts \\ ePortfolios \\ electronic performance support systems \\ PDAs \\ MP3 Players with multimedia capabilities \\ Web-based teaching materials \\ Hypermedia \\ Multimedia CD-ROMs \\ Web sites and web 2.0 communities \\ Discussion boards \\ Collaborative software \\ Email \\ Blogs \\ Wiki \\ Text chat \\ Computer aided assessment \\ Educational animation \\ Simulations \\ Games \\ Learning management software \\ Electronic voting systems \\ Virtual classrooms
}

Similarly, Zhu and McKnight (2006, p. 1) list a range of online instruction techniques:

- Sharing information on a web site (example: course syllabus/web site))

- Providing practice for new concepts by using online activities such as simulations and games 
- Communicating one-to-one or one-to-many via email for instructional purposes

- Conducting discussions by using a threaded discussion board

- Conducting discussion by using chat

- Holding office hours by using chat or bulletin board

- Delivering library resources via the Internet (example: Electronic databases, electronic course reserves)

- Giving practice tests or evaluating performance by using online assessments

- Submitting assignments electronically

The role of the lecturer as a facilitator, regularly interacting online is seen as essential to maintenance of activity and focus by students in the online environment. The teacher can model online communication strategies and encourage a high quality of interaction by frequently updating and communicating through the LMS. Salmon (2004) outlines extensive research and practice at the University of Leicester particularly focussing on the role of the emoderator, a term describing the role of online facilitation. Some online courses are unsuccessful because of a lack of involvement by the teacher (Stacey \& Rice, 2002). This also has implications for unsuccessful students. “The failing students in the unit had also failed to interact, their absence online reflecting their lack of engagement with the course through group interaction which provided feedback from other students and from staff” (Stacey \& Rice, 2002, p. 3).

Academic staff are the ones who should determine the extent to which web-based learning is applied in a course. The lecturer, in the tertiary environment, is the person who knows the structure of their course, who is in charge of the instructional pedagogy that is involved in their course, who creates the assessments associated with the course, and who is familiar with the type of students in the course and how they might interact (Chang \& Fisher, 2003). This viewpoint places the teacher at the centre of the development of web-based learning systems. 
Successful attributes within the online learning environment include the clarification of ideas, feedback to ideas, diverse perspectives, group solutions and group resource sharing as well as factors of socio-affective collaborative support (Stacey \& Rice, 2002). Stacey and Rice also talk about the concept of 'social presence' in online courses with virtual substitute techniques for invoking social interaction, atmosphere and other psychological factors. The idea of 'presence' is also finding an audience in the corporate world as promoters of voice over internet protocol (VoIP) systems are showcasing software systems that allow staff and customers to communicate by various telecommunications means; legacy phone, mobile phone, chat msn window, blackberry, email and video phone (Gen-i, 2007). The implication of this multi-threaded system is that one's 'presence' is available at any time or place thus breaking the barriers of the structured academic or corporate timetable or schedule. However, there are some weaknesses to the virtual classroom. Feldstein and Masson (2006) point out that the physical classroom can be changed and varied according to the needs of the learning group, but the virtual classroom tends to have a generic similarity. Even across 26 different learning management systems (LMS) for example, Blackboard, WebCT, Moodle, and other similar systems, all display similar content display with lecture notes, forums, chatrooms, wikis and other similar features and tools.

The rise and increased popularity of the Internet as a means to distribute information has changed the way tertiary educators have presented learning materials (Chard, 2006). The web has also replaced, at least partly, the face-toface component of teaching and learning. In some cases, the web has entirely replaced the face-to-face teaching delivery system and entire tertiary institutions are delivering programmes mainly in online or distance mode (Udas \& Brown, 2005). Typical online learning system components include lecture slides, lecture notes, weekly comments, practical exercises or worksheets, and other content replicated from workbooks or references. "The information published is available to learners as required learning materials for a subject area” (Chard, 2006, p. 604). Web-based learning environments may also aim for closer, more dynamic interaction with the learner with the use of asynchronous communication (email, 
discussion forums) and synchronous communication (chat, shared whiteboards, voice and virtual scenarios). As Chard (2006, p. 603) points out “learning environment research has now moved into distance and web-based learning environments”.

The New Zealand Education Minister (2005-2007), Steve Maharey, has acknowledged the revolution taking place within all sectors of education especially in the context of active learners in newly designed classrooms with more space and flexibility.

New technologies are allowing a shift in the way learners access knowledge and the relationship between the learner and teacher. It is now understood that learning takes place everywhere and the more we can involve parents and the community the better.

(Maharey, 2007, p. 20)

This is an interesting acknowledgement that the physical classroom and school or campus should also adapt and change in conjunction with the changes in provision of online learning environments. This concept broadens the change required to include larger classrooms with learning pods or break-out rooms which synergise better with other learning hours that are spent off-campus and online. There is still a need for teacher-student interaction regardless of the mode of delivery and motivation factors are important to keep students engaged.

Collins and Berge (1995) break down the tasks and roles of the online teacher into four areas: (1) pedagogical, (2) social, (3) managerial, and (4) technical. The pedagogical area can be described as the function and task that revolves around educational facilitation. Social function is a role associated with the promotion of a friendly social environment which is needed in the process of online learning, while the managerial components of online learning include setting the agenda, aims, guidelines and decision making norms. The technical aspect covers the teachers' skill in using the necessary technology for online systems. The teachers or lecturers in charge of an online course should make sure that they themselves 
are secure in their use of this technology to impart knowledge to their students (Chang, 1999).

A current snapshot of online education reveals a number of drivers: technological, higher education, globalisation, mass higher education, and increasing managerialism in higher education.

Since 2000, many universities have tried to implement a virtual learning environment (VLE) or managed learning environment (MLE) that will provide a unified technology platform from which to embed ICT in learning and teaching. These resources are usually available to all courses, modules, staff and students in the institution, and raise expectations that academic staff will provide some level of online resources to their students.

(Bach, Haynes, \& Lewis Smith, p. 35)

The online learning platforms are now readily available in commercial forms such as Blackboard and WebCT. There are a number of open source applications such as Moodle, which share common features with the main commercial online systems. 


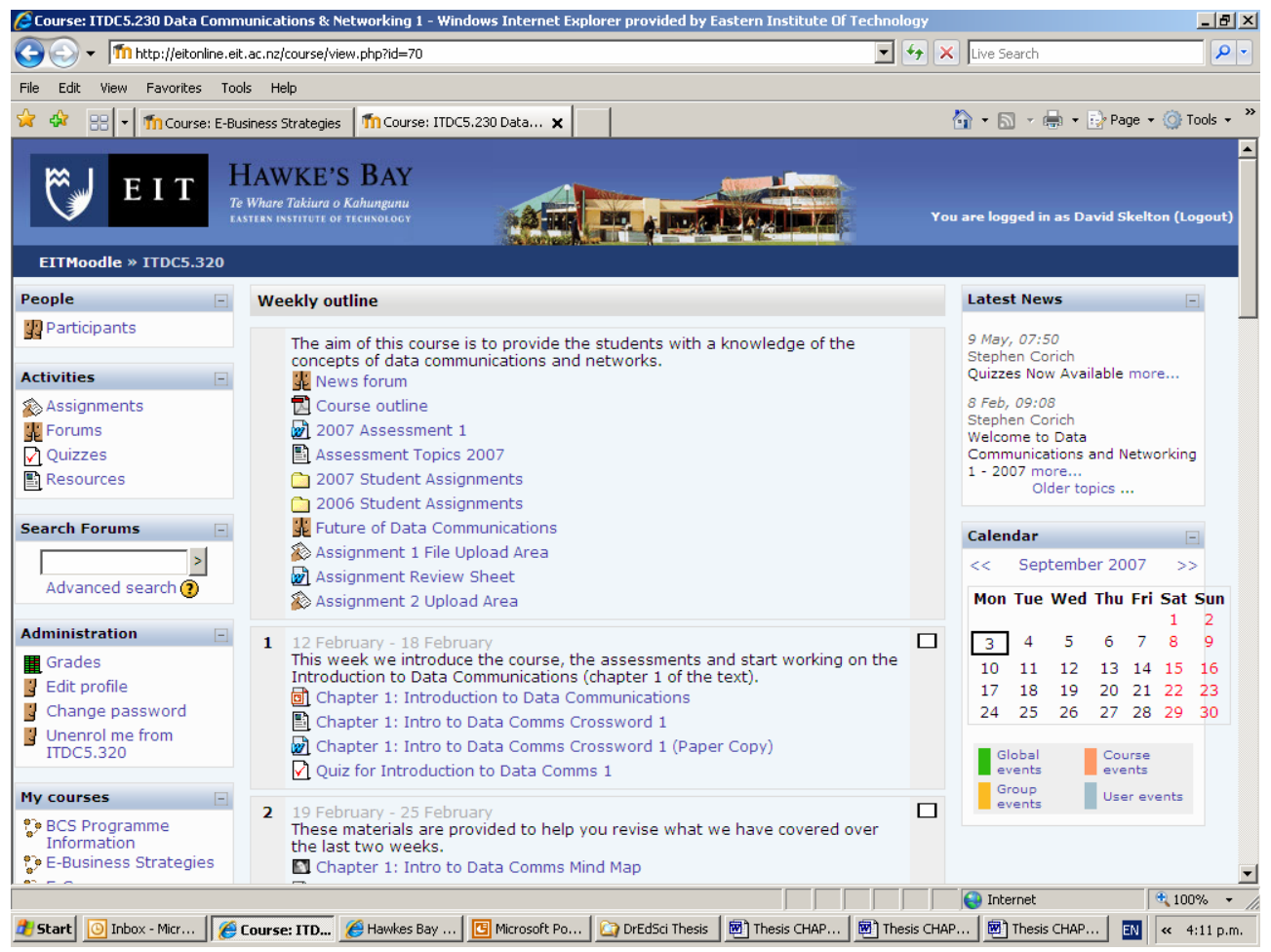

Figure 2.1. Screenshot of Moodle, Eastern Institute of Technology (2007).

The typical current tertiary LMS, as displayed in Figure 2.1, includes an individualised student and staff portal, message board, areas for posting course information, course materials, group discussion forums, links to other websites, wikis (open editable databases), blogs (online journals), email, and teacher managed tracking and learning management.

Three phases of online learning is typically undertaken by a tertiary institute or university. A pioneer phase begins with a few teaching staff investing time and experimenting with new websites and online systems. This is followed by a "communities of practice" phase where pioneers begin to group together and share with each other prime examples. Hopefully, a mature stage can be achieved with institute managers able to implement 'best practice' for online learning with all academic staff (Bach, Haynes, \& Smith, 2007).

There are some concerns that "in the new knowledge economy and global society we will see the commodification of knowledge and that this will undermine traditional university values and supercede learning with a market-based value 
system” (Bach et al., 2007, p. 51). However, this tension and debate about vocational qualifications and traditional higher education has been in existence before the advent of online e-learning. Bach et al. (2007) argue that online learning will not necessarily undermine interactive ideal higher education or be only associated with skills-based qualifications.

\subsubsection{Concerns about online learning}

The reputation of pure online e-learning for potential employers has been expressed as a concern by students (Gansler, 2007). Students want to be assured that industry employers will regard a qualification obtained through a pure online delivery mechanism as valuable as a qualification obtained through a traditional campus-based course.

Improvement in the quality of the teaching and learning environment is not simply guaranteed because of the implementation of new technologies, as the emerging technologies possess no inherent property that guarantees the success of their implementation. "New technologies may be used inappropriately or in ways that replicate teacher centred approaches and thus may contribute little to improving the quality of the learning environment” (Torrisi-Steele, 2002, p. 1).

A practically-based Bachelor of Computing Systems qualification, for example, would be difficult (although not impossible) to place entirely online as practical laboratories and evidence-based systems need to take place in a controlled time and space.

There may be some dangers in an over-dependence on the learning management system for all knowledge delivery. As Grandzol and Grandzol (2006, p. 4) point out "passive learning should not be the sole, or primary, model for collegiate business education. Faculty members' presentations or lectures, absent of any additional interaction, are simply a form of information delivery, not higher education.” 
Quinton (2006) also confirms the popular misconception of academic administrators that teaching is primarily about delivering content in a similar manner to channelling water through a pipe. A simplistic content delivery model will suit a web-based e-learning system but may not embrace the necessary complexities of learning.

While tertiary managers and academic leaders may be initiating and increasing online courses and options, there remains some unanswered question by lecturers and individual academics.

Questions remain about equity of access, cost-effectiveness, the quality of courses, the impact on learning outcomes and the impact on academic work. Previously integrated activities undertaken by an individual academic - such as course design, materials preparation, lecturing and tutoring, assignment marking and assessment - are being 'unbundled'. New specialisations of labour in relation to the delivery of teaching and learning have been established. The existence of the university as a physical space has been called into question as technologies create the potential for higher education to develop as an intellectual or virtual space.

(Department of Education, Science and Training, 2002, p. 16)

Not least of these questions is whether the academic staff member is building online systems that ultimately may lead to the loss of their job and position.

\subsubsection{What constitutes a course? Pedagogical and delivery changes}

The New Zealand Government has been grappling with defining what actually constitutes an authentic course in the light of rapid changes of delivery modes. The New Zealand Ministry of Education through the Tertiary Education Commission has recently reduced funding to tertiary providers who were providing free community courses such as community computing where students register for a course, then work through a workbook in flexible time slots assisted 
by roving tutorial assistants. The reason for the reduction in funding was partly due to the popularity of such courses causing high levels of student enrolments for which the Ministry of Education was unprepared. Another possible reason for the reluctance of the Government to fund these flexible-delivery courses uncapped is the uncertainty around the authentic nature of the course itself, and the public perception of the value in funding such courses. Noble (1998, p. 1.) warned some time ago that:

We have entered a new era in higher education, one which is rapidly drawing the halls of academe into the age of automation. Automation - the distribution of digitised course material online, without the participation of professors who develop such material - is often justified as an inevitable part of the new knowledgebased society.

The question may be; should courses strongly influenced by IT, the Internet and multimedia still be managed and academically supervised by lecturers? Already some flexibly-delivered courses are supplementing instructional components supported by partly qualified tutorial staff with fewer qualifications than academic staff normally teaching traditional class-based courses.

The changes in pedagogy for online courses may include less emphasis on content (less amount), little note-taking by students, more constructivism, and the very concept of a "course" radically changed. This also leads to the issue of what is now meant by "attendance", and what this means for online e-learning courses, blended delivery courses, and flexible-delivery courses. Funding for the university or tertiary institute is often dependant on institutions proving that the declared students enrolled and did attend or participate authentically in the course. This funding dependency requires any tertiary institute to provide mechanisms that allow evidence, for example through email or participation in online discussions that the enrolled students did engage throughout the course (de Freitas \& Oliver, 2005). 
Commentators have also warned that an attractive display of multimedia materials presented online with entertaining graphics does not in itself constitute a course. The potential separation of the professionally trained academic and the e-learning artefacts may lead to factual inaccuracies or failure of students to meet academic standards.

Once faculty put their course material online, moreover, the knowledge and course design skill embodied in that material is taken out of their possession, transferred to the machinery and placed in the hands of the administration. The administration is now in a position to hire less skilled, and hence cheaper, workers to deliver the technologically pre-packaged course.

(Noble, 1998, p. 4)

There does appear to be an issue of authentically integrating IT and online elements within the overall pedagogy of a course, programme and institute. If this integration is not undertaken then the online e-learning elements simply become a 'clip-on' component. "Research indicates that integrating ICT is a gradual, reflective process for most teachers and one that is influenced by a complex mix of factors. In particular, effective practice involves developing new forms of pedagogy” (Hennessy \& Deaney, 2004, p. 1). Lipponen, Lallimo, and Lakkala (2006) also observe that applying new technology in learning environments in order to reproduce previous practices of learning and teaching is widely recognised as undesirable.

The creation and raw development of teaching materials by publicly funded universities and institutes of technologies may diminish as an increasing volume of educational web-based materials are developed by purpose-driven commercial organisations whose sole aim is to produce quality education materials and software packages. The presentation quality of this type of website or multimedia package is often superior to university academic staff productions. Tertiary institutes and universities are already observing this phenomenon with international certification programmes such as MSCE (Microsoft engineering 
certification), A+ (computer hardware certification) and many others being used by students enrolled concurrently. In these cases where the commercial provider can produce online content more efficiently and of a greater quality, then the institute may provide online access to these materials through the third party content provider. However, in these cases, the institute may still enrol the student, provide course advice, and supervise the assessment regime locally. As a functional substitution the institute would pay the content provider for the materials on their website rather than include this in the teacher's duties. Therefore, the role of many academics in the future may emphasise the selection and coordination of quality resources and the 're-packaging' of these materials skilfully for their classes. Conversely, in some situations, some academics may be involved primarily in multimedia production of course materials leaving the teaching and course management to other faculty members.

If faculty-student relations are perceived to be weak in a tertiary environment then academic staff need to be more actively involved with students in mentoring, advising and general availability (Huang, 2006). The strength or weakness of faculty support to students in a mentoring or advising sense may be magnified or diminished by the online learning environment. Therefore, care should be taken to fully evaluate the current learning environment situation generally before implementing new online or blended systems, otherwise a weak communication ethic may be made worse by the separation implied in online systems.

\subsection{MIXED-MODE, FLEXIBLE LEARNING OR BLENDED DELIVERY}

"In mixed mode courses, the e-learning element begins to replace classroom time. Online discussions, assessment, or project/collaborative work replace some faceto-face teaching and learning. But significant campus attendance remains part of the mix" (OECD, 2005, p. 1). Lecturers in the mixed-mode environment have demands from students in the bricks and mortar classrooms as well as from the online systems. In some cases these online and offline demands may come from the same students, while some online demands may arise from students who are enrolled largely off-campus. Activities such as checking email and online discussion groups must be conducted with far greater frequency than the weekly 
lectures and tutorials. When demands for assistance are made by students, they need to be acknowledged and addressed promptly, and this can disrupt the normal pace of interaction between teacher and students (Downes, 2006).

Tertiary institutes are changing and adapting mainly as a consequence of their response to the various forces associated with broader access levels, commercialism and developments in the web and information technologies. "The adoption of the concept of flexible delivery has been a key initiative in many institutions although this concept has been interpreted in many ways. One interpretation has been to initiate web-based design and delivery of courses” (McDonald \& Postle, 1999, p. 2). This would tend to suggest that participation in online learning environments is becoming mandatory with commercial pressures also influential.

Ellis and Phelps (2000) warn that an online presence and blended delivery requires an examination by teachers and entire faculties of maintenance and updating problems, the expectation of teachers by students, and the emphasis given to online content and communication. It is also useful to view the various learning environments in the context of the type of student. Students may be enrolled as full-time on-campus, part-time on-campus, full-time online, part time online only, block mode on-campus with some being a mixture of these student modes. This warning would suggest that the overall teaching load is more difficult to accurately ascertain in the blended environment compared with the traditional course, where the availability of a teacher for specific timetabled periods would normally suffice for the creation of viable learning environments.

Wilson and Smilanich (2005, p. 3) define blended learning as "the use of the most effective training solutions, applied in a coordinated manner, to achieve the learning objectives that will attain the desired business goals". While this definition is set in a business context, there are parallels from this statement which can be applied to the tertiary academic environment. The most effective learning delivery mechanisms perhaps, applied in a coordinated manner, to create 
an excellent overall learning environment to achieve students learning goals, may be an appropriate paraphrase for tertiary institutes.

Singh and Reed (2001, p. 3) describe blended learning as “a learning program where more than one delivery mode is being used with the objective of optimizing the learning outcome and cost of program delivery”.

Other names for this mixture of delivery modes include 'hybrid learning', 'mixed learning' or 'mixed-mode' delivery. All current tertiary teachers and lecturers probably practice some form of blended delivery in the sense that they might mix projected lecture slides, classroom tutorials, practical laboratories, individual interviews and some general email or notice-board communication. Blended delivery now would include the mixture of conventional offline delivery with Internet, and technology delivered teaching services (McSporran \& King, 2005).

Picciano (2006) describes how the recent past has seen the evolution of blended learning where tertiary institutes offer parts of their courses online and parts in face-to-face mode. Institutes are making decisions about blended learning often for pedagogical reasons and are trying to capture the best of online and traditional face-to-face modalities. The reasons for the setting up of blended learning environments has not always been to create greater access, but rather to create the best mixture of online and face-to-face elements of the overall learning environment. For example, a degree in computing may offer six papers purely online, while the rest of the courses will be available as blended courses.

There is increasing evidence from commentators (Clayton, 2003; Picciano, 2006) that online learning is now perceived to be at least as effective as face-to-face classes. Such practices as reflective teaching practice, collaborative learning and web-based research are possibly more effective in a fully online or blended learning environment. Tertiary providers are therefore now forced to make decisions for all programmes on offer on how to mix and match the two teaching modes (Picciano, 2006). 
Student satisfaction with any tertiary program is now based on a wide range of factors beyond pure academic matters. Seemingly external factors such as work commitments, family responsibilities, financial concerns and transport are often barriers or factors bearing on the overall perceived learning environment. Online learning, of course, is already seen as having the flexibility to overcome many of these problems for the modern student, thereby increasing student satisfaction rates.

Tertiary institutes are also concerned with student retention and online provision is now part of the many-faceted strategy to remove the barriers preventing student success and completion. Picciano (2006, p. 3) supports this by claiming:

The blended learning model may be more effective in this regard in retaining students than either the fully online or fully face-toface model. This is speculative but the assumptions, on which it is based, are real. Blended learning provides additional tools for faculty to design multimodal activities that better address the diverse learning styles of students be they visual learners, adult learners, or ESL (English as a second language) students.

If lecturers and administrators focus on designing sound pedagogical approaches and use a variety of tools to meet diverse student needs then probably blended learning may improve retention and if implemented will be more effective than either fully online or fully face-to-face environments. This reinforces the view that tertiary institutes may achieve more overall success with blended environment aims than a single online e-learning goal.

Tertiary institutes and universities are renowned for their resistance to change; however many are now re-examining their teaching practices and balancing of timetables (Calgary-University, 2007). This re-examination includes reducing the number of contact hours per week for a standard undergraduate course and substituting online activities and content for some normally timetabled classes. This blending of Internet and ICT technology with traditional campus strengths, 
such as research and the challenge to students to perform critical thinking, needs to be thoughtfully designed, planned, and implemented. "Meaningful learning events that are active, intentional, authentic and collaborative are fundamental to facilitating effective blended learning, and can capitalize upon the unique properties of Internet technology" (Calgary-University, 2007, p. 1). Online discussion forums and the use of email can encourage reflection and class communication which combines well with real-world classroom discussions and verbal lectures. These kinds of combinations have the potential to create a deeper, unique learning environment that exceeds the quality and enjoyment of the classroom-only learning environment. Blended learning environments have the potential to extend opportunities for students to learn how to navigate the emerging technology-based world which tertiary institutes are seeking to prepare them for. The implementation of rich blended learning environments by tertiary institutes also serves to demonstrate inquiry-based learning approaches, cost effectiveness, and to perform curriculum re-design where needed (CalgaryUniversity, 2007).

Blended learning environments are also called 'hybrid' environments where the divide between traditional and online instruction is aimed at being reduced. Saving money in delivering courses is one outcome along with meeting the students' needs more flexibly. An examination of a typical classroom-based lecture where some students are not fully engaging with the lecturer may provide reasons to provide some lectures online or in some other format (Young, 2002). In the online version of the class lecture, students may access the lecture anytime in any location. Students may also review previous lectures, and also participate in an online discussion if they are unable or unwilling in normal class time. Some universities now require first year students to enroll in at least one purely online course. The intention is to acquaint newer students to online delivery and it may be easier and quicker if students are immersed in an online learning environment to teach them the skills required to survive the online environment. From then on the students can adapt more quickly to the increasingly blended learning environment in all their other courses or subjects within their degree. So as oncampus students mix and match a variety of delivery modes, the blended or 
hybrid campus is emerging. The success of the blended model has caused some tertiary institutes to abandon their single focus on pure online e-learning courses which have experienced high drop-out rates and prompted them to re-focus on the more successful blended models (Young, 2002).

Hybrid or blended learning environments do seem less controversial than pure elearning courses and less likely to be resisted by academic staff in the tertiary sector (Young, 2002). Fungaroli-Sargent (2000) believes that the physical teacher relating to the student via campus classes and personal mentoring is the simplest and least expensive method of establishing a relationship with the student. The elearning and distance education proponents may have been forced to compromise to a blended approach as the pure e-learning model has not been as widely successful as first predicted. This adapted approach towards blended learning rather than e-learning alone has been less visible and most tertiary institutes are quietly working on converging online and on-campus classes without great publicity. She and Fisher (2003) in a particular study in a number of Taiwanese schools found a direct correlation between student satisfaction in the real-world classroom and enjoyment of the associated web-based learning. This may indicate that the same factors (student cohesiveness, support, and equity) that are normally sought in a traditional classroom-only environment are also critical for success in a blended learning environment.

Up until 2002, Harvard University had a requirement that undergraduate degree students must spend their entire academic year physically on campus. "If a person is never on this campus and never gets to be a part of a community, then I think that really does start to raise concerns about whether they're really getting a Harvard education” (Young, 2002, p. 2). This demonstrates that universities with a top reputation and long-standing pedigree are not necessarily keen to dismantle their physical campus facilities and reputation in favour of pure online options. However, universities such as Leicester University in the United Kingdom are moving towards a full mixed-mode environment with 50 percent of their 18,000 students being campus based, and 50 percent studying at a distance (Salmon, 2007). 
Other reasons for moving to a blended environment include a need to address a shortage of classrooms. Rather than spend three million dollars on a new building complex, far less money can be spent reducing the demand for physical classes by 20 percent by increasing online integration. This may be the preferred solution to tertiary corporate managers, reducing the cost for buildings and facilities and helping the expansion for growth at greater economy. Cost savings on parking, power, internal information technology, and general campus services are also beneficial within the blended model (Kruse, 2004).

Another reason that a number of universities cite for blended courses is to accommodate students who are already working either full-time or part-time. As students typically have greater work commitments than in previous eras, if they only need to commute to the university twice a week instead of five days then they are more likely to stay enrolled and continue their studies. Interestingly, students appear to appreciate the campus classes more when they occur with less frequency within the blended learning environment. These experiences seem to show that pure face-to-face courses are not necessarily the best environment, or that face-to-face environments are the standard by which all other learning environments are judged. The particular mix of online and traditional elements may be at different levels for different courses. This flexibility of deciding the effective mix can be accommodated by still allowing academic staff full control over their particular courses (Young, 2002).

Van Tartwijk, Wubbels, den Brok, and Jong (2003) describe an intentional blended learning environment with scheduled face-to-face meetings, a specific content website, combined with a structured LMS (Blackboard). "The dilemma is that introducing face-to-face contacts may make electronic communication superfluous while on the other hand the face-to-face contact is mentioned as a prerequisite for productive electronic communication” (van Tratwijk, et al., 2003, p. 277). The issues faced in creating this intentionally blended environment included creating and organising content, deciding the proportion of campus classroom time, and teacher professional development. The study also confirmed that substantial time and resources are required for a successful blended learning environment which is often underestimated. Quek and Wong (2003, p. 302) 
conclude that "the incorporation of online learning does not rule out the importance of face-to-face interactions in any teaching and learning situation in schools”.

It is interesting that at EIT, computer classrooms are mainly used for teaching information technology subjects only. Whereas in the school sector, e-classrooms are increasingly used holistically as a tool for a range of subjects (Falloon, 2006).

\subsubsection{The influence of pedagogy on the blended environment}

The concept of blending can also be used in the sense of a balanced pedagogical approach with a mixture of instructor-led learning environments and studentcentred learning with collaboration. The link between the pedagogical approach of the teacher and the successful implementation of e-learning and blended learning environments has also been validated as academics with constructivist leanings are more likely to be early adopters of technology-enhanced learning environments (Trinidad, 2003). Thus, optimal mixtures of traditional and elearning technologies may be related to ideal mixtures of teacher-led and constructivist teaching approaches. In teacher-centred environments, the typical technology use may include PowerPoint presentations, rote learning and associated assessment consisting of exams and essays. In learner-centred learning environments, the technology may facilitate communication, collaboration, and elearning with likely assessment to include portfolios and performance-based assessment items. This association between teaching philosophy and use of technology-enhanced learning environments may be useful when constructing a set of goals for future blended learning environments. This association would include information technology embedded within the classroom (Mumtaz, 2000). The professional development of teachers themselves is seen as an essential forerunner of enterprise-wide implementation of technology-enriched learning environments (Rickards, 2003). A growing requirement for academic staff involved with blended course development is the ability to work in teams which may include lecturers, IT specialists and web developers. 
In resident lecture-hall courses, the subject matter expert is the professor delivering the lecture. In on-line courses, the subject matter expert is part of a team comprised of an experienced on-line faculty program planner, Web technician, software programmer, editor, copyright expert, and an independent evaluator.

(Gould, 2003, p. 1)

Deubel (2003, p. 2) asserts that "it takes both technical competence and effective pedagogy to teach in an e-learning environment”. The instructors' general attitude toward setting up online courses will influence the overall quality of the online environment (Deubel, 2003).

“Unsurprisingly, in the 'technology-rich learning environments' here we're back to the core question: what pedagogical practices and interactions with, in, around, through and about blended communications media can serve powerful educational ends?” (Luke, 2003). It is useful to consider that whatever the era of technology, the same issues surrounding the ideal learning environment will still remain constant. The idea here is that the channels of technology themselves, whether they be teaching websites, training multimedia, or email, should not be the prime focus but rather the effective pedagogical practices when these tools are in fact used.

Involvement of the subject specific teaching staff when designing online learning systems is recommended which helps staff to accept and support the particular LMS. Kesner, Frailich, and Hofstein (2003) describe how secondary science teachers set up and developed an Internet site specifically for their own students rather than use an existing system. This also involved utilising public domain science modelling examples as well as developing their own in-house material. Discussions about how such websites will change classroom practice and pedagogical approaches are useful for groups of teachers in the process of implementing new online learning environments. This type of approach assists user acceptance of newly emerging systems as well as help academic staff adjust to the new realities of working within a new learning environment. Academic 
staff who become enthusiastic developing web-based materials and integrating Internet activities can become useful 'agents' of change within an organisation and can be used as examples of changing teaching practices alongside technology changes for other staff (Kesner, Frailich, \& Hofstein, 2003).

Quek and Wong (2003) discuss the changing roles of teaching staff and students alongside the influences of technology and the Internet. Academic staff need to adapt their teaching role towards managerial functions such as updating online content, being responsive to electronic communication, and fostering a sense of community amongst students. "During the entire on-line learning process, the teachers' pedagogical knowledge and skills in facilitating, mentoring and managing are crucial in helping the community of learners achieve their learning goals” (Quek \& Wong, 2003, p. 288). Teachers may also need to re-examine their traditional timetable and contact hours, classroom practices, and student interaction to accommodate the new blended learning environment. Teachers developing web-based systems are more likely to work collaboratively with colleagues as similar programmes are delivered by multiple teachers hence there is a greater transparency in content preparation and display.

Van Petegem and Donche (2006) discuss the need for researchers and teachers involved in creating ideal learning environments to investigate many student factors such as socio-cultural capital, personality traits, motivational aspects, and study choice. Ideal learning environments also need consideration for teachers conceptions of their own learning, attitudes towards assessment, characteristics of course design, and attitudes towards educational change.

\subsection{LIMITATIONS OF IDEAL LEARNING ENVIRONMENTS: CONTEXT OF THE MODERN MEDIA ENVIRONMENT}

The idealized tertiary learning environment should be viewed in the context of the online and media-immersed nature of modern life, particularly for the younger tertiary student. The typical tertiary student is influenced by many nonstudy hours such as; using the Internet for social networking, television viewing, 
cell phone communications and ipod delivered music. The classroom, in all its forms, is competing for attention and satisfaction amidst this background 'noise'. One of the questions that Joyce (2006) asks is: Are we attempting to create classroom environments as entertainment rather than enjoyable yet effective learning centres? There are many entertainment environments that the average student is exposed to and comparisons with the classroom by students are inevitable.

Learning, at least when it involves the deep ideas you are expected to handle in college, is not an easy or quick process. It takes time, sustained effort, and clear focus in order to be successful at it, so you can not approach it with the attitudes that society has instilled in you. A student who says on his course evaluation that the class needs to be more exciting is looking for entertainment, not an education.

(Cervone, 2002, p. 1)

Part of the student responsibility is to accept that ideas have an interest of their own and that their perception and interaction with their learning environments can have a strong influence on their learning and teacher interactions. Modern daily life for a young person appears to affect their ability to enjoy seriously studying a subject within a purposeful learning environment (Joyce, 2006). This expectation of entertainment by the modern tertiary learner is also reinforced by tertiary administrators who attempt to comply with perceived governmental expectations by setting institutional student survey satisfaction rates of 80 to 90 percent with a course and attempt to eliminate perceived 'failure' by recategorising students as 'withdrawn' or 'never enrolled' instead of forcing students to face their own unrealistic expectations of course enjoyment or genuine academic failure (Tertiary Education Commission [TEC], 2007). Lecturers faced with students expecting and insisting on entertainment can be aided by the concept of the carefully crafted blended environment where Internetmediated discussions, online coursework and vibrant campus classes can give students the sense of immersion in a modern responsive learning environment. 
However, it is likely that the social networking phenomenon taking place on the Internet will influence web-based learning environments in the future with the ability of students to upload photos, assignments and general comments in a kind of merged environment with the social internet sphere and the working/studying internet environment overlapping. Nash (2007) discusses the potential influences of the celebrity news and social networking sites on the e-learning environment. Increasingly, the e-learning environment may soon be expected to entertain with short video clips in a similar manner to youtube.com and other social networking sites. The production of online material should be 'live' or authentically presented in a manner similar to reality TV shows as opposed to highly produced 'official' news. Many viewers (and by implication online students now) are suspicious of large media formats (Nash, 2007). Entertaining 'viral' videos may sustain a life of their own being replicated in many other websites, so authors of online material should be prepared to see some of their material taken out of context and replicated elsewhere. Nash (2007) also reinforces that modern Internet users expect interaction in the form of online or texted opinions with transparent posting so all participants can view the overall interaction. E-learners may become bored easily with plain text discussion boards that are not controversial or infused with modern media life.

“The average course is likely to feel like a tight, closed-in box rather than an elearning space where memes can flourish and students can engage in the kinds of real-world discussions, media evens, and communication that makes them feel connected" (Nash, 2007, p. 2). So online and blended learning may need to be planned as co-existing alongside fast-moving and influential social phenomenon within the overall Internet environment.

Quinton (2006) discusses the younger generation, profoundly influenced from childhood by cell phones, computers and cable TV, as being innovative users of new technology. This emerging generation will adapt to new e-learning systems quite readily, probably with the minimum training required in the use of new online learning systems. 


\subsection{HISTORIC AND TECHNOLOGY ISSUES}

The integration of technology has been an issue in education well before the contemporary use of more sophisticated e-learning systems.

Moran and Payne (1998) discuss how to humanize the integration of technology. This was in the era of computerization of classrooms internally on campuses and at the beginning stages of the utilization of the Internet for class communication and research. This previous era discussed by Moran and Payne (1998) dealt with implementing application software tools such as PowerPoint for academic staff, the use of computer rooms, exposure to information technology, and the use of faculty mentoring to assist teaching staff to be effective in their use of technology in the classroom. Henriksen (1998) also commented on ways of identifying and implementing emerging technologies for higher education including considering the organisational culture when faced with technological changes, deconstructing the 'campus', viewing the university as a 'learning organisation' itself, and planning strategically. Although this advice was set in an earlier period in the 1990s, the advice can be generalized for the newly emerging e-learning and blended environments developing today.

Oblinger and Rush (1998) predicted nearly a decade ago that tertiary education faced the challenge of creating a future compatible campus as technology trends disintermediate the traditional provider of learning and student services. This ideal of a future compatible campus proposed a robust yet flexible information technology infrastructure which would be agile enough to accommodate flexible learning environments, strong IT systems, and adaptability by tertiary staff (Anandam, 1998).

Investigations into the use of computer laboratory classroom environments (Newby \& Fisher, 1997) and studies of computer-facilitated learning environments (Bain, McNaught, Mills, \& Lueckenhausen, 1998) have shown positive outcomes for students utilizing these IT-based learning environments in the 1990s. 
These historic issues, of implementing internal IT environments, have largely been dealt with over the last 10 to 15 years by tertiary institutes. This historic era, although only a few years ago, illustrates that the integration of technology has been addressed before and can achieve successful outcomes for tertiary institutes.

"There will always be a role for the teacher, professor, or subject-matter expert to teach and entertain us in the classroom. Instructors convey enthusiasm, expert knowledge, experience, and context. They can answer questions and change the pace and direction of a class based on the audience” (Bersin, 2004, p. 2). The issue here is: can this function of the teacher be replicated in an online or blended environment?

However, there are a number of issues and limitations of the traditional learning environment. One limitation is the lack of scalability as large or very large classes are very difficult to deliver. Another problem is the time period of duration of a particular course - teacher-led courses normally have a start date and a finish date with little flexibility of speeding up course duration or completion dates. Technology can theoretically extend the instructor model in space and time (Bersin, 2004).

The role of technology in creating ideal learning environments is described by Jonassen, Howland, Moore, and Marra (2003) as a tool for knowledge construction, an information vehicle to support learning, as a context to support learning by doing and conversing, and as an intellectual partner in its own right.

\subsection{CONCEPTUAL FRAMEWORK FOR EVALUATION OF THE ONLINE LEARNING ENVIRONMENT}

Chang and Fisher (2003) describe the rationale for the development of the Webbased Learning Environment Instrument (WEBLEI) which attempted to focus on the Internet based teaching platforms. The advent of e-commerce and the use of the Internet have impacted all industry sectors so it should come as no surprise 
that tertiary education has experienced an evolution in learning style where the disintermediation of the information broker (teacher) has led to information being shared with potentially all Internet users (Brodsky, 1998). Chang and Fisher (2003) outlined the rationale for conducting research into the social and psychological aspects of the online learning environment in the context of the growing use of Internet mediated learning and teaching. They also undertook studies to focus on the online learning in tertiary education and sought to measure its effectiveness as a learning environment.

Previous research studies by Jegede, Fraser, and Fisher (1998) helped develop the Distance and Open Learning Environment Scale (DOLES) designed for university students studying in distance education. Chang and Fisher (2003) also built on the learning environment research by Tobin and Fraser (1998) who described a framework used for the evaluation of learning environments in interactive environments. Chang and Fisher (2003) thus created the WEBLEI to attempt to comprehensively assess online learning environments for tertiary education and this instrument went someway to address the lack of research into the psychosocial view of online learning environments.

\subsection{RELATING TO THEORIES OR THEORETICAL DEBATES IN THE FIELD OF LEARNING ENVIRONMENTS, E-LEARNING AND MIXED- MODE DELIVERY}

All educational institutions at various levels are grappling with how the online learning environment 'fits' within their current organization in all areas; financial, marketing, educational quality and competition. As institutions approach the e-learning issues such as the dangers of the e-learning environment undermining their physical campus appeal and the perceived lack of educational quality of a pure e-learning course then the examination of e-learning and mixed mode delivery in the light of learning environment effectiveness may be helpful.

The New Zealand government has recently been challenged on the financial nature and educational quality of a number of popular flexible-delivery or online 
courses, for example free community computing, CD-ROM based computer training and radio Maori language courses. The public perception and political viewpoint still illustrates that the public requires the assurance that tertiary courses will require students to attend physical classrooms of some description and be accountable for their navigation of the course. The acceptance (or not) of e-learning as a valid "classroom” by the government and the general public will have an impact on many stakeholders in education.

It is useful to view the student as central with the other variables in the environment as consisting of teachers, peers, physical settings, subject materials and other unique factors. Given the number of different factors constituting the overall learning environment, then the research instruments should attempt to evaluate as many of these factors as possible (Chandra \& Fisher, 2006).

The blended and e-learning environments depend heavily upon constructivist frameworks. As Khine (2003, p. 37) pointed out, “constructivism does not mean that the instructor can leave the learners to explore all by themselves. A great deal of scaffolding, coaching and modeling are necessary to ensure that learning is on task." The evolution and growth of constructivism combined with the advent blended learning systems have created an even stronger argument for appropriate support for the learner lest they be left stranded by both constructivism and technologically-delivered learning systems.

\subsection{OTHER STUDIES EVALUATING LEARNING ENVIRONMENTS}

Chard (2006) describes a study evaluating the virtual learning environment at Whitireia Community Polytechnic in New Zealand. This study used the WEBLEI instrument and concluded that enhanced virtual online learning systems were perceived favourably by students and experienced a greater engagement in their learning. The learning environment under study (Chard, 2006) utilized a virtual Internet web-system similar to Second Life (a virtual world replicating social and business life online). 
Some studies have attempted to evaluate online courses with traditional courses. However, McDonald (2002) questions whether the comparison between face-toface education and online or distance education is still a valid comparison. Are we still measuring all new forms of education by the older traditional framework? The other question McDonald asks is: If we achieved distance education as good as face-to-face education would we then say online/distance education had achieved full success? There are already a number of deficiencies in the traditional university and tertiary learning environments including lack of full preparation of course material by lecturers, lack-lustre lectures, lack of personal communication with students when class sizes are large, and a sense of bureaucratic isolation by the institute shielded by policies and procedures. The advent of online e-learning may expose these deficiencies as new learning environments are devised and planned, and provide opportunities to improve the learning overall not just in technologically supported learning systems.

Online learning still involves reasonable amounts of text-based communication leading to less responsiveness and requiring more work to key information or causing less content to be covered. "Another consequence of text-based communication is that online education is less responsive than face-to-face, potentially inhibiting expression and eliminating non-verbal communication” (McDonald, 2002, p. 14). The arguments for and against online learning models are extensive and also have an impact on accreditation of an institution's programmes. An institution may integrate online components within an already accredited programme, but if the institution offers a pure online e-learning course then special accreditation may be necessary (McDonald, 2002).

Alternative studies evaluating non-traditional courses have focused on the 'Flexible-Delivery' course. Quinton (2006) describes a future scenario for various types of learning environments under the definition of flexible delivery. Flexible delivery would include the concept of accessibility any time and anywhere, and imply a multiplicity of media from traditional paper-based workbooks to DVD's, websites, audio and video. Quinton (2006) cites the Department of Education, Science and Training (2002, p. 51) defining flexible environments: 
Quality teaching is about finding the right balance between faceto-face communications, interaction via other media and individual work so that each learning experience is maximized. Flexible delivery of teaching is not intended to cut costs but to improve access and the quality of the learning experience for students.

Quinton (2006) expresses three aspects of flexible delivery; firstly: Flexible delivery itself with the many modes of content and environment, from face-toface to online discussion boards. Secondly, flexible teaching means lecturers and teachers must be responsive to the various modes of delivery and environments to be created and maintained online and on campus. Thirdly, flexible learning and thus flexible learning environments is dependant upon the institution providing a range of learning modes open to customization and personalization with a technical infrastructure for delivery.

Chandra and Fisher (2006) describe a study on the effectiveness of a blended web-based learning environment in an Australian high school. This study sought to use the results of the quantitative survey data to refine the learning environment.

"There are lots of examples in the blended learning environment where you can say you are comfortable doing something face-to-face and you know it works, but you can also look at parts of it that can be moved into the online environment," (Picciano, 2007, p. 1). In one course, blended learning may be used to enhance the traditional lecture with electronic instructor notes, additional readings, and images of charts, graphs, or other handouts. In another course, online learning may be combined with face-to-face instruction so that rather than meeting in a classroom three hours a week, a course meets two hours per week with the third hour consisting of an online threaded discussion.

Another study discusses some of the economic motivations of the tertiary sector for entering the e-learning and online course delivery relatively quickly. High 
levels of employment and the diminishing enrolments into New Zealand tertiary education generally have provided incentive for tertiary institutes to implement more flexible learning options. E-learning courses, it is thought, should provide enough flexibility to allow those in full or part time employment to continue with professional development, without the need to attend on-campus classes (Pascoe, 2007).

Another bonus of offering online learning is the ability to reach prospective students who live outside main centres, or are unable to attend classes due to family commitments. While there appears to be no problem in attracting students willing to enrol in online learning, there are problems with student retention and completion.

(Pascoe, 2007, p. 2)

Pressure to move towards online courses as an alternative is often driven by management however there is often some resistance from academics as lecturers are reluctant to leave the familiarity of the classroom or lecture theatre. Academics' general information technology skills may not be fluent enough to easily learn configuring and adding content to a learning management system (Pascoe, 2007). These issues need to be taken into account when the decision is taken to change existing courses towards online versions. Academic managers seem to hold a widespread belief that e-learning environments can reduce costs of buildings, campus resources, travel, and academic remuneration. This opinion asserts that the delivery of learning resources to distance and online students is ultimately more cost effective than primarily campus-based learning environments. In some examples the economies of scale required do actually reduce costs over the medium term, but this is less common. For most tertiary institutes, the longer time required to develop good quality, responsive online and multimedia resources often impede any prospect of cost saving, and often generate higher workloads and problems for teachers and managers in the tertiary environment. In the experience of some tertiary institutes, the attempted initiation of online web-based learning systems results in a higher comparative cost for courses and no guarantee of a return on investment (Wheeler, 2006). 
It appears that an increased workload is one effect of an online course compared to a traditionally delivered course. Many lecturers find they are to be responsible for the course design, content and facilitation without much assistance, and with very little training or knowledge of the skills required.

(Pascoe, 2007, p. 3)

As tertiary institutions begin engaging in online distance learning, there are some major assumptions that are being made. The planning around e-learning makes the assumption that lecturers will know how to teach in the online environment and that students will intuitively know how to manage the learning process. Many tertiary institutes have discovered when implementing online courses and when consulting with academic staff and administrators that the lecturers do not naturally and easily begin to teach online effectively. Academic staff need training and guidance in making the transition to the online and blended environment, and students also need instruction on how to learn online (Palloff \& Pratt, 2001).

Even in cases where specialist instructional designers and content managers are employed as part of an online project, there are difficulties in interaction between team members. Lecturers who are accustomed to total control of the courses they teach may feel uncomfortable handing over materials and course content to a content manager or instructional designer.

(Pascoe, 2007, p. 3)

\subsection{THE EFFECT OF EMERGING TECHNOLOGIES ON THE ONLINE LEARNING ENVIRONMENT}

The online environment is changing quickly and constantly with Web 2.0 technologies and virtual realistic environments expected to cause another wave of Internet influenced features. Chard (2006, p. 609) describes the virtual 
environment in the context of the web having "developed from an information publishing space to an interactive communication space”. The Internet supports online games with interaction and has developed entire 'worlds' such as Second Life where avatars are used to create user embodiment which are able to interact, communicate, and visually sense a three dimensional world. Authors of educational media are now beginning to investigate utilizing the three dimensional interactive virtual online environment which was originally developed by the gaming development community (Squire, 2003).

Nelson Marlborough Institute of Technology is investigating using the Second Life Internet website for teaching students (NMIT, 2007). The institute has been renting 'land' on an island which is shared and managed by 14 education institutes in a number of countries within Second Life.

Already, tertiary teaching is taking place around the world using Second Life, in areas such as arts and graphics, and health training. You can see the possibilities when, for example, you want to teach students how to deal with an accident situation, you can set up a virtual accident and have students react to it.

(NMIT, 2007, p. 1)

Second Life is an Internet hosted virtual environment managed by Linden Labs, California.

Users of the software sign up for a free account, create an 'avatar' to represent themselves and become members of the Second Life world. If the user (avatar) wants to buy land there is a monthly subscription. A growing number of educational institutions as well as businesses are offering courses from within this virtual world”. Dr Atkins says there are countless possibilities for translating real world scenarios into a virtual landscape which could make distance learning more visual and more engaging.

(NMIT, 2007, p. 1) 
The University of Leicester is leading research and experimentation with the SEAL (Second Environment Advanced Learning) project investigating the use of Second Life and interactive technologies with communities of practice and learners (Salmon, 2007). This emerging technology takes the potential online learning environment to the next level with the student experiencing a fuller immersion while utilising online resources. The issue of the balanced blended learning environment will remain however, as it is unlikely that the enrolled tertiary student will spend their entire learning time and classes within the virtual online environment for the duration of the course. One issue with the use of technology such as Second Life may be the ease with which the learnerparticipant can move from the online environment to the real-world environment. This transition may be more difficult with the use of systems such as Second Life or Virtual World. The unusual juxtapositioning of the 'real-world' and the virtual world is illustrated by the appointment of a 'real-world' economist to the Eve Online virtual world (NZ Herald, 2007, p. 13).

There are some technical infrastructural problems with leading-edge e-learning features. Ironically, the tertiary institute may be unable to provide the Internet and IT access for the advanced features offered on leading edge online systems. In order to secure an internal university network, often the Internet access is severely limited, with barriers to online shopping sites, blocking on video and audio files, and generally restrictive proxy Internet settings. This may have a negative impact on students who may be studying on campus from the library or computer rooms set up for flexible learning. Many students will have broadband Internet access at home however, so will not experience the same potential restrictions in their home environments given that 75 percent of New Zealand households have Internet access. Rickards (2003, p. 129) also confirms that "often students at all levels of education have better access to educational technologies at home than they do at school”.

Hung and Tan (2003) describe another set of emerging technologies with the growth of handheld devices incorporating cell phone, wireless Internet connectivity and small-scale software applications. This technology may have an 
impact on the conventional computer classroom or laboratory. "No longer do we need to 'go to the computer lab' where tables and chairs are 'rooted' to the positions in a rigid manner” (Hung \& Tan, p. 396). So even the traditional oncampus experience may be changing to a more fluid and flexible arrangement with the possibility of students supplying the 'workstation' and the tertiary institution supplying the IT infrastructure.

\subsection{NEW ZEALAND E-LEARNING PROJECTS}

The Mahara project is an open source electronic portfolio and system funded by the New Zealand Tertiary Education Commission and is managed by a consortium including Massey University, Auckland University of Technology, the Open Polytechnic of New Zealand and Victoria University. "Mahara is designed to provide users with the tools to demonstrate their life-long learning, skills and development over time to selected audiences” (Mahara, 2008, p.1). This type of nation-wide project has shown the collaborative advantages that are possible by tertiary institutes implementing education systems using emerging technologies across an entire country.

Flexible Learning in New Zealand is another country wide association as an online community that aims to develop resources and share knowledge and projects within flexible learning throughout the tertiary education sector in New Zealand (FLINZ, 2006). FLINZ also organizes workshops to help teachers throughout the tertiary sector in New Zealand to improve flexible teaching skills and create awareness of emerging technologies and to showcase other flexible learning projects that other universities and polytechnics are involved with.

Otago Polytechnic based in Dunedin, New Zealand has embraced the use of Wikieducator and Creative Commons Licensing for building online content with open access and utilizing “open” content from other sources rather than developing all online teaching materials internally (Otago Polytechnic Wikieducator, 2007). 
These New Zealand examples illustrate the variety of initiatives which are influencing flexible, blended and e-learning in the tertiary sector. A number of drivers for flexible learning are evident from these New Zealand projects including economic, pedagogical and the harnessing of emerging technologies, for example the use of the wikieducator (wikipedia based knowledge). This study seeks to set itself within the context of these wider national flexible learning projects and consortiums.

\subsection{BLENDED EXAMPLES FROM E-BUSINESS}

Education research is often criticized for introverted self-analysis, only seeking answers from within academia. However, the concept of blended models of delivery can be also found in cross-industry examination (Jelassi \& Enders, 2005, p. 42). For example, the news media is now broadening its audience channels by combining traditional media such as television and newspapers with newer channels such as news websites and the use of social networking websites. How this newly emerging e-business blended model will develop is not clear, but traditional media is still strong and is actively influencing the e-business channels and vice-versa. Other industries where the online channels are becoming very successful also demonstrate that the bricks and mortar segments are still popular long after the online success. These other examples would include Barnes and Noble which is one of the largest book sellers globally, but still maintains a network of 'bricks and mortar' book shops with book buyers still enjoying browsing and purchasing books in physical book shops as well as online. The success of eBay, and in New Zealand, Trademe.co.nz, have seen the phenomenal success of consumer to consumer e-business, but traditional classified advertising in newspapers and buyer guides are still providing viable marketing for consumers.

Lipponen, Lallimo, and Lakkala (2006) describe the area of Computer-Supported Cooperative Work (CSCW) involving networked learning environments, knowledge spaces, and discussion forums, for example, and how these concepts 
and practices from another field can be used to influence e-learning and blended learning environments.

These examples of blended business models from other industries combining ebusiness and traditional physical business channels help to illustrate the possible directions of tertiary education. The pure e-business models are likely to be successful for only a few large players, for example Amazon and, in education, a few large online globally positioned universities. For most businesses and organizations, e-business is being integrated into their overall business channels and environments and this is likely to be the case for tertiary institutes as well (Jelassi \& Enders, 2005).

\subsection{LITERATURE REVIEW SUMMARY}

This literature review has provided the theoretical framework on which the remainder of this study on optimization of blended learning environments will build upon. This chapter on learning environments for a mixed-mode (e-learning and traditional) learning environment for a tertiary institute or university has outlined some of the foundations of this field, in pure e-learning, in blended delivery models, and in the general field of learning environments.

This review is distinctive in the particular combining overview of online elearning developments affecting the learning environment, the traditional physical classroom learning environment, and the historic measurement of these two different environments. The literature reviewed has attempted to strike a balance between pure online e-learning environments, physical learning environments and mixed-mode environments. Effectively, most tertiary learning environments are blended environments, over a graduated spectrum, and so it is useful to consider the full range of literature in the learning environment field.

First, this review underlined the importance of the climate of learning environments (campus-based and online) given the significant number of hours that typical students experience over the duration of their tertiary education. The review described some of the methods by which learning environments could be 
evaluated which included instruments and surveys that have been used particularly for science, mathematics and technology in schools and in higher education. The online e-learning environment overall was described by several commentators in this growing domain, and the uniqueness and recent history was described. Some mention of the concerns of academics and commentators was outlined in the section on the online environment. The challenge of how to define the authenticity of a course was also discussed within the context of online and flexible-delivered courses.

Definitions of the blended or mixed-mode learning environment were reviewed with some researchers recommending the blended model as possibly having more merit than the purely online model. The influence of changing pedagogical practice on the newly emerging technologically-based courses was also discussed.

The role and presence of the teacher within the context of the online learning environment was discussed along with the government's positions. An overall description of typical learning management systems (LMS) was outlined.

The influence of the modern entertainment media upon web-based learning environments was discussed and the changes in students' expectations of tertiary institutes. The advent of social networking websites on the Internet was described with some comments on how this may affect blended learning in the near future.

Historic issues of integrating technology into university environments were covered with some similarities between the IT classroom integration issue of the 1990s and the current issues facing the tertiary sector with regard to e-learning and blended implementation.

Several definitions of "mixed-mode" or blended learning environments were outlined with similarities to other online learning experiences. Alongside this, some limitations of the learning environment in general were described, giving 
some broader social perspective on the issues facing teachers desiring optimal classroom environments.

Other studies which have researched the effectiveness of newly emerging learning environments, such as the virtual world of Second Life, were cited as parallel examples set alongside this particular study. Some technological issues were raised as practical implementation issues relating to creating the concrete reality of e-learning and blended tools and features. Recent country wide initiatives in e-learning and e-portfolios in New Zealand were outlined also.

Finally, this literature review considered some cross-industry analogies in the related field of e-business and drew some examples of successful blended approaches in other industries with some possible implications for blended tertiary education learning environments. 


\section{CHAPTER 3}

\section{METHODOLOGY}

“One ought to be more or less master of one’s model.” Paul Cezanne

\subsection{INTRODUCTION}

The previous chapter provided a review of the literature surrounding e-learning and traditional environments and how measurement and optimisation has been attempted by researchers and teaching institutions. The historic development of the WEBLEI instrument also was reviewed in the previous chapter.

After an examination of the research literature regarding the evaluation of online and traditional learning environments it was decided to perform a case study on the Eastern Institution of Technology, New Zealand. The overall investigation essentially takes a case study approach supported by triangulated data. Triangulation is an accepted means of reducing bias and reducing reliance on a single interpretation of a single source of data and results (Atkins \& Sampson, 2002). The WEBLEI instrument was chosen as the key research instrument in this study at EIT. The quantitative data from the WEBLEI completed by EIT students formed the centrepiece of this research along with student discussion feedback. Supplemental qualitative data in the form of emails and discussions were also sought from staff at EIT about their experiences and perceptions of the e-learning and blended learning environments. Clayton (2003, p. 157) confirms that "student and tutor reactions to and perceptions of this environment will have a significant impact on their performance”.

Qualitative data were also captured from the WEBLEI discussion questions completed by the EIT student participants. Additional qualitative data were also 
elicited from staff at the EIT who responded directly to the key research questions in this study.

\subsection{PREPARATION FOR THIS STUDY}

A previous literature review and paper was completed by me in 2006 with general observations of the blended learning environment as part of the preparation requirements for the Curtin University of Technology science education doctorate. As an information technology lecturer in a tertiary environment with several years experience with teaching in traditional classrooms and more recently setting up courses online, I had the opportunity to further this research with a quantitative instrument.

The WEBLEI has been used for investigating various features of e-learning (Chard, 2006) such as virtual environments, but it was decided that the peculiar blended environment of online and traditional would be a unique investigation together with a proposed recommendation for an optimised 'mix'.

EIT has a new appointment of an e-learning advisor and has also set up a new Teaching and Learning group charged with improving teaching effectiveness across the entire campus. This study could provide useful research and recommendations on both of these roles and functions at EIT. Further, the study could provide useful recommendations on optimising the blended learning environment in any tertiary environment.

As an active information technology lecturer, I am able to observe student behaviour and learning environments in the tertiary field on a daily basis as well as discuss online/traditional environments with other tertiary teachers in the school of information technology at EIT so this has provided in-depth preparation to this research. This ethnographical element of this research, engaging in participant observation, allows a deeper understanding of the overall context and environment of the organisation under study (Hall, 2005). However, there is the 
possibility of some bias on the interpretation of results given the diverse nature of the insiders’ world of meaning (Jorgenson, 1989).

\subsection{RESEARCH QUESTIONS}

This section introduces the essential research questions for this study. The questions take a holistic approach to the entire learning environment at EIT, which is an example tertiary institute or university typical in its approach to implementing e-learning and online courses within the overall offering of traditional and newer flexible programmes.

Are modern tertiary students experiencing a sense of being in a positive, encouraging learning environment? Has the recent addition of the LMS really enhanced the overall learning environments from the student's perspective?

Previous research has provided some warnings for the losses which may be incurred when online courses replace face to face interaction without adequate replacement for the traditional interaction. The competitive advantage of using the LMS may already be over with all tertiary institutes now utilising a webbased learning management system to some degree.

What elements help construct an ideal or optimal blended learning environment in a tertiary setting? How can the best components of online e-learning be combined with the best components of the traditional 'bricks and mortar' classroom learning environments? Is there an ideal mix of the two types of environments?

Does e-learning in some form of implementation actually undermine or damage the 'real-world' learning environment? Are we simply forced by the trends and increase of Internet activity to 'jump on board' regardless of the cost to academic quality and sense of community? 
With the research questions outlined and described, suitable instruments and methods were considered for this study. The next section describes the instrument selection, the use of the research questions amongst staff, and the discussion questions attached to the WEBLEI for the student respondents.

\subsection{DESCRIPTION OF THE WEBLEI INSTRUMENT}

A wide range of instruments have been developed by researchers in the learning environment field. The WEBLEI was chosen as a prime candidate as it has a proven track record in a number of studies and has documented validity. Other qualitative techniques were seen as additional sources of rich data to contextualise the WEBLEI data.

The WEBLEI instrument is divided into four scales called Access, Interaction, Response, and Results. As Chang and Fisher (2003) describe, in order to study in an online environment the student requires access to web-based materials, then students need to interact with one another and their teacher through various online mechanisms. Thirdly, a response is useful from the student to indicate their perception of this learning environment. Finally, the Results scale allows the student learner to provide feedback on the advantages of this online learning environment. These four scales were also influenced and adapted from Tobin's (1998) work on learning communities.

In this current study, the overall structure of the WEBLEI was retained; however a small number of questions were changed to attempt to collect students' experiences of both the traditional learning environment as well as the online environment. These changes allowed a wider reflection from students regarding not only the online environment but also the overall totality of environments (including classrooms and laboratories). Details of the adapted WEBLEI for the EIT study are fully described in a following section (3.6) of this chapter. 
The WEBLEI instrument contains four scales as outlined in Figure 3.1.

\begin{tabular}{|c|c|}
\hline $\begin{array}{c}\text { Scale II } \\
\text { Co-participatory }\end{array}$ & $\begin{array}{c}\text { Scale I } \\
\text { Emancipatory }\end{array}$ \\
\hline $\begin{array}{c}\text { INTERACTION } \\
\text { Participation, collaboration and } \\
\text { cooperation }\end{array}$ & $\begin{array}{c}\text { ACCESS } \\
\text { Virtual subject }\end{array}$ \\
\hline $\begin{array}{c}\text { RESPONSE } \\
\text { Perceived student responses }\end{array}$ & $\begin{array}{c}\text { RESULTS } \\
\text { Scope, structure, content, learning } \\
\text { objective }\end{array}$ \\
\hline $\begin{array}{l}\text { Scale III } \\
\text { Qualia }\end{array}$ & $\begin{array}{c}\text { Scale IV } \\
\text { Information Structure and Design }\end{array}$ \\
\hline
\end{tabular}

Figure 3.1. WEBLEI scales (Change \& Fisher, 2003).

Although the WEBLEI was seen as the main instrument, some changes were foreseen for its adaptation to the tertiary environment and specifically the Eastern Institute of Technology environment. Also, some additions were seen as beneficial to explore the balance and tension between campus and online learning environments as this study sought to recommend optimal combinations of learning environments.

A number of recent studies have validated the use of the WEBLEI instrument. For example, Chang and Fisher (2003) described a study with 344 students using a web-based learning management system at Curtin University of Technology and confirmed that the concept of online learning was received positively by the majority of students. A number of other studies outlined in section 2.10 of Chapter Two confirmed the effective use of the WEBLEI instrument and the generally positive effect of web-based learning systems on the learning environment (Chard, 2006; McDonald, 2002; Pascoe, 2007; Picciano, 2007; Quinton, 2006; Wheeler, 2006). 


\subsection{SELECTION AND DESCRIPTION OF THE SAMPLE}

The tertiary educational environment increasingly emphasises the student learning experience within a constructivist framework. This philosophy lends itself readily to online e-learning student-centred environments and flexible oncampus classrooms.

The Eastern Institute of Technology with a student population over 3,500 (equivalent fulltime) and offering a range of bachelors degrees and diplomas, is a typical example of a small to medium institute of technology or university in the New Zealand or Australian environment.

There are strong external drivers causing changes in the tertiary sector in New Zealand. The New Zealand government is reverting to funding regionally focused courses and trying to devolve from the 'bums on seats' funding model where funding was based purely on the numbers of students enrolled to a more focussed set of goals that are regionally based (Cullen, 2007). In addition to this environmental change, the typical tertiary classroom is no longer primarily populated by young school-leavers but rather by a wide range of ages and demographics. Added to these changes is a strong push to e-learning models fuelled by economic incentives with tertiary institutes seeking early competitive advantages and aligning to a governmental social agenda to break down all barriers to tertiary education.

There is increasing pressure for teaching staff in the tertiary sector to personally 'engage' each learner in their care, whether that be online or classroom based. The era of two hundred or more tertiary students passively listening to a lecturer at the front of a classroom with an overhead projector is no longer acceptable in this marketing age where students have many choices of tertiary study.

Forty five percent of tertiary students at EIT are aged over 25 years. Some of these students have relevant work experience in their field of study and are simply attempting to gain an official qualification for a career/job they already 
may possess. The Business and Computing Faculty at the Eastern Institute of Technology was chosen as a representative mix of student subjects ranging from highly skilled IT students through to general business students at an introductory level.

Student descriptions in the survey form included whether the student was a year one, year two or year three student. Gender was also recorded in the WEBLEI survey form, as well as four age ranges, the school in which the student was enrolled (School of Business or School of IT), and the type of programme (Certificate, Diploma and Degree) in which the student was enrolled. The student sample was chosen from the Faculty of Business and Computing and included 151 students from 12 different classes within various Business and IT Diploma, Degree and Certificate courses within the faculty. The students were largely enrolled as traditional campus-based students but all had access to the EIT online learning management system (Moodle). The breakdown of how many students were in first, second and third year as well as male/female is displayed in Table 3.1.

\begin{tabular}{|l|l|}
\hline Composition of Students & Number of Students \\
\hline Male & 64 \\
\hline Female & 71 \\
\hline Certificate & 2 \\
\hline Diploma & 49 \\
\hline Degree & 84 \\
\hline First Year & 57 \\
\hline Second Year & 33 \\
\hline Third Year & 45 \\
\hline Total Sample (135 valid) & 151 \\
\hline
\end{tabular}

Table 3.1: Composition of Student Data Sample 


\subsection{JUSTIFICATION OF THE ADAPTED WEBLEI FOR THE EIT ENVIRONMENT}

As displayed in Table 3.2, the changes made to the standard WEBLEI included changing question 8, within the Access scale, from: "The flexibility allows me to explore my own areas of interest"; to "I prefer online learning rather than realworld classroom learning from a lecturer”. It was thought that there was a reasonable overlap between question 7 and question 8 on the standard WEBLEI as question 7 covered the flexibility issue but for this investigation on blended optimisation, student preferences for online versus traditional was an important issue to address. All other questions in the Access scale were retained although the name of the LMS, Moodle, was added to prompt students in question 2: "The on-line material (Moodle) is available at locations suitable for me”; to ensure students easily identified EIT’s main online learning environment.

In the Interaction scale, question 14, question 15 and question 16, relating to self and peer evaluations, were replaced with questions on reliance, frequency and community as these were considered key perceptions of students that could influence any recommended blended environment. So, question 14 invited response to the statement; "I would find it difficult to study on this course without regular interaction with the Moodle resources”. This was an attempt to evaluate students' interaction with the course content and learning resources and was intended to indicate where any group of students felt that the course completion was dependant on Moodle participation. question 15 stated; "I regularly interact with Moodle (at least twice a week);" and question 16 stated; "I felt there was an 'online community' with other students on the course”. These two questions tried to ascertain just how regularly students were accessing and interacting with the online resources and whether they felt a useful group of other students were doing the same. 
Table 3.2.

Adapted Blended-mode WEBLEI Scales and Items

Scale I: Access

1. I can access the learning activities at times convenient to me.

2. The on-line material (Moodle) is available at locations suitable for me.

3. I can use the time saved in travelling and on campus class attendance for study and other commitments.

4. I am allowed to work at my own pace to achieve learning objectives.

5. I decide how much I want to learn in a given period.

6. I decide when I want to learn.

7. The flexibility allows me to meet my learning goals.

8. I prefer online learning rather than real-world classroom learning from a lecturer.

Scale II: Interaction

1. I communicate with other students in this subject electronically.

2. In this learning environment, I have to be self-disciplined in order to learn.

3. I have the autonomy to ask my tutor what I do not understand.

4. I have the autonomy to ask other students what I do not understand.

5 . Other students respond promptly to my queries.

6. I would find it difficult to study on this course without regular interaction with the Moodle resources.

7. I regularly interact with Moodle (at least twice a week).

8. I felt there was an "online community" with other students on the course.

Scale III: Response

1. This mode of learning enables me to interact with other students and the tutor asynchronously (e.g. forum and email).

2. I felt a sense of satisfaction and achievement about this learning environment.

3. I enjoy learning in this environment (Moodle).

4. Moodle is no substitute for on-campus classes.

5. It is easy to organise a group for a project.

6. It is easy to work collaboratively with other students involved in a group project.

7. The web-based learning environment held my interest throughout my course of study.

8. I felt a sense of boredom with the online material towards the end of my course of study.

Scale IV: Results

1. Each Moodle course is setup clearly with learning objectives clearly stated.

2. Links to other websites are no substitute for printed references or articles.

3. The structure keeps me focused on what is to be learned.

4. I am happy to print lecture and exercise material from Moodle.

5. I can see the connection between the Moodle course and the campus course.

6. The subject content is appropriate for delivery on the Web.

7. The presentation of the subject content is clear.

8. Online resources plus the classroom teaching enhances my learning. 
Within the Response scale, question 20 stating; "I could learn more in this environment" was replaced with; "Moodle is no substitute for on-campus classes". The original statement was slightly ambiguous as it could mean that the student thinks they can learn more than in the traditional classroom or it could mean that there is potential for the student to get more out of the online resources than they are currently achieving. For the purposes of this study, it was important to keep the tension between online and traditional learning environments as a defining nexus in the eyes of the student/respondent.

In the last scale of Results, as displayed in Table 3.2, there were more significant changes as the purpose of this particular survey was not to just critically evaluate the particular features of the EIT learning management system and how well lecturers were presenting materials. This survey wanted a more philosophical approach and insight into the general preferences of tertiary students towards the online and campus environments. question 25 was slightly re-worded to; "Each Moodle course is setup clearly with learning objectives clearly stated" in comparison to the original; "The scope or learning objectives are clearly stated in each lesson”. The original statement for question 26 was removed as there was an overlap with question 25. This was replaced with; "Links to other websites are no substitute for printed references or articles”, as this has been an issue with EIT students and with staff undertaking distance education.

A new statement for question 28; "I am happy to print lecture and exercise material from Moodle” replaced; "Expectations of assignments are clearly stated in my unit” as printing charging has been a contentious issue with students who, historically, have not been charged for IT services. Question 28 also allowed students to indicate the potential disadvantage of learning content that was presented online only and requiring printing at home or at EIT while being charged for pages printed. This question allowed a potential disadvantage of the online learning environment to be explored. Question 29 which stated; "I can see the connection between the Moodle course and the campus course” replaced the standard; “Activities are planned carefully”. This was to explore the notion of students' perception of the relationship between the online course and the campus 
course. These changes that have been outlined brought the adapted WEBLEI into alignment with the aims of this particular study without reducing the integrity of the instrument.

\subsection{DESCRIPTION OF THE QUALITATIVE METHOD}

\subsubsection{Justification of including supplementary qualitative approaches}

By complementing the quantitative data from the student WEBLEI with students' discussion questions and collecting tertiary staff feedback on the research questions it was thought to gain a richer understanding of ideal blended learning environments.

Combining qualitative and quantitative methods in learning environment research has been demonstrated to be complementary and is expected to yield deeper and richer results in learning environment case studies (Fraser \& Tobin, 1991). The group mean of any quantitative study alone may not itself reveal the differential experiences of students or teachers. "We cannot envision why learning environment researchers would opt for either qualitative or quantitative data, and we advocate the use of both in an effort to obtain credible and authentic outcomes” (Tobin \& Fraser, 1998, p. 639).

\subsubsection{Collection of student qualitative data}

The qualitative student data were collected through additional discussion questions added to the WEBLEI form. After completing the quantitative section, students were invited to write short comments on five questions. These questions were:

1. Why are you studying in an on-line/blended mode?

2. What are the advantages of studying in an on-line/blended mode?

3. What are the disadvantages of studying in an on-line/blended mode?

4. Are they any suggestions to improve the delivery of your courses in an 
on-line/blended mode?

5. Do you prefer traditional classes and lectures with paper-based workbooks and reference materials?

The student data from these questions were collected on the paper-based WEBLEI forms which were distributed to students through various lecturers within their classes over a six week period in March and April 2007. The student comments are recorded on the WEBLEI forms. The results of the student qualitative data are presented and discussed in Chapter Five of this study.

\subsubsection{Collection of staff qualitative data}

The staff qualitative data were collected through responses to an email sent to all 350 staff at the Eastern Institute of Technology. The email invited all staff to respond to the research questions outlined in this study and described in section 3.3. Twenty five staff responded to this email and these staff email responses are archived on the EIT email system. The contents of the email sent to all staff are displayed in the Appendices of this study.

Interviews were held with the e-learning advisor, the academic manager, and the head of the Information Technology School. These interviews were focussed on expanding those staff responses to the email and research questions. The interviews also clarified the e-learning strategy of EIT and the programmes that are aiming to help achieve the goals of the EIT e-learning strategy. The interview with the IT Head of School also further explained the concept of flexible delivery programmes as another alternative to the traditional concept of e-learning.

The results of the staff qualitative data are presented and discussed in Chapter Six of this study. 


\subsection{DATA COLLECTION FOR WEBLEI QUANTITATIVE DATA}

Generally, the WEBLEI was distributed as a paper-based instrument through 16 lecturers within the Business and Computing Faculty. The WEBLEI was handed out to students at the beginning of class sessions and a verbal description of the study was given. The advice to respondents was also read to the class. In most cases, the completed WEBLEI was retrieved by the lecturer at the end of the class session. Some classes did need reiteration that this study was independent of EIT academic management, and that no direct changes to their courses would necessarily be made by EIT management as a result of student responses.

Some completed surveys were returned by students, lecturers and administrators individually over the six week period that the surveys were undertaken. The surveys were undertaken in March and April 2007.

All 151 surveys were collected and stored by myself in my EIT office, and are to be transferred to Curtin University of Technology at the end of this study.

\subsection{DATA ANALYSIS}

SPSS data analysis software was set up with summarised question headings and short headings ready for data entry. The 151 WEBLEI surveys were manually entered into a SPSS data file. These data were analysed for frequency of responses for each question and for overall number of responses.

The student discussion questions were collected and stored on the WEBLEI forms. The discussion comments by students were sorted into three main categories for further research discussion.

The staff qualitative data were received by multiple email documents and recorded into the EIT email archives. The comments and discussion by staff were copied and recorded in MS Word format and are discussed in Chapter Six of this 
study. The majority of staff comments have been recorded and presented within Chapter Six.

\subsection{ETHICS CONSIDERATION}

The type of data included responses to paper-based surveys of students and email responses from a staff questionnaire. The WEBLEI instrument was distributed to classes within the Faculty of Business and Computing at EIT early in semester one of 2007. The staff email questionnaire was distributed in August, 2007.

Approval was granted for this research by the Research and Ethics Committee at the Eastern Institute of Technology in February, 2007. Approval was granted from the Curtin University of Technology Human Ethics Committee in January, 2007. The Eastern Institute of Technology allowed its name to be used in this thesis but names of individual students were not used.

The procedures for survey participation included safeguarding student participants' privacy and setting up non-intrusive classroom surveys where consent had been gained from teachers. Surveys were distributed to classes and programmes not taught by the researcher/teacher involved to avoid undue personal influence.

Staff who participated in the email survey have remained anonymous, however some staff comments from interviews could be identified through the position description.

\subsection{METHODOLOGY SUMMARY}

The research basis of this study is based on an overall case study approach with a mix of quantitative and qualitative data collection and analysis. An adapted WEBLEI survey of Business and IT tertiary students within the Eastern Institute of Technology, associated discussion questions, and a qualitative survey undertaken by staff at EIT. This survey is encapsulated within other case study 
elements of the current usage of the LMS at EIT and the researcher's observations and informal interviews with staff and students.

The quantitative results of the WEBLEI were analysed and are presented in Chapter Four of this study. The qualitative results from the discussion questions with students are presented in Chapter Five of this study. The qualitative results from the research questions discussed by tertiary staff at the Eastern Institute of Technology are presented in Chapter Six.

This chapter has provided a description of the methodology used to undertake this study of optimal blended learning environments in the tertiary sector. The chapter presented seven research questions that have guided the study and have also been directly responded to by the staff at EIT. These research questions also underpinned the WEBLEI questions undertaken by the EIT student respondents. The rationale for selecting the data collection instruments was described in this chapter, and the reasons for supplementing the quantitative data with more generalised qualitative comments based data was outlined. In Chapter Four, students' perceptions of their experiences within a blended learning environment are examined and analysed statistically. 


\section{CHAPTER 4}

\section{VALIDATION AND APPLICATION OF THE WEBLEI}

“I have gotten a lot of results. I know several thousand things that won't work.”

Thomas Edison

\subsection{INTRODUCTION}

Chapter 3 outlined the preparation for this study and described the research questions. This section describes evidence to support the validity of the WEBLEI instrument and some supporting rationale for an adapted WEBLEI aimed at tertiary information technology students. The experiences and perceptions of the students are presented with regard to online e-learning environment features and traditional learning environment features. This chapter also presents data describing differences (if any) between gender, age group, school, year of study, and type of programme within the context of the students' experience of the blended learning environment.

\subsection{STUDENT DATA}

This chapter presents results of the statistics calculated from the EIT WEBLEI database consisting of the responses of 151 students across multiple Degree, Diploma and Certificate programmes within the Faculty of Business and Computing at the Eastern Institute of Technology, Napier, New Zealand. The data were collected over the March to April period in 2007 from a range of classrooms within the Faculty of Business and Computing. 


\subsubsection{Demographic profile}

Demographic information was gathered about the students who responded to the WEBLEI within the Faculty of Business and Computing at EIT. Sixty two percent of students were enrolled in a degree programme, $36 \%$ enrolled in a Diploma programme, while only two students were enrolled in a certificate course. Thirty one percent of respondents were aged 16 to 20 years of age, the largest group, while all other age groups were approximately evenly distributed.

Fifty five percent of student respondents were within the Information Technology school while the remainder were from the Business school within the Faculty of Business and Computing. Gender was reasonably evenly balanced within the sample group with $47 \%$ being female and $53 \%$ male.

\subsection{RELIABILITY AND VALIDITY OF THE WEBLEI (ADAPTED)}

A factor analysis was carried out to verify the internal structure of the WEBLEI instrument. Table 4.1 displays the analysis of the internal consistency, using the Cronbach alpha reliability coefficient, and discriminant validity, using the mean correlation of a scale with all the other scales as an index, of the EIT adapted WEBLEI. The Cronbach alpha reliability coefficients shown in Table 4.1 show the figures ranging from 0.65 through to 0.79 suggesting that the scales are reliable. The discriminant validity displays the mean correlations that ranged from 0.33 to 0.39 which suggests that the scales of the EIT adapted WEBLEI measure distinct but related areas of the blended learning environment. 
Table 4.1.

Cronbach Alpha Reliability and Discriminant Validity of the EIT WEBLEI

Validation

Statistics

\begin{tabular}{lllll}
\hline Scales & Items & $\begin{array}{l}\text { Valid } \\
\text { Cases }\end{array}$ & $\begin{array}{l}\text { Alpha } \\
\text { Reliability }\end{array}$ & $\begin{array}{l}\text { Discriminant } \\
\text { Validity }\end{array}$ \\
\hline Scale I: Access & 8 & 140 & 0.79 & 0.39 \\
Scale II: Interaction & 8 & 142 & 0.65 & 0.33 \\
Scale III: Response & 8 & 128 & 0.76 & 0.37 \\
Scale IV: Results & 8 & 142 & 0.73 & 0.39 \\
& & & & \\
\hline
\end{tabular}

\subsection{VALIDATION SUMMARY}

Although the WEBLEI instrument has had previous validation from many other studies (Chang \& Fisher, 2003; Chard, 2006), it was important to validate the adapted EIT WEBLEI for this particular study. The four core aspects of the WEBLEI were retained in this adapted instrument with some individual statements changed. The adapted WEBLEI has been shown to have factorial validity and the WEBLEI scales within this adapted instrument have acceptable reliability and discriminant validity from a statistical perspective. In this study, the adapted WEBLEI has been used in a tertiary environment with particular focus on evaluating the blended learning environment. The survey of 151 tertiary students show that online learning coupled with traditional delivery is appreciated and even expected now from typical tertiary students. Further results from this adapted WEBLEI instrument are presented within this chapter.

\subsection{MEANS AND SCALE RESULTS}

The mean scores, as displayed in Table 4.2, (3.62, 3.31, 3.06, 3.83) for the four scales show that on average the student respondents gave a response of "Sometimes" to "Often" on the items in these scales. This would indicate a favourable response on most statements with an overall mean of 3.45 which indicates a relatively high mean over the 32 statements. 
Table 4.2

WEBLEI Descriptive Statistics

\begin{tabular}{lllll}
\hline Scales & Items & $\begin{array}{l}\text { Valid } \\
\text { Cases }\end{array}$ & Mean & sd \\
\hline Scale I: Access & 8 & 140 & 3.62 & 0.39 \\
Scale II: Interaction & 8 & 142 & 3.31 & 0.33 \\
Scale III: Response & 8 & 128 & 3.06 & 0.37 \\
Scale IV: Results & 8 & 142 & 3.83 & 0.39 \\
& & & & \\
\hline
\end{tabular}

The mean score of Scale I (Access) of 3.62, displayed in Table 4.2, indicates that students in the Faculty of Business and Computing at EIT generally agree that they can access the online learning materials within their overall mixed learning environment in a reasonable manner. The Moodle learning management system at EIT seems to provide them with autonomy of choosing when and where to gain access to learning materials. One key statement (Q.8) within this Access section asked whether the student prefers online learning compared to classroom learning. It appears that students who are comfortable with online e-learning and are satisfied with the provision and access to the online learning environment may still have a strong preference for either online learning or for classroom environments. This is reflected in the fact that approximately $60 \%$ of respondents replied "never" or "seldom" to this statement, indicating that students still value the real-world physical interaction with teachers despite an accompanied satisfaction with an online learning environment running in parallel.

The mean score of Scale II (Interaction) of 3.31, reflecting the range of "sometimes" to "often", shows that the students at EIT believed they were able to participate and interact with other students within the online environment. Students generally sensed that there was a form of online community with lecturers and other students in the general learning environment. This is an important aspect of the blended learning environment as students may learn more from engaging in the Faculty community than studying alone. 
A mean score of 3.06 was calculated for Scale III (Response), and indicates that generally students feel a reasonable sense of achievement and satisfaction after using Moodle to help complete their particular course. The mean score of 3.06 was the lowest score of the four scales and may reflect some disdain for group work (Q.22) in general and some feedback that online courses have difficulty sustaining a high level of interest throughout a semester period. The Response scale includes feedback from students on how they experience and perceive the web-based system in terms of interaction with other students and the lecturer. The mean score of 3.06 would indicate less agreement with this interaction than other aspects of the web-based learning environment.

Finally, Scale IV (Results) had a mean score of 3.83, shown in Table 4.2, which would indicate that students at EIT agree that the learning aims and general organisation of the online course materials were crucial in helping them in their studies. Variations between classes of students may of course reflect different lecturers' level of skill in making use of the Moodle features and the quantity and quality of learning materials made available to each different class. This mean score of 3.83 in the Results scale was the highest score of the four scales of access, interaction, response and results. Student respondents were positive towards the presentation and effectiveness of the Moodle environment at EIT admitting that overall the Moodle courses were improving their learning and results regardless of how integrated the online learning was structured. The high mean on this Results scale was in spite of the statement regarding printing online material having a lower score than most other statements on the entire WEBLEI survey.

\subsection{GENDER DIFFERENCES IN THE WEBLEI RESPONSES}

Gender differences in the online and blended environments were examined using an independent sample test in SPSS with the four WEBLEI scales as dependent variables. Males ( $n=64$ or $47 \%)$ and females ( $n=71$ or $53 \%)$ were represented reasonably equally in the study. 
Table 4.3

Scale Means and Standard Deviations for Male and Female EIT Students' Scores on the Four WEBLEI Scales

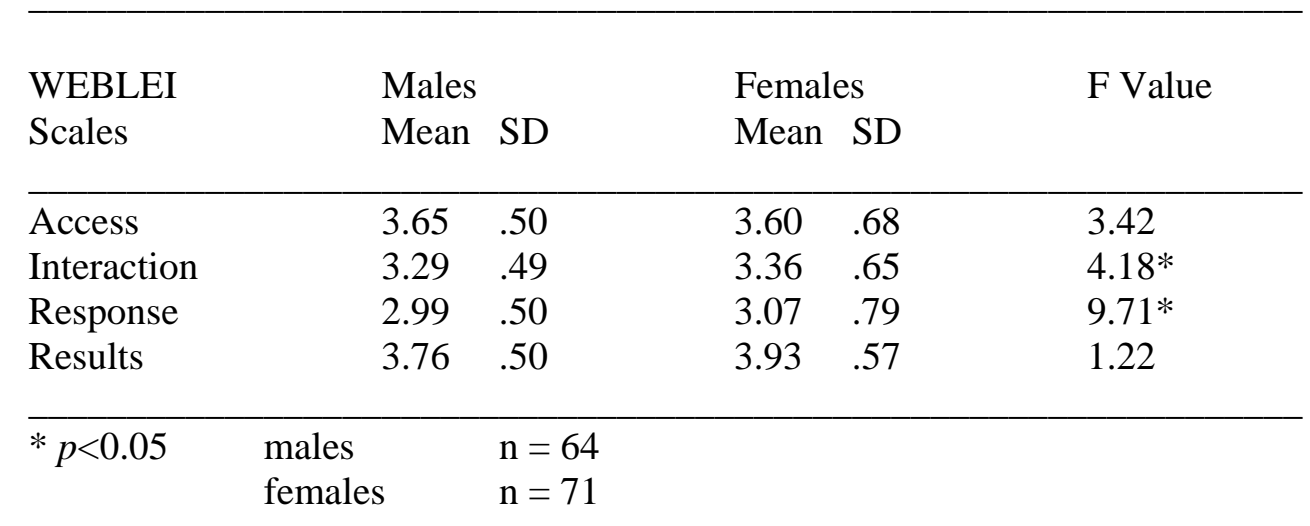

Statistically significant differences in students' mean scores were apparent in responses to the Interaction (Scale II) and Response (Scale III) scales as shown in Table 4.3. Female respondents scored greater on those statements relating to student interaction with each other in the online environment, and on those statements relating to group work and positive response to the completed course. These differences may generally indicate that females are more likely to interact with other students in an online environment and also respond more positively to undertaking study online.

This finding may have implications for any proposed ideal blended learning environment. Any mechanisms aimed at improving interaction and response by online means or through improvement in other communication vehicles will be positively received by students, particularly females. Another possible interpretation of these results is that females may act as an effective catalyst within groups of students where good interaction, online and in classroom situations, is desired. This may have implications for courses which are populated with predominately males, and may imply that less online interaction between male students and their teacher may occur. 


\subsection{YEAR DIFFERENCES IN WEBLEI RESPONSES}

Table 4.4

Scale Means and Standard Deviations for Year Levels of EIT Students' Scores on the Four WEBLEI Scales

\begin{tabular}{|c|c|c|c|c|}
\hline $\begin{array}{l}\text { WEBLEI } \\
\text { Scales }\end{array}$ & $\mathrm{N}$ & Mean & SD & F Value \\
\hline \multicolumn{5}{|l|}{ Access } \\
\hline Year 1 & 57 & 3.60 & .65 & \\
\hline Year 2 & 33 & 3.63 & .49 & \\
\hline Year 3 & 45 & 3.63 & .61 & \\
\hline Total & 135 & 3.62 & .60 & .046 \\
\hline \multicolumn{5}{|l|}{ Interaction } \\
\hline Year 1 & 57 & 3.38 & .59 & \\
\hline Year 2 & 33 & 3.33 & .51 & \\
\hline Year 3 & 45 & 3.21 & .58 & \\
\hline Total & 135 & 3.31 & .57 & 1.056 \\
\hline \multicolumn{5}{|l|}{ Response } \\
\hline Year 1 & 57 & 3.11 & .67 & \\
\hline Year 2 & 33 & 3.03 & .61 & \\
\hline Year 3 & 45 & 3.00 & .64 & \\
\hline Total & 135 & 3.05 & .64 & .388 \\
\hline \multicolumn{5}{|l|}{ Results } \\
\hline Year 1 & 57 & 3.84 & .51 & \\
\hline Year 2 & 33 & 3.91 & .51 & \\
\hline Year 3 & 45 & 3.76 & .59 & \\
\hline Total & 135 & 3.83 & .54 & .766 \\
\hline
\end{tabular}

There were no significant statistical differences between the three year levels of the student respondents as shown in Table 4.4. The spread of students in year levels showed as: Year 1 ( $n=57$ or $42 \%)$, Year $2(n=33$ or $24 \%)$ and Year 3 ( $n=45$ or 33\%). This even result across all year levels for each of the four scales of the WEBLEI may indicate that final year students do not perceive their use of the online learning environment as any more critical than the first year students. 
There are perhaps different, yet still important reasons, for engaging online and on-campus regardless of the stage of the tertiary student. Year 1 students may have a greater urgency for access to materials online, while the final year student may enjoy the greater flexibility the online environment gives and may spend less time on campus. So each year group may have a similar level of satisfaction with online engagement yet this satisfaction may arise from different reasons and motivations. In summary, it appears there is no significant difference in the level of appreciation, usage and perception of the online component within the overall blended learning environment across the three year levels.

The implications for any recommended blended learning environment may be influenced by this evenly distributed positive response from a wide selection of student levels. The factors that create an optimal blended environment may be effective across a variety of student levels (academically and institute embedded). This may imply that a completely separate mix of flexible, online, web and classroom-based environments for Diploma, Degree and Certificate programmes may not be necessary. 


\subsection{AGE DIFFERENCES IN WEBLEI RESPONSES}

Student respondents at EIT were divided into four categories; (16-20 years), (2125 years), (25-40 years), and 40 years and over. There were no significant statistical differences between the age levels for three (Access I, Interaction II and Results IV) of the four WEBLEI scales. However, there were statistically significant differences between age level groups within the Response scale III. The age levels 25 - 40 years and the 40 years and above both reported lower agreement levels than average within the Response scale. Table 4.5 presents the means for all four age groups within the four statement scales. It appears that older students may experience less satisfaction with the responsiveness of other students using the learning management system as they may have a greater expectation of participation by other students.

Comments within the discussion questions also supported this concept of older students, 25 years and older, having a higher expectation of themselves, of the course they were enrolled in, and the resources available to them. This higher level of expectation may be manifest in an online web-based learning environment where these students expect most other students in their course to be adding comments within the discussion forums, posting material on the wikis, and generally communicating online via chat mode or email. When these mature students discover that only two or three students and the lecturer are actively participating online, on a course with 30 students enrolled and attending physical classes, they may experience some disappointment with the reality of online communication and engagement.

Younger students, under 25 years of age, may hold a more pragmatic viewpoint of navigating an online course and not have a high expectation of frequent online communication and responsiveness. Some comments from the discussion questions confirm this attitude where younger students are satisfied with informational content provided online, together with clear assessment definitions, so these students just "get on with the course requirements" regardless of the paucity of online responsiveness. 
Table 4.5

Scale Means for Age Ranges of the EIT Students' Scores on the WEBLEI

\begin{tabular}{|c|c|c|c|}
\hline $\begin{array}{l}\text { Scale } \\
\text { Age }\end{array}$ & Mean & $\mathrm{SD}$ & F Value \\
\hline \multicolumn{4}{|l|}{ Access } \\
\hline $16-20$ & 3.76 & .54 & \\
\hline $21-25$ & 3.64 & .55 & \\
\hline $25-40$ & 3.53 & .77 & \\
\hline 40 or more & 3.50 & .44 & 1.370 \\
\hline \multicolumn{4}{|l|}{ Interaction } \\
\hline $16-20$ & 3.44 & .51 & \\
\hline $21-25$ & 3.33 & .49 & \\
\hline $25-40$ & 3.27 & .67 & \\
\hline 40 or more & 3.20 & .65 & 1.060 \\
\hline \multicolumn{4}{|l|}{ Response } \\
\hline $16-20$ & 3.18 & .61 & \\
\hline $21-25$ & 3.22 & .59 & \\
\hline $25-40$ & 2.88 & .75 & \\
\hline 40 or more & 2.83 & .64 & $3.073 *$ \\
\hline \multicolumn{4}{|l|}{ Results } \\
\hline $16-20$ & 3.81 & .49 & \\
\hline $21-25$ & 3.79 & .55 & \\
\hline $25-40$ & 3.80 & .60 & \\
\hline 40 or more & 4.05 & .54 & 1.525 \\
\hline
\end{tabular}

$* p<0.05$ 


\subsection{OVERALL RESULTS FOR ALL WEBLEI QUESTIONS}

Table 4.6

Descriptive Statistics of all Questions of the EIT WEBLEI

\begin{tabular}{|c|c|c|c|c|}
\hline \multicolumn{5}{|c|}{ Descriptive Statistics } \\
\hline Aspects & Question & $\begin{array}{l}\text { Valid } \\
\text { Cases }\end{array}$ & Mean & sd \\
\hline \multicolumn{5}{|l|}{ Scale I: Access } \\
\hline Access to learning & 1 & 151 & 3.70 & .61 \\
\hline Moodle Available & 2 & 148 & 4.41 & .75 \\
\hline Use saved time & 3 & 147 & 3.56 & 1.09 \\
\hline Work at own pace & 4 & 146 & 3.61 & .93 \\
\hline Decide how much & 5 & 145 & 3.80 & .99 \\
\hline Decide when learn & 6 & 142 & 3.89 & .98 \\
\hline System flexible & 7 & 146 & 3.85 & .87 \\
\hline Prefer online learn & 8 & 149 & 2.82 & .95 \\
\hline \multicolumn{5}{|l|}{ Scale II: Interaction } \\
\hline Communicate other students & 9 & 149 & 2.19 & .97 \\
\hline Disciplined learner & 10 & 147 & 4.05 & .90 \\
\hline Autonomy ask tutor & 11 & 148 & 3.82 & .93 \\
\hline Autonomy to ask students & 12 & 147 & 3.45 & 1.02 \\
\hline Students respond online & 13 & 143 & 3.12 & 1.06 \\
\hline Difficult without Moodle & 14 & 149 & 3.44 & 1.12 \\
\hline Use Moodle regularly & 15 & 151 & 3.97 & 1.12 \\
\hline Online community & 16 & 146 & 2.33 & 1.00 \\
\hline \multicolumn{5}{|l|}{ Scale III: Response } \\
\hline Interact online & 17 & 145 & 3.34 & 1.05 \\
\hline Satisfaction learning environ & 18 & 144 & 3.28 & .88 \\
\hline Enjoy Moodle environ & 19 & 144 & 3.45 & .97 \\
\hline Moodle no substitute & 20 & 142 & 2.44 & 1.21 \\
\hline Moodle group work & 21 & 136 & 2.85 & 1.01 \\
\hline Moodle helps group work & 22 & 137 & 3.00 & 1.02 \\
\hline Moodle interesting & 23 & 142 & 3.12 & .93 \\
\hline Bored with online work & 24 & 140 & 3.11 & .90 \\
\hline \multicolumn{5}{|l|}{ Scale IV: Results } \\
\hline Moodle courses clear & 25 & 142 & 3.83 & .90 \\
\hline Links no substitute & 26 & 141 & 2.87 & .90 \\
\hline Structure keeps focus & 27 & 142 & 3.68 & .85 \\
\hline Happy to print material & 28 & 144 & 3.92 & 1.10 \\
\hline Moodle \& Campus connect & 29 & 144 & 4.10 & .79 \\
\hline Moodle content suits Web & 30 & 143 & 3.96 & .79 \\
\hline Presentation of content clear & 31 & 142 & 3.94 & .83 \\
\hline Online + classroom helps & 32 & 142 & 4.29 & .73 \\
\hline
\end{tabular}




\subsubsection{Access Scale - discussion on individual questions}

The average response of 2.82 on statement 8; "I prefer online learning rather than real-world classroom learning from a lecturer” is lower than most responses on the WEBLEI, as shown in Table 4.6. Analysis of individual responses shows a wide divergence of responses from five to one. This may reflect some strong feeling from students that classroom learning is still valued regardless of the extra value that has been added by the online systems. Statement 16; "I felt there was an 'online community' with other students on the course”, had a mean response of 2.33 which is significantly lower than most other statements on the WEBLEI. This may indicate that EIT students using Moodle do not utilise the online forums, email and chat facilities, and that lecturers in charge of Moodle courses do not actively encourage or require student participation in the online forums. There is potential for an 'online community' to emerge and commentators are enthusiastic about the 'virtual community' potentially surrounding online courses, however that reality is yet to emerge on the EIT virtual campus.

\subsubsection{Interaction Scale - discussion on individual statements}

The mean response of 2.19 on statement 9: "I communicate with other students in this subject electronically” is comparatively low and signifies disagreement with this statement. Comments from students about this issue indicate the reasons for the low student-to-student communication online include that there is no compelling reason for this idealised communication. The course requirements in most EIT online or blended courses do not specify electronic communication or attempt to measure the activity. In one example, lecturers set up the online forum as a mechanism for students to record and display a portion of their assignments. This illustrates that just as in a traditional classroom environment, there needs to be a motivation for utilising group discussion or peer interaction, although teachers can encourage this without compulsory assessment requirements. 
Students also indicated in relation to statement 9 that as the semester advanced they simply wanted to "get the information" from the Moodle course and apply this to the assignment or assessment and complete their requirements. For these students any interaction electronically was an optional feature and enjoyed, but was not viewed as essential for completing requirements. Lecturers and students commented in their discussions that online interaction often just "happened organically" depending on the mix of students, how many were geographically distant, and whether one or two students acted as a catalyst for sharing information and encouraging communication.

The mean response of 2.33 to statement 16: "I felt there was an online community with other students on the course" also reinforced the student's response to statement 9 . This relatively low response illustrates the difficulty of creating an authentic community online at a similar level to the physical campus community where everyday events and interaction occur spontaneously.

The highest mean scores in the Interaction scale were statement 10; "In this learning environment, I have to be self-disciplined in order to learn” (4.05), and statement 15: "I regularly access Moodle (at least twice a week)” (3.97). This average response would imply that generally students were aware that increased motivation was required to regularly glean information from the online learning environment. The mean score of 3.97 for regular access (Q.15) confirmed that for this sample of blended Business and Computing Faculty students that the Moodle courses were being utilised at least twice a week. On an individual course basis lecturers can check within Moodle the last access date and time for each individual student. This can be a useful feature allowing lecturers to make enquiries on students who have not accessed course materials for some weeks or at all. The WEBLEI survey indicated that EIT students were aware of the requirements to stay disciplined with their online course material access, and also indicated that EIT students did in fact regularly access the online course materials. 


\subsubsection{Response Scale - discussion on individual statements}

The majority of the EIT students in the sample indicated a high level of enjoyment with the Moodle courses provided even though in most cases the students were not totally dependant on the online resources. The EIT student respondents indicated a mean score of 3.45 on statement 19: "I enjoy learning in this environment”. This may indicate a generic willingness and enjoyment of Internet-based course materials, and may also indicate satisfaction with the quality and features of the specific EIT Moodle enabled systems. This positive satisfaction rating for online enjoyment would tend to indicate that tertiary students are not resistant or dissatisfied with the provision of online learning environments at any level of blended delivery. EIT academic management would view this result positively given that a wide range of quality and quantity of resources would be experienced by the students in this sample. Some lecturers may have only uploaded course outlines and skeleton lecture notes, while other lecturers may have offered a full featured set of resources utilising many features of Moodle.

The mean score of 2.44 for statement 20: "Moodle is no substitute for on-campus classes” provides the lowest score within the Response scale. It appears opinions are divided on this issue as some respondents fully agreed with this statement while others strongly disagreed. The comments within the qualitative section discussed in Chapter Five confirm this polarising of students with some strongly maintaining the necessity of the traditional classes despite the services of online systems. However, the mean result would indicate that a slight disapproval of this statement (20) overall is confirmed. We could therefore reverse this statement to say that "Moodle is a reasonable substitute for on-campus classes" and say that student have slightly agreed with this statement. This may indicate that students can visualise a future situation where they experience more of their classes purely online. 


\subsubsection{Results Scale - discussion on individual statements}

The highest average score (4.10) within the Results scale was for statement 29: "I can see the connection between the Moodle course and the campus course”. This can be seen as a positive result for the concept of a blended course with students expressing agreement with the conceptual connection between the learning environment in physical lectures, laboratories, and tutorials with the content and interaction within the related Moodle-based course material. The types of connections that students may perceive may include the course description, the calendar and planning, the academic content, and the electronic interaction. Lecturers have opportunities to strengthen the links between physical classes and content by actually navigating the online LMS and displaying this on the class projector for all students to see. This high score relating to the perceived connection between online and campus resources may indicate that EIT lecturers are performing well in this area and are aware of the need for academic alignment within the blended environment.

The lowest mean score of 2.87 within the Results scale was statement 26; "Links are no substitute for printed references or articles”. This may imply that generally students did in fact value the web-links offered within the online environment reasonably highly. However, this average result is non-conclusive and may also imply a "neither agree nor disagree” opinion by the students. Some students agreed strongly with this statement while others strongly disagreed. Discussion comments by students showed that some students found themselves confused with too many Internet links causing those students to be unsure whether the links were compulsory reading or placed by the lecturer as general background. They also made comments that too many links may leave them with a concern that they may be missing some material if they do not investigate all the links offered within the Moodle course. 


\subsubsection{General comments on the overall WEBLEI results}

Overall the results from the WEBLEI survey were positive with students expressing general satisfaction with their use of online or flexible learning environments. The mean result for the Access scale was 3.62, Interaction scale 3.31, Response scale 3.06, and the Results scale mean result was 3.83. This would also provide a satisfactory result if EIT was using this WEBLEI instrument as a general faculty satisfaction evaluation feedback mechanism. The Response scale scored the lowest average of the four scales probably due to a perceived low level of interaction and group work currently experienced by EIT students.

If a tertiary institute were to implement wide ranging improvements and enhancements to its online and blended learning environments, this WEBLEI could be used before and after any such implementation to test the student satisfaction and response to these initiatives. However, it should be cautioned that student responses to the WEBLEI may also be influenced by the personality and pedagogical skill of the teachers involved and therefore the WEBLEI results may not be simply evaluating the efficacy of the online mechanisms used in conjunction with an ideal blended learning environment but also individual lecturer effectiveness.

\subsection{BLENDED DELIVERY STUDENTS}

All of the students, with the exception of three purely online students, would be classed as participants within a blended learning environment (campus and online). Within this blended environment, the main emphasis of the courses that the student respondents were involved in during this research was the traditional on-campus course supplemented with online or flexible delivery materials. In this sense, the online environment is currently supplementary to this case study with a classroom-based and timetable course construct. 


\subsection{KEY INDIVIDUAL STATEMENTS}

Within the adapted WEBLEI for EIT, there were several key statements which were of special interest to this study because they reflected a potential tension between online learning environment features and traditional classroom delivery. These items included item 8; "I prefer online learning rather than real-world classroom learning from a lecturer", item 20; "Moodle is no substitute for oncampus courses", item 26; "Links to other websites are no substitute for printed references or articles", item 29; "I can see the connection between the Moodle course and the campus classes", and item 32; “Online resources plus the classroom teaching enhances my learning”. These items were designed to explore the preference and experience of EIT students with regard to pure elearning environments, blended environments or campus classroom environments. Table 4.7 isolates these "blended delivery" items for inspection and displays the responses to these items overall.

Table 4.7

Blended Learning Environment Items

\begin{tabular}{lcllll}
\hline & Item 8 & Item 20 & Item 26 & Item 29 & Item 32 \\
\hline Mean & 2.82 & 2.44 & 2.87 & 4.10 & 4.29 \\
Valid Cases & 149 & 142 & 141 & 144 & 142 \\
$\quad$ sd & 0.95 & 1.21 & 0.90 & 0.79 & 0.73 \\
\hline
\end{tabular}

Item 8: I prefer online learning rather than real-world classroom learning from a lecturer. Item 20: Moodle is no substitute for on-campus classes.

Item 26: Links to other websites are no substitute for printed references or articles. Item 29: I can see the connection between the Moodle course and the campus course. Item 32: Online resources plus the classroom teaching enhances my learning.

As displayed in Table 4.7, the mean for item 8 is significantly lower than averages for most of the other items on the WEBLEI. This result may show that although most students are conversant with the online environment and are reliant on this mechanism they still would not choose pure online learning instead of campus classes if they were fully able to participate in campus activity. This lower average for item 8 indicates that generally students do not prefer online learning over real-world classroom learning environments. This may hold 
some warning for tertiary administrators when considering replacing traditional courses with a pure e-learning environment. However, this result for item 8 should be held alongside the data for all other items which suggests these same students express satisfaction with access to Moodle learning materials - indeed they have come to expect the e-learning resources as standard learning materials.

The mean for Item 20; Moodle is no substitute for on-campus classes, was 2.44 signifying a slight disagreement with this statement. This may imply that students did slightly agree with the concept that the online resources were an acceptable substitute for campus classes. However, this mean of 2.44 is very close to a neutral position and to some degree confirms the wider findings of the study where students have a fairly even appreciation of both environments. It was an interesting finding to verify that there was no strong opposition to either mode of learning environment.

The mean of Item 26; Links to other websites are no substitute for printed references or articles, was also relatively low at 2.87. This average rating by students may imply that students did, in fact, view links to other useful websites as beneficial and valuable resources within the context of their other specific online lesson materials.

Relatively high means of 4.10 and 4.29 for Items 29 and 32 relating to students perceiving a useful connection between the classroom activities and the online resources may reflect that students have experienced this alignment in their overall learning environment at EIT, and that they also find this alignment and mixture of online materials and classroom interaction as beneficial in any future idealised environment. 


\subsection{STUDENT DATA SUMMARY}

This chapter presented data to validate the use of the adapted WEBLEI survey instrument within largely campus-based courses supported by online systems at the Eastern Institute of Technology, Napier, New Zealand. The results and data from the WEBLEI were also presented showing differences by age, gender, year level and other factors.

The general mean results for each question were discussed and reasons were explored for the students' experience of the online learning environment in conjunction with their on-campus course requirements.

Key specific questions and results from the WEBLEI exploring students' experience and perception of the blending of online resources and campus-based classes were also examined and discussed. Chapter Five continues the investigation into the EIT student experience of the blended learning environment by presenting and examining the discussion questions responses by the same students who completed the WEBLEI survey. 


\section{CHAPTER 5}

\section{QUALITATIVE DATA FROM STUDENTS}

“I have never let my schooling interfere with my education.” Mark Twain

\subsection{INTRODUCTION}

In the previous chapter, the quantitative results from the application of the WEBLEI instrument were presented with statistical analysis of student responses to questions about their experience of the EIT blended learning environment. The WEBLEI data presented generally positive experiences of the tertiary students for both traditional face-to-face learning environments as well as appreciation for the flexibility offered by online learning features. This quantitative data produced from the WEBLEI applied in a tertiary setting presents one type of research data. However, the use of some qualitative data in addition to a quantitative study can provide a richer picture of the field studied as evidenced by Salazar (1988) who confirmed that the narrative from the "additional comments" section of educational surveys enhanced the quantitative data analysis from the surveys.

This chapter reports data from written comments recorded within the adapted WEBLEI for tertiary students within the Faculty of Business and Computing. The written comments from the students were recorded at the end of the WEBLEI questionnaire. This qualitative data allows a wider and richer examination of students' experience and preferences with both the online and traditional classroom environments.

Students were able to provide reasons and some background to their WEBLEI survey responses while responding to the discussion questions. These students had not experienced this type of survey before during their time as a student at 
EIT. However, they had undertaken a number of course and lecturer evaluations previously.

\subsection{A SEEMING CONTRADICTION}

Many students commented that they appreciated and expected online content to be made available through the Moodle system. Some groups of student were satisfied with the content and general environment, however others were concerned at the lack of resources or the timing of, when content was provided (for example, sometimes not at the start of the course). However, these students also preferred on-campus environments and indicated that lectures and labs were still the best place for a holistic learning environment despite still appreciating online course resources.

\subsection{FIVE DISCUSSION QUESTIONS ATTACHED TO THE WEBLEI}

The five questions in the open-ended comments sections of the adapted WEBLEI were as follows:

1. Why are you studying in an on-line/blended mode?

2. What are the advantages of studying in an on-line/blended mode?

3. What are the disadvantages of studying in an online/blended mode?

4. Are there any suggestions to improve the delivery of your courses in an on-line/blended mode?

5. Do you prefer traditional classes and lectures with paperbased workbooks and reference materials?

The responses from a wide sample of respondents are recorded in this chapter along with some interpretive comments from the author. 


\subsection{COMMENTS PRESENTED FROM THE WEBLEI}

The comments sections were read through for all completed survey forms and analysed for any major emerging themes. Three main themes emerged, with each group of respondents expressing a clear preference from their comments within each survey form.

\subsubsection{Group 1: Blended Preference}

Students in this group appeared to display a preference for a balanced blended learning environment; good physical classes combined with rich online learning environments (with interaction) in a relatively even mixture.

The following are a cross-section of the responses within the "mixed-mode preference group” to discussion question 1:

\section{Why are you studying in an on-line/blended mode?}

I find using both Moodle and class lectures appeals to more modes of learning when done in correlation. Also some things not accessible in class are accessible from Moodle.

Because it's good to check both ways of learning.

That's the way my course is structured.

Often can result in less travel, by doing work at home.

As this just feels normal.

More convenient for me. Can access resources when and where I need.

To gain experience in using computers while learning.

It was the option available.

Some students view the provision of Moodle within the current blended environment as standard provision within tertiary courses over the last few years. The convenience of choosing whether to attend classes or to occasionally access 
online material as a substitute is viewed positively by these students. One interesting opinion was to view the navigation of online material and interaction as a learning exercise in its own right. It appeared evident that some lecturers were providing some information online that was not evident in the classroom; this may have been attempted for motivational purposes to ensure students accessed the Moodle website for course information. Included in this cluster of comments is an interesting insight from a young student who recognises a need for a "mood for learning". This respondent feels that the traditional classroom creates a better learning atmosphere.

The following are a cross-section of the responses within the "mixed-mode preference group” to discussion question 2: What are the advantages of studying in an online/blended mode?

Information being regularly accessible is a lot easier to follow.

Can check class notes if sick and reference for assignment.

The resources are already in electronic digital format. Information available at all times. Have a reference when unsure of something.

It's there whenever you need it. You can take your time reading through it.

Having resources to back-up lectures and links to other websites.

You can work out how far ahead/behind you are from home.

Don't have to be on-campus all the time.

Because it helps with info on assignments and due dates.

Students appeared to particularly appreciate the ability to pace themselves to the weeks and materials, including the ability to catch up after sickness or a break. Hence, the transparency that occurs when a course is outlined, described and 
presented with lecture materials is seen as beneficial by students. The absence of time pressure is an advantage of the online learning environment for some respondents.

The following are a cross-section of the responses within the "mixed-mode preference group” to discussion question 3: What are the disadvantages of studying in an online/blended mode?

Moodle is not always a reliable source of instruction.

Sometimes valuable information can be left out.

If you do not understand, it may be hard to read.

No disadvantages of the online systems.

It can lack in student / teacher and student to student communication some times.

Sometimes out of synch with lectures. Never have an excuse for time out.

Not having contact with other students and teachers as much.

It is interesting to note that the downside of the ubiquitous nature of the online learning environment affecting some students with one student reporting that they have no perceived 'down-time', although they are satisfied with a blended approach with an openness to more online dominance in the future. Other students in the blended preference group report that sometimes the content on Moodle is not in full alignment with what is happening in the classroom or laboratories. Another cluster of comments revolved around the fact that it is difficult to comprehend and learn new material without a classroom experience of some kind. It is perceived as more difficult by some students to learn from an online system if some understanding is not already in place. 
The following are a cross-section of the responses within the "mixed-mode preference group" to discussion question 4: Are there any suggestions to improve the delivery of your courses in an on-line/blended mode?

\author{
Moodle should record the topics covered in class for \\ later reference. \\ Not really. \\ Have cheaper printing. Too expensive. \\ Increased student online community, e.g. encouraging \\ forum usage to ask questions, discuss topics etc. \\ Better presentation types would be good e.g. PowerPoint \\ not the best for review.
}

Some students wanted the lecturer to update Moodle after campus classes to reflect what happened in the class. This can be problematic for academic staff as a perfect match between presentations in class and the online content can demotivate students to attend classes, however this is obviously a demand from some students. The issue of printing was noted by some students as the increase in online content, combined with lecturers handing out less paper-based content, along with EIT introducing "user-pays” mechanisms for printing has seen a rise in dis satisfaction with the current provision of printing and printed materials.

Other students would like to see lecture content displayed in different formats than PowerPoint - perhaps PDF file format, or Word format for ease of reviewing material. Another area for improvement which students raised was the level of student participation in the discussion forums. Students suggested that lecturers should attempt to provide incentives for student participation - perhaps marks allocated for discussion material. 
The following are a cross-section of the responses within the "mixed-mode preference group” to discussion question 5: Do you prefer traditional classes and lectures with paper-based workbooks and reference materials?

Yes and no. It is a much more familiar learning environment, I find simply being in class encourages a mood for learning. This does not happen when browsing Moodle. But Moodle is easier to follow.

Both combined are good - so no.

No preference, blended is very good.

No, I prefer both.

Yes, but also Moodle helps.

I prefer a mixture/blended learning environment for the lecturing / interaction side of it, but prefer online or digital workbooks and resources.

No - prefer a mixture. Online would be better if more detailed.

Not all the time. Classes are good for contact time but having learning resources available over the web is good as well.

Both.

Most student respondents (75\%) appear to appreciate a balance of both online and traditional so do not support one mode over the other. One comment described being in a class "encourages a mood for learning" which supports the physical classroom environment as a more powerful stimulus and motivator than the online environment. This cluster of students all strongly supported a blended learning environment describing a need for both online and campus based learning experiences. 


\subsubsection{Group 2: Online Preference}

The second group showed a preference for online learning environments mainly, although the group tolerates the physical classes.

The following are a cross-section of the responses within the "mainly online preference group” to discussion question 1:

\section{Why are you studying in an on-line/blended mode?}

Easier to access information from different locations.

It's how the course is set out.

It encourages me to study online to expand on the material taught in class, a skill that would be very handy in the workforce.

So I can learn when I want.

Easier to understand. Always there when you need it.

I can read course material in my own time.

It's standard now but gives me the flexibility I need.

I now live in Wellington and can continue my course.

This group of “online-preference” students made more positive statements about why they were studying in this mode. One comment made reference to the online learning helping to build online skills which would be transferable to a workplace environment. These students made positive comments about availability of course content, and the ability to access this content from any location including work, home and on campus. A small number of students do relocate during their studies, particularly near the end of their qualification, and the online learning environment enables them to complete their studies although their course may not be purposely setup as a purely online course. 
The following is a cross-section of the responses within the "mainly online preference group” to discussion question 2:

\section{What are the advantages of studying in an online/blended mode?}

\section{Easier to check dates.}

I can study at my own pace when I am home with fewer distractions.

I can learn when I want.

Being able to study at home anytime.

Get to see dates for assignments and online material for projects.

The ability to preview lecture notes ahead of time

Being able to overview all the weeks and PowerPoints over the whole course

These typical responses from mainly young students (16-20 years) may represent a prevalent pragmatic attitude where students simply want to know the requirements of the course and get on with the work. This group is less interested in the 'class atmosphere' whether that be online or in the classroom. Most of this “online-preference” group talk about studying at home as one of their preferred academic working places. Students in this group are also concerned with dates and the ability to scan the calendar and assessment milestones of a course. This may imply that students who prefer online learning are more self-motivated and directed on meeting requirements - more in line with an experienced employee than a student dependant on teacher direction.

The following is a cross-section of the responses within the "mainly online preference group” to discussion question 3:

\section{What are the disadvantages of studying in an online/blended mode?}

Not as much tutor information.

I don't always have access to the online material.

Must stay focussed.

Not having tutoring with lecturer.

I probably need more self-discipline. 
If I don't come to class, I sometimes miss the informal comments from tutors.

Reading from screens can be tiresome.

The "online-preference” students felt that by mainly using Moodle for resources they were missing out on direct tutorial support and interaction even though they would still choose a mainly online system for themselves. Some students did not always have convenient Internet access at their place of study - whether this is in the campus library, or in a household without broadband Internet, or were competing for access with other family members. Other students in this group discussed the need for self-discipline and focus on their overall study as the sense of urgency and pace were not necessarily evident within the online environment.

Some students acknowledged that a campus-based lecture or class may provide some extra information or guidance that the online resources could not provide consistently. A comment was also made regarding the physical nature of reading predominantly from a computer screen and how this can become physically uncomfortable with long study periods.

The following is a cross-section of the responses within the "mainly online preference group” to discussion question 4:

Are there any suggestions to improve the delivery of your courses in an online/blended mode?

No - fairly happy.

Perhaps an audio or video of some lectures.

Sometimes different courses/papers have varying levels of content.

No.

Some guidelines on attendance requirements.

Upskill some lecturers for Moodle.

Consistency across different courses 
Students in the "online-preference” cluster appeared to be reasonably satisfied with the content and online environment provided by Moodle and their lecturers utilising this system. However, there were a small number of comments about some variation in quality and quantity between individual lecturers and between different schools within the Eastern Institution of Technology. One student was concerned about attendance requirements - although some students are coping with utilising Moodle while absent, they wonder whether they are transgressing any course rules by not attending some classes. This is probably a grey area for the institute as a growing number of students are picking and choosing which classes they attend as they can keep up with course content through Moodle. Other "online-preference" students would like to see more audio or interactive lecture content on the online system. When students do stop attending classes due to Moodle availability, they may have a negative effect on the class atmosphere of the physical classes as there may be less students physically attending. It may then be difficult to facilitate dynamic classroom discussions while a significant proportion of students are not attending regularly.

The following is a cross-section of the responses within the "mainly online preference group” to discussion question 5:

\section{Do you prefer traditional classes and lectures with paper-based workbooks and reference materials?}

No.

Only sometimes.

No.

Sometimes.

No

I am happy with normal classes but I prefer online access due to work commitments

Hard to say, but now dependant on Moodle to a large extent.

This group of students with some representative comments did not prefer traditional classes and paper-based materials. Although this preference was not 
statistically analysed, there appeared a cluster of young (16-20 age) students and another cluster of older students (40 years and over). There appeared to be some ambivalence regarding this question, but ultimately the practical advantages outweighed the attraction of campus classes for this group of students. Some students could not envisage participating in a tertiary course without some form of online access.

\subsubsection{Group 3: Traditional Classes Preference}

The third group indicated a strong preference for traditional physical classes and on-campus learning environments. However, they were still satisfied with the provision of the online learning environment - although saw this as a complementary service rather than a full learning environment.

Some students expressed some frustration with e-learning materials provided on their courses. These students preferred a printed paper-based workbook with all the necessary resources bound within this. Then, according to these traditionallyminded students, the online environment could be freed up for discussion forums and interactive communication rather than primarily serve as a repository for all course materials. Some students reported tiring of reading computer screens and said they would prefer paper books and reading materials. Paper-based materials are easier to annotate and 'make your own' whereas the digital versions are comparatively aloof from this personalisation despite some software annotation tools now available.

The following are a cross-section of the responses within the "prefer physical classes group" to discussion question 1 :

\section{Why are you studying in an on-line/blended mode?}

Distance prohibits on-campus attendance therefore most of my contact with EIT is via online means.

I mainly learn from lectures but can catch up on stuff I have missed through Moodle. 
Because I can study either way, but prefer in-class.

I need to for my course.

Because this is offered.

Gives me another resource to help studying.

It increases the different learning styles available to students and provides a learning tool available offcampus.

Enables access whenever I want to study.

Because it is difficult to get complete notes and pay attention in the lectures at the same time.

Sometimes helps for preparation/study.

Interestingly, one of the student respondents in this "physical classes preference" group was actually a purely online student who states that they would still prefer a traditional class and workbook but appreciates the online environment due to distance constraints. These comments also may indicate that these students see Moodle as supplementary to the main event which is the lecture or class.

The following is a cross-section of the responses within the "physical classes preference group” to discussion question 2:

\section{What are the advantages of studying in an online/blended mode?}

I find there is not really an effective substitute for personal contact with lecturers' on-campus. Online methods are a way of staying in contact with course requirements and other students.

Access to more materials.

I can access at times suitable to me.

If you miss a class you can catch up online.

Work at your own pace.

Can access learning materials in our own time.

Smarter people help me and I can get answers fast.

Access from home. 
Enhances the classroom lectures - no time restraint.

If you miss the class you can study the class material

online. Blended mode is better.

Can do it from home.

From the range of positive responses to Q.2, it is apparent that students who preferred traditional campus-based classes still appreciated the online resources through Moodle.

The online environment is seen here as a catch-up mechanism, by some students, after missing physical classes. This viewpoint of the online lecture material may provide more incentive for these students to skip more classes as the online LE is always available as a backup. The online learning environment is also viewed by these students as serving to enhance the campus-based lecture signifying that these students see the physical lecture as the main event and the online materials serving to enhance that main event.

The following is a cross-section of the responses within the "physical classes preference group” to discussion question 3:

\section{What are the disadvantages of studying in an online/blended mode?}

Online learning requires much self-discipline - it is easy to "put off" study. On campus classes provide for instant interaction between student and lecturer.

Felt like harassment to get every communication from every student - hated it.

It is easier to miss classes and catch up later on Moodle.

There is no tutor or student interaction e.g. questions and answers.

Being on my own away from home is a disadvantage sometimes.

No interaction.

Motivation, self-discipline. 
No tutor help.

Limited access to tutors.

I place most of the importance on the physical classes

and only use Moodle as an aid. The importance of

Moodle is different for various tutors.

Cannot discuss it with the teacher.

No disadvantages in blended mode.

Some students saw no disadvantages in the online learning environment but still preferred a traditional classroom environment. Some students viewed the online learning environment as an opportunity to 'get answers' from other students or perhaps wider on the entire Internet. However, they still preferred the traditional classroom if given the choice. Students also felt that online learning requires more self-discipline and this can be magnified by a lack of personal interaction.

Students also observed that varying levels of importance was placed on Moodle by different lecturers as well which could have an influence on the students' perception of its importance.

The following is a cross-section of the responses within the "physical classes preference group” to discussion question 4:

Are there any suggestions to improve the delivery of your courses in an online/blended mode?

I find that in many cases Moodle is not up-dated with course material on a regular basis. The facility to post grades is under-utilised. In the past I have found quizzes that have been included as part of the course material to be of value.

Have a direct link to the tutor

Some courses need more notes, but usually ok.

I need online help to help me pass the workbooks I am doing in level 2. 


\section{Animations.}

Ensure that the lesson is aimed at the right level.

Give handouts in class so students don't have to pay for printing.

Force teachers to keep their online material in one place not many links to many external websites.

I miss the digital drop-box of Blackboard (previous system).

No.

Some of these comments concern implementation issues with Moodle and the lecturers' individual utilisation of Moodle features. This may explain to some degree why these students still prefer campus classes. Students appear to experience varying levels of content provision from different lecturers in charge of a course. Experiencing some form of lecturer 'presence' online would improve these students' satisfaction as they feel the content and their navigation are not accurately aligned to their actual perceived course.

Students also indicated a preference for all course content to be available in one main easily identifiable location even if this is online. The advantage of a physical workbook was observed by students as having definable limits, portable and easily located. This is not necessarily true of online lecture material in multiple folders online, combined with many related website links.

The following is a cross-section of the responses within the "physical classes preference group” to discussion question 5:

\section{Do you prefer traditional classes and lectures with paper-based workbooks and reference materials?}

Yes - prefer traditional classes with workbooks.

Yes! Yes! Yes!

Yes, this is better than just learning online. 
I find online references have been my way of learning for

years but still prefer some class contact.

Maybe. Because some of the words are the ones I have never heard of - and they are new words most times.

Yes.

Yes.

Yes, saves on printing costs.

Yes - the tutor is right here to answer any questions.

Yes, I think discussion is the most important part in learning.

Yes, but it's great to have Moodle as an aid that enhances the learning environment.

These respondents all expressed a strong preference for traditional classroom delivery as indicated in their response to Q.5. One of these comments regarding not being aware of some terminology online was from a student who is studying at certificate level through a physical workbook both on-campus and at home/workplace. Lower level students do require extra tutorial assistance and discussion which the online content and workbooks cannot always anticipate ahead of time. A greater number of first year certificate-level students than diploma and degree students prefer traditional classes even though they are effectively set up as “distance” learners with full resources provided and limited class times.

Some students maintained a preference for physical classes with interaction with the lecturer seen as important as a reference point, real-world guidance and the ability to give instant feedback. Some positive answers from students were quite emphatic, for example, one student replied “Yes! Yes! Yes!” perhaps indicating some frustration in their experience with utilising online materials or their strong preference for campus-based classes. 


\subsection{THREE GROUPINGS OF STUDENTS}

Three main groups emerged from the survey comments. Representative sample comments were presented within these three groups in this chapter.

Group One: Students with a preference for a balanced blended learning environment, good physical classes combined with rich online learning environments (with interaction).

Group Two: The second group showed a preference for online LE mainly although they tolerate the physical classes. This second group may be working full-time or have family commitments which would prevent them from enrolling in a full-time campus-based course.

Group Three: The third group indicated a strong preference for traditional physical classes and on-campus learning environments. However, they were still satisfied with the provision of the online LE - although saw this as a complementary service rather than a full learning environment. So this third group viewed the ideal learning environment as mainly physically on-campus.

\subsection{SUMMARY OF STUDENT COMMENTS}

The comments, recorded at the end of the WEBLEI, from the 151 student participants were consistent with the numerical responses to the questionnaire. The written section of the questionnaire did however provide more freedom for students to express themselves in other areas on the outer edges of the study. This included comments about the IT computer classroom equipment and the individual characteristics of each lecturer's method of running an online environment.

It appeared from the quantity of written comments from students that the EIT students had not been given opportunity in the past to give feedback on how the online environment in particular was meeting their expectations. Current student 
evaluations at EIT are generally focussed on general course outcomes and lecturer satisfaction ratings.

The three main groups that emerged from the survey comments could be used to consider a proposed optimal blended learning environment. The students with a preference for a balanced blended learning environment, i.e. good physical classes combined with rich online learning environments (with interaction) are a good indication of the reception that a purposeful blended learning environment model might achieve. The second group which showed a preference for online learning environments mainly tend to reveal an underlying circumstantial reason for this preference. That is normally due to working full-time or having family commitments which would prevent them from enrolling in a full-time campusbased course. So for this second group the pure online option is not chosen for learning efficacy or superiority but rather on student circumstances.

The third student group emerging from the written comments on the WEBLEI instrument indicated a strong preference for traditional physical classes and oncampus learning environments. However they were still satisfied with the provision of the online LE - although they saw this as a complementary service rather than a full learning environment. So this third group viewed the ideal learning environment as mainly physically on-campus, with a smaller component provided in online or flexible mode.

This chapter has presented a representative range of written comments from students about the online, traditional and blended learning environments experienced at the Eastern Institute of Technology. These student comments were discussed and some reasons were explored for likely student attitudes, experiences and any reinforcement of the quantitative WEBLEI results. The following chapter presents the qualitative results from the tertiary staff comments on this study’s research questions. 


\title{
CHAPTER 6
}

\section{TERTIARY STAFF VIEW OF THE BLENDED ENVIRONMENT}

\author{
“The purpose of a university is to make students safe for ideas - not ideas safe \\ for students.” Clark Kerr (Shapiro, 2006, p. 1)
}

\subsection{INTRODUCTION}

In the previous chapter, the qualitative results from the discussion questions associated with the student WEBLEI were presented and discussed. The WEBLEI discussion responses provided some explanations for the statistical results presented in chapter four.

This chapter describes the discussions and email responses from staff at EIT directly addressing the central research questions of this study, and reports discussions held with lecturers and senior academic management with regard to optimal blended learning environments and recent experiences with e-learning implementations.

This study actively collected qualitative data to determine whether the expressed opinions and comments from staff, in this chapter, supported or augmented the findings generated from the WEBLEI data. The feedback from staff also contributed to explored answers to the research questions within this study.

\subsection{LECTURER AND TERTIARY STAFF COMMENTS}

All staff at the Eastern Institute of Technology, Napier, New Zealand were invited to comment verbally and by email to the research questions stated in this study. 25 staff out of 380 equivalent full-time staff responded with comments 
from a wide range of perspectives including marketing, academic, managerial and administration viewpoints. Some of the email feedback was augmented with background interviews. Interviews were held with the Academic Manager, the Elearning Advisor, a Head of School responsible for a successful flexible delivery certificate programme, and a group of lecturers involved in a flexible mixedmode cluster of certificates.

One academic with experience in setting up online and blended courses at various levels was supportive of the blended approach.

No one ideal mix, but blended is definitely the best of both worlds allowing students flexibility but maintaining contact to prevent feelings of isolation and being "disconnected" from the learning process as many students (and lectures) feel.

I don't believe e-learning damages or undermines traditional learning; it offers alternatives to those who cannot attend on campus classes. Some students however have difficulty in adjusting to the learner centred study mode. Palloff (2006, p. 12) advises that teachers and students need to realize that the online learning process occurs, for the most part, through the formation of a learning community and is reflective in nature. Students may enter an online course expecting to be educated by a content expert, just as in a traditional classroom. When they discover that the most profound learning in an online course comes through interacting with other students, they may become confused and sometimes feel cheated by the process. Our culture has led students to believe that education happens through exposure to "the sage on the stage", as many might describe the traditional academic. In the online environment, in contrast, the instructor acts as a facilitator, or a "guide on the side", enabling students to learn collaboratively from one 
another. For many students, this is a significant shift, and one for which they need to be adequately prepared.

Administrators of regional centres were often in a unique position of being able to observe limited groups of students and lecturers operate in flexible delivery modes. These regional administrators were perhaps closer to the learning and teaching nexus than most managerial or administrative staff. These comments also confirm the importance of peer support while studying in flexible or online mode.

As the Manager of a regional centre, my experience is that the students that study online need a lot of support to stay motivated. We have some that come into the Centre and work regularly with another student that is doing the same online paper. This seems to work better. Most of them say they would prefer to be in a classroom situation. From my own personal experience I am studying First Line Management online. I find I want someone at the end of my emails that will respond almost instantly to my queries. I find it very discouraging if my tutor doesn't respond for a couple of days. I'm working on the paper with another colleague and we keep each other motivated. As I work full time I find it great to be able to do the study during my work day when I get the opportunity. All my assignment questions are on the computer and I key my answers in whenever I want too (Works well).

Another regional administrator had slightly different experiences of the flexible delivery courses which are based on workbook/CD materials which are able to be studied at home or in the regional centre classrooms and computer room. As indicated in these comments, the skills of the teaching staff may be substantially different from the traditional classroom lecturer in terms of quick responsiveness online and in helping on-campus in tutorial mode. 
At the Regional Centres the online/flexible learning goes really well. We need to have well trained tutors who are able to cope with all sorts of questions though - and that can be hard to achieve. I am lucky because I have some key experienced tutors who bring a wealth of experience. I think a new tutor would find it hard to cope (with the wide range of enquiries generated from a blended or flexible programme) especially at a Regional Centre. As more and more courses become flexible the administration side has to be well organised as it can get very confusing as to where results go etc. We try to hold the traditional courses but these are getting harder to fill. They are mainly at Certificate level though and it might be different with higher level courses. The calibre of the flexible student seems to be much better (they want to learn) compared with some of the full time students.

It seems that today's youth find it hard to get up in the mornings so flexible learning suits them. But as you say is this just a trend? - But we all like a challenge and we all just keep adapting.

A senior manager's viewpoint seemed to imply that the traditional learning environment may be holding the institute back from higher enrolments and from providing for the potential students requirements. These comments may indicate a managerial viewpoint that converting more courses to a pure e-learning mode would benefit EIT financially and broaden the access levels of more potential students.

To create an optimal blended learning environment we should find out what our students and potential students want - and then give it to them. No doubt we need to do more research in this area - we are currently doing some research in the community - which will at least give us a touch point. 
It's about helping people get the knowledge - some want to come on campus and others don't. So for those that don't, why do we insist that they come here for orientations and classes? The best of each (campus and online) will not necessarily combine - as that might not be what the students actually want. Does e-learning in some forms or implementations actually undermine or damage the 'real-world' learning environment? No - this sounds kind of precious - isn't learning really about ensuring that people get the knowledge - does it matter if it's delivered on line or in a classroom? Just because that's what we've always done doesn't mean it's the wave of the future. The way forward is more about creating new communities and ensuring that academic quality occurs, I believe.

Some teaching staff involved with online or newer flexible courses shared their knowledge of features that help with blended delivery. Discussion forums provide a medium for class participation with the advantage that students have time to consider the question and think about their answer. One lecturer discussed his/her experience with students who may be reluctant to contribute to a discussion in the classroom or lecture theatre but may be happy to join in because they feel somewhat anonymous in a discussion forum, and are more comfortable writing than speaking. However, there are some students who, due to language difficulties, or the perception that their writing skills are inferior to those of their peers, will need some encouragement to put their thoughts into writing. Those who seem reluctant to participate in discussion forums should be recognised by the lecturer/facilitator and early intervention by way of an email or even a phone call may elicit a reason for their reluctance. Often some advice or encouragement will be all that is required to increase their participation.

Teaching staff involved with recent online courses reflected that they had experienced students who had withdrawn quite early from an online course stating that this mode of learning is not for them. 
These staff related that the EIT eLearning Advisor has produced a set of guidelines that can be given to students who are considering enrolling in an online course. This document asks students to respond to a set of statements which provides early feedback to the student and to EIT on whether the student is ready to engage successfully in an online course. For example, the first group of statements should be responded to positively by the student in order for them to be considered ready for online learning:

- I have reliable access to a computer with recent software and an Internet connection.

- I like working independently.

- I am willing to dedicate the same amount of time and effort to an online learning course as I would to a traditional course.

In the next group, the student should answer "True" to the majority of the seven statements, such as:

- I'm confident about downloading files or installing a programme,

- Working at a computer is not a trial for me.

When considering the last group of statements, the student is advised that each "True" answer increases the likelihood of success in online study. For example:

- I am comfortable communicating through email, discussion groups and chat rooms,

- Sometimes I find that when I write, I can organise my thoughts better than when I speak.

Ideally, this type of questionnaire should be integrated as part of an initial sample course and be available in the same format as the potential students will eventually use for the online courses in which they enrol. 
One EIT staff member involved with commercial course delivery and management had received feedback from business clients who send their staff on EIT business courses. The business clients indicated:

They want quick responsiveness to technical issues when engaging in the online environment. Businesses think that the online system should look slicker and more up-market Moodle is primarily built for academics by academics.

Businesses with students on online courses want more structured groups and classes in physical settings to complement the online materials. This should be regular and structured. There are some issues with assignments and assessment but this may be more pedagogical rather than caused by the online environment.

Students sponsored by businesses appear to require structured class tutorials to support their online courses. These comments would indicate that online courses designed for students involved in the workplace cannot be left in a purely online environment.

Some lecturers reported verbally that managing the online learning environments and mentoring remote individual students can take more time and resources per student than a standard class of on-campus students. An example was given of one remote student in another city who required special assessment locations and invigilators, and special tutor assistance which utilised at least one lecturer for several hours each week. These sorts of examples helped illustrate that institutions must sometimes absorb uneconomic enrolments in an overall programme which includes online, flexible or distance students.

Some lecturers felt strongly that the personal contact by students with other students is often a strongly motivational factor in the enjoyment of any course. They also pointed out that institutes cannot assume that fluent use of computers 
by students and full access to broadband Internet exists in all homes (currently 74\% saturation of NZ households, 2007).

I feel that many people enjoy the people contact in education, and would not choose a purely online environment. However some people like the flexibility of pure online learning which allows them to work around work, family etc commitments or because they are not very mobile (e.g. older people, people in wheelchairs etc). Pure online learning can also be easier for people coming back to study - several people have told me that enrolling at a tertiary institute is quite scary. Staff and academics in IT have quite a skewed view - we think everyone has a computer and is a fluent user of the Internet. Quite a lot of people - for example tradespeople - don't use a computer in their jobs a lot, if at all, and don't have a computer at home. These people would be unlikely to choose a pure online course and may be intimidated by a blended course. For all these reasons, there is obviously no one right answer - a range of options (pure face-to-face, blended, pure online) is desirable.

The blended approach appeared to be widely supported by most academic staff. However, there was no particular consensus on how this could be defined, or indeed whether an ideal blended prescription could ever be defined given the wide range of learners and breadth of programmes. This respondent also included a warning about implementing e-learning courses too quickly without adequate academic training, and raised the issue of retaining a unique set of knowledge.

I think blended learning can be valuable in many ways. One is to encourage independent study. Rather than the lecturer presenting information, learners can be tasked with investigating topics. It is also easier to create learner activities - learners can do the activities online outside of class, rather than in a tight time-frame in class. The blended learning 
environment can also act as a repository of course information, and a gateway to wider information. It can also facilitate conversations for learners who are unlikely to talk in class maybe because of shyness or language difficulties.

I don't think implementations of e-learning damage the face-toface learning environment necessarily, although I do know of students who decide not to come to class and think that they can catch up by reading the class slides on Moodle instead. They don't realise that they missed the learning activities and lessons learned from class discussion.

However I do think that some implementations of elearning damage the reputation of elearning and put people off it. There are courses out there that are just sequences of independent "read this" activities, which is not at all interesting or engaging. Why would someone pay a lot of money to do what they could do themselves using Google or by borrowing a book from the library? I think there are many institutions jumping into elearning, with various degrees of success - and I think that it is important that people doing elearning are trained in how to develop good elearning courses before being let loose. Otherwise the result is something that doesn't help students, and damages the lecturer and institution.

Some academics were supportive of a blended approach to learning environments but saw the need for adaptability of the learning environment according to the type of learner and the type of course. This staff member also felt there would be considerable overlap of materials in a more blended approach with the student able to pick and choose what they required. This would also involve more resource and cost. 
An ideal, optimal, blended learning environment (if it exists at all) really depends on the skills and level of the student. As well as on the type of student. One student is really helped with verbal, interactive explanations, whereas the other, for instance, wants to see graphical structures. A blended environment would offer all sorts of education materials, resulting in a lot of redundancy, so that the student can pick his favourite track, and gets the 'recognition' feeling when browsing through the other education forms. But now the quantity of the offer/environment increases significantly which requires a student with basic research skills; able to find his way through the available materials. A lesser skilled student might loose his grip due to the quantity. A structured introduction to the material seems to be a good choice to reach both types of students. However, in my experience we now just lifted the original problem to a meta level: how to present the organisation of the education materials? Soon, a lot of overhead exists, out of balance with the actual contents, and the student is not really helped. So, my approach would be to go to a matrix-like paper, where the students' skills are a discrete variable, and have an answer to your question per skill set. Maybe you also differentiate the student learning styles?

The adaptability of the e-learning environment was also mentioned by academic staff where the scaffolding and depth of material can be changed automatically according to the usage of the student. This is one clear advantage of e-learning compared with traditional classroom settings. One lecturer also saw the role of the lecturer or teacher as the custodian safeguarding the academic quality regardless of the type of learning environment.

I see a working combination of e-learning and the classical classroom approach, where the classroom approach typically 'teases' the student to find his way in the e-learning 
environment. That meta problem described above is now back on the tutor's plate, and will be applied to get the student to conquer to offered materials. The Internet is indeed a trend, and still arises in all aspects. E-learning might be something that goes with the flow without a firm argument if you just take into account to succeed at the exams. In real-life one encounters the Internet. In real-life one has to be able to do some sort of e-learning just to keep up with the pace of progress in technology. So, I'd say, e-learning is not just potentially an efficient environment to reach more students, but also a necessary preparation to succeed in real-life careers. But to safe-guard academic qualities and sense of community I see a clear role for the tutor. It's exactly what a tutor needs to guide and verify.

Another academic staff member considered the modelling of usage of the blended environment by the lecturer as a critical success factor for students observing:

Online Accessibility. The system has to be reliable and fast (even for dialup)

Integration: Any online system has to be an integral part of the overall blended course. E.g. does the lecturer use the online system in class or just use it like a text book. Does the lecturer walk the walk! Online material consists of two parts: Handouts and delivery content (includes lectures /quizzes, etc).

Is there an ideal mix of the two types of environments? Again it depends on the level of integration wanted. Does e-learning in some forms or implementations actually undermine or damage the 'real-world' learning environment? Students can access 
material online and avoid coming to class as it is online anyway.

Staff were also aware of the potential resistance amongst non-IT teaching staff who may be mandated by the administration to launch online courses or move their courses into a more blended mode. This raises the issue that if a recommended blended learning environment was defined, the implementation of this may require additional time and training for all staff.

Mandating a minimum level of activity in a blended learning environment is ok. Insisting that everyone have everything online is doomed to failure through lecturer resistance. However a sense of community can be enhanced. For example, a lecturer can use a discussion forum to send replies to what would normally be single responses via email. As in all teaching, if the lecturer is not passionate about using the technology there is a high probability of failure.

A comparison by one academic staff member of the most useful elements of the campus classroom with the best features of the online environment was useful to gain insight into the perceived strengths of each.

The best components of the classroom in my opinion:

1. Immediate availability of the tutor.

2. Immediate availability of other students.

3. Class atmosphere.

Students learn much from each other and being in the same room creates the opportunity for sharing.

The best components of online learning in my opinion:

1. Teacher is only a facilitator.

2. Students do more on their own and are more responsible for their own learning.

3. All students have to participate. 
Some staff at EIT have experience with flexible delivery courses that also attempt to provide a 'smorgasbord' of different ways of accessing materials whether by CD-ROM, printed workbook, Moodle website, drop-in classrooms, together with a number of other mixed options. These courses are not primarily online e-learning courses.

For me the ideal would be to offer the flexibility of online learning but have more regular on-campus workshops for those students that need the f2f contact. Everything done in a f2f class can be done online as well and sometimes in a better way. So, in combining the two:

Have more office hours available for online students so that there they feel the tutors are more available

The chatrooms can be managed so that general chats can strengthen the sense of community (class atmosphere) and specific chats for students only, can allow the students to discuss issues and learn from one another Participation forums allow every student the opportunity to express their own views without worrying what the others would think. I must admit, though, that many online students have indicated to me that they still prefer f2f giving reasons such as missing the "buzz" of the classroom and missing the presence of other students.

Most staff did not believe that e-learning in some forms or implementations undermined or damaged the 'real-world' learning environment. They mentioned examples where students had thrived in the online environment.

I don't think it does and I think the flexibility of online learning has opened pathways for many students who are too shy to speak up in class, as suddenly with online learning they get to have their say as well without others being present to "judge". In my experience I have found a greater sense of community in 
the online groups than some of the face to face classes. With online learning, students and tutors get to know one another better than face to face as there is more opportunity for communicating about other things than the academic work. But, as with face to face classes, a lot depends on the personality of the tutor.

It was also evident from staff comments about the blended environment that the learning styles of students were an important issue for them.

I assume that an optimal or ideal blended learning environment is one that presents materials to students in timely manner and in a way that best suits their learning style.

Materials are delivered in a format that suits the individuals learning style. Materials are delivered in a time and place that suits the students using them.

A learning management system that allows the previous two goals to be achieved. Materials must be delivered in a timely manner and must be accurate and reflect the course objectives.

For optimal blended environments, staff also reinforced the idea that online materials should be specifically designed with the overall learning environment in mind.

E-learning materials should be designed for the purpose and not just duplicate traditional classroom materials. E-learning materials should add value to the learning process. E-learning materials could be used to expand the traditional materials.

Once again, another lecturer reinforced the view that a fixed ideal mix of the online and class environments may not be achievable. However, if the two 
environments were considered in the development of teaching materials then a better integration can take place.

The mix will vary depending on the type of course and the learning styles of the students. I do not believe there is such a thing as an ideal mix. The two environments should not be developed separately; the e-learning materials and traditional materials must be considered together as important components of the learning experience.

Another repeated reflection from active teaching staff was that in their recent experience some students were attending fewer classes due to available materials online.

If online materials duplicate the traditional materials students often stop attending class and this can give students the impression that attendance is not necessary.

One lecturer responded to the question of whether tertiary universities or institutes are simply forced by the trends and rise of Internet activity to 'jump on board' regardless of the cost to academic quality and sense of community with a warning.

If managed poorly, it is very likely that an organisation could "jump on board" resulting in poorly designed and poorly delivered online courses. Impressions formed by students undertaking such courses would naturally impact on their overall impression of the institute.

Another staff member indicated what, in their opinion, were the most important elements that help construct ideal or optimal blended learning environments in a tertiary setting, with a strong emphasis on retaining traditional face to face contact with students. The suggested elements included: 
face to face contact

very well produced course materials

many support mechanisms, not only online

variety is the key to deep learning, superficial 'bells and

whistles' becomes very annoying and frustrating

Face to face 'standard' elements of the traditional classroom (although this should be a quantum leap into the $21^{\text {st }}$ century!) with e-learning as a support mechanism only.

Once again a warning was given by an experienced academic about e-learning having the potential for creating additional requirements that are not always necessary in the classroom.

\section{E-learning has a vast collection of 'hidden curriculum' elements. Assumptions are often made on equipment, connection speeds, pre-existing skills, etc - a mine field!}

In response to the question: Are we simply forced by the trends and rise of Internet activity to 'jump on board' regardless of the cost to academic quality and sense of community? One staff member had some misgivings and a warning for EIT.

It seems that NZ has jumped on board the e-learning gravy train... there appears to be a huge wad of cash for development with very little thought to the 'human' element. At the end of the day - people want people, people need people, people want to interact with people - time will tell that e-learning is innovative if done correctly, it is not an 'online' repository for course materials, and once the novelty wears off, there is very little 'learning' taking place! I think e learning is here to stay with the electronic era that we are in. But for effective utilisation, there needs to be a robust training for teachers, and 
students also need to know how to use it effectively. Otherwise there is the initial use, and then people lose interest.

A non-teaching staff member with a strong interaction role with external organisations implied some resistance from teaching staff with the comments:

We have to 'jump on board' with the internet and e-learning. We talk about 'lifelong learning', well that applies to teaching staff as well as students! I know that many teachers are 'fearful' of the power of the internet but I think that is because they don't understand its capabilities. We should all be learning new ways to teach more effectively and if that involves using the internet then 'bring it on'. I don't think that this needs to be at the cost of academic quality or the sense of community - it's more of a challenge for teaching staff to be creative about how they use it and how they monitor the use. We should use a combination of teaching methods to enrich learning.

I think what undermines academic quality is acceptance of lower standards of the basics - spelling, grammar, handing assignments in on time, research, multiple choice questions (I'm not a fan of these!)

Lecturers also considered the resources needed by the students with e-learning requirements. Some lecturers attempted to view the online requirements through the students' paradigm. According to these viewpoints, students required a minimum level of equipment, resources and readiness to engage online.

Students having good computers/access outside class time.

Focused students prepared to take responsibility for their own learning 
Most probably need an overlap between different types of offerings to allow students to choose how/when they want to engage.

Students' backgrounds and pre-knowledge will determine the ideal mix. Is there an ideal mix of the two types of environments? No

Does e-learning in some forms or implementations actually undermine or damage the 'real-world' learning environment? Students may end up with information overloading.

Are we simply forced by the trends and rise of Internet activity to 'jump on board' regardless of the cost to academic quality and sense of community?

That may be the case sometimes - but by not forcing people into some type of participation - you might not make any progress. Our customers - the students- enter with a wide knowledge of technology and they are used to a different learning environment and need to be accommodated.

One EIT staff member felt that the practical considerations of the effects of online learning were as important as the pedagogical aspects. The teaching load is often measured by the number of timetabled hours in a semester. As this teacher pointed out, that measurement technique may no longer be a fair assessment of teaching workload in the mixed-mode environment.

Clear timetable of both in-class and online activities is needed for clarification to student and to staff. Step by step introduction to the technology - demonstrated, written, and practiced. i.e. accessible to learners at any time. Clear ground rules and realistic expectations for online participation and contribution 
High value placed on relationship with learner and the collective of learners both in-class and online. There needs to be regular contact by facilitator/tutor in online environment. Online and class-based activities are participatory and contribute to a collaborative learning environment.

The insight required by the online teaching staff was also acknowledged by one respondent, as well as the potential for students to be contributing to the course knowledge and assessment framework. Training for staff was also seen as essential for the success of new programmes that include online learning.

High value placed on the co-construction of knowledge by learner group which may include co-construction of assessment material online. In-class use of internet sites can provide a valuable bridge to more complex e-learning. The availability of vibrant and relevant training opportunities for teachers looking to develop blended learning courses/programmes is essential.

Staff also acknowledged that under some conditions staff themselves could be resistant to engaging with the e-learning environment. If the environment is driven from senior management rather than grown 'organically' then the institute may not achieve optimal results.

Another opinion from an academic covered the threat of the costs of top-down driven e-learning causing teachers to be forced to deliver online or blended programmes without the relevant theory, skills and experience, to the detriment of the learning experience. Transitioning from in-class to a blended learning environment should not be assumed to be natural or easy. It requires existing teaching skills to be utilised in a very different context, and the transition can be enhanced through training, peer support and other techniques. Top-down driven e-learning may foster teacher resistance to engaging with the environment in positive and exciting ways to add to learning opportunities. 
Respondents also considered that the academic level of the programme should be an influence on the weighting of online e-learning versus on-campus or traditional materials. In fact, the lower level certificate courses appear to favour a more traditional structure with workbooks (paper-based) and more hands-on materials than Internet-based materials.

At foundation course level I think that it is critical not to overdo the online 'stuff' at the expense of the development of basic study skills and interpersonal skills. Learning communities developed in the classroom at this level are, I believe, more likely to become learning communities online as a result of a positive in-class learning experience at the time of their foundation learning experiences. Poorly facilitated elearning may result in learners becoming isolated and ultimately dropping out.

Blended learning which creates an environment which really makes learning more accessible for all students is the only valuable option. Where accessibility, for some, comes at the expense of the majority of learners then it may be that the more appropriate (and flexible) approach is to provide a fully online learning environment for those unable to access class based learning and to build a class-based environment which incorporates e-learning at an appropriate level for the other group. Resourcing both, of course, is likely to be problematic, however is worth consideration to maximise learning opportunities.

Another lecturer viewed the blending in terms of 'learning styles' as well as mixing the learning environment. This also allows the agility of teachers to create their own ideal mixture of delivery styles and environments. This type of 'blending' already occurs in the same way when lecturers book additional 
laboratories, or mix levels of slide shows and whiteboard discussions in class according to the needs of their particular class of students.

That probably depends on what you mean with a blended learning environment. I would see that as a learning environment where several learning and teaching methods are combined to stimulate student learning. Combining different methods like theory and practical sessions; students working on their own on exercises either at home or in the institute; students doing research at library or on-line; doing an on-line quiz to do some self-testing; etc. All these methods can blend into an optimal setting for the students in your course. I think variation is an important factor here. In itself using the Internet or a computer for some of these aspects is just another tool in the toolbox. Nothing more, nothing less.

Once again, this lecturer implied that perhaps the institute should not prescribe the exact blend of online and campus learning environments but leave some discretion to individual lecturers or at least course controllers. This raises an interesting issue of how online courses often need to be prepared well in advance of their delivery period. This may cause problems in fast-changing fields such as e-commerce where events are changing the industry on a daily or weekly basis and these events need to be incorporated into the course immediately.

Think of what you want to achieve in your course, what types of students you are likely to have and how the complete set of tools that you have available will suit these needs.

Several teachers thought that prescribing an optimal ideal mix of learning environments is not possible unless the level, size and nature of the course is known. 
No. That totally depends on the course and the students in the course. I don't think that carpentry students will have much use for online learning. There may be some, but it will be quite different from, for example, business students.

One respondent also gave a warning against trying to apply online learning across all levels of the institute without examination of the benefits and risk factors.

If it is applied just for the sake of doing online learning, yes, it is likely to happen from time to time (undermining of the campus facilities). You need to choose the right tools for the job. You cannot use a hammer to create a beautiful origami figure. So think about what suits before you apply it. And make sure you have a good reason to do it and can explain why you want to apply it for this group of students in that course or topic.

It is easy to fall into the trap of following the trends just for the sake of it. And I would not be surprised if this has already happened on several occasions. There are strong forces out there that may not always understand education very well but try to push these things regardless.

One Head of School felt that labelling a course as "online” may not always be helpful to the students. Students may wish to enrol in a particular course and then decide upon which delivery options are most suitable for them.

There are difficulties creating and maintaining a community of learners with online systems. The mix of blended learning environments should be adaptable to the learning style of the student. The use of the word "online" tends to stereotype the course which can be off-putting to teachers involved and also 
students. Sometimes we find that students wish to enrol as a traditional campus student but reserve the right to invoke flexible, online or workbook-delivered learning environments after the initial enrolment.

Some practical courses (for example, computing or carpentry) will probably always require a minimum of campus based activities.

The flexible and blended courses must compromise some things, for example, the access to software applications, laboratory facilities and still need a physical resource for assessments.

From a management viewpoint, it can be difficult to prove that all students have been learning and undertaking the course apart from the assessment results. This is an issue with institutes and universities required to report to the government on the numbers of bona fide students actually enrolled, current and engaged in the course.

It can be difficult to measure the level of 'engagement' within a blended environment as attendance no longer is required necessarily. The number of 'contacts' may help e.g. phone calls, emails, use of drop-in classes, and assessment performance, but these may not equate with the normal scanning and interaction that takes place in a classroom-based course.

Some commercial providers, such as Skillsoft have Internet delivered packages for most of the IT certification courses then direct students to independent certified assessors.

As indicated in this last comment, commercial providers of online systems often provide a web-based and/or DVD learning environment but assessment for 
industry certification is undertaken independently by another company. Therefore, as long as the student makes maximum use of the resources and achieves a successful result on an external test the student and original provider are satisfied regardless of the learning style or type of usage of parts of the learning environment.

One EIT manager discussed how academic quality can be measured by what the institute does and also by what the student brings to the blended learning environment. Another question for the practitioner of the blended environment is: What does the learner bring to the environment? There are social implications to the move to more online e-learning, perhaps leading to less physical social interaction between students. However, the flexibility may free up time for more unstructured social activities.

Another staff member asked whether our campus will become just a place for students to plug in their laptops? At the lower levels students need to learn from other students - we may lose this in a pure online environment. Pure online courses can actually be less efficient than traditional campus classes in terms of economies of scale and number of tutor hours required to complete one cohort of students from start to finish.

One team at EIT has pioneered a new flexible National Certificate of Computing Level 2 (NCC2) and NCC3 programmes, providing workbooks, CD and bag, some online material together with drop-in computer classrooms with tutors. Assessment is performed on campus and through online evidence. This flexibledelivered programme has been very successful but is not dependant on online elearning but a mixture of traditional resources, email contact, and the ability to work from home, work or on-campus. An interesting outcome has also been the new teaching environment of the lecturers involved - most of the contact is by email or phone, with assessment verification also an integral part. The drop-in classes are mainly staffed by tutorial assistants rather than fully qualified lecturers. This example of an ideal blended environment has been successful in terms of student numbers and course satisfaction. Whether it has an adverse 
effect on "pipeline” growth, where lower-level students may or may not enrol in higher-level programmes, has yet to be determined.

One academic with significant experience in developing and managing online courses had some warnings for institutes and universities.

In the race to get courses online many organisations are neglecting those aspects of course design and development that may be the pivotal factors in retaining students and ensuring their success. Lecturers and course designers (often one and the same), need training in both the pedagogical requirements of online learners and the technology skills to provide a seamless learning environment. They also need an allocation of time for course development and support of their students.

The ability or inability to connect with students and teachers is one practical issue already experienced in some online courses at EIT.

In our experience at EIT it is not just the students who suffer the feeling of being disconnected from the learning process, lecturers also feel disconnected from their students. This has been alleviated by some lecturers who keep in touch with their students through weekly telephone calls. It seems that to those students who are faltering, a voice at the end of the phone gives enough encouragement to carry on.

One staff member believed that there are lessons that can be learned from the environmental ways in which students learn outside of the structured teaching delivery and assessment methodology. This opinion illustrated the widespread belief in the powerful effect of the learning environment in general.

Students 'soak knowledge in' from the example of teachers, the lecturers personality, values etc. Students also benefit from talk and conversation - "as you walk around" doing daily tasks in the presence of the class and students. Also the general 
environment is important: the physical landscape, buildings, use of music, books, journals, and that feeling of general absorption. So official curriculum content may not be as persuasive as person-to-person content. How can these types of environmental and emotional experiences be incorporated into an online or blended learning environment? It will be a challenge, but I feel that we still need the personality of the teacher to be able to shine through. If we lose the personal influence of academics we run the danger of becoming a faceless institution driven by policy and procedures.

Other examples of lecturers at EIT utilising features of the Moodle e-learning system include the use of online discussion forums encouraging students to participate in class discussions online. Some lecturers are beginning to provide incentives for student participation by making the forum comments contribute to assessment for the subject. This also allows students who may be reluctant to verbally participate in class to use the discussion board as a backup mechanism.

Online multimedia business games are another growing area which is proving highly motivational for students including competition and reward with a full immersion factor. One EIT management lecturer has set up a complex business online game (Mikes Bikes) in conjunction with Auckland University. In this online business game, students form companies and then configure many settings within the game in order to maximise profitability for the company. Groups of students compete with each other to finish with optimum profitability, production, market penetration, along with other business functions based on their configuration decisions over one semester. A further competitive element is added as the University of Auckland runs teams of students concurrently. Course credits and marks are also allocated based on the student's participation and achievements in the online game. 


\subsection{RESULTS OF INTERVIEW WITH THE ACADEMIC MANAGER, EIT, AND THE E-LEARNING ADVISOR, EIT:}

The following section paraphrases interviews and discussions with the Academic Manager and E-learning Advisor at EIT.

EIT is not at a mature stage with e-learning currently, and does not have the resources available yet to fully support e-learning other than as an "add-on”. The culture at EIT needs to allow staff better linkages and cooperative development amongst themselves which will help the e-learning development.

Benchmarked with other tertiary institutes, EIT is probably in the mid-range, neither leading nor lagging in its development of online learning systems. Perhaps in the future a typical degree student at EIT may attend on campus for one hour per course per week or attend a three day block course with additional online systems in place for the framework of the programme. Lecturers may need training in formal 'instructional design' for effective use of blended or online systems.

The Academic Manager and E-learning Advisor saw a need to develop a “Community of Practice” amongst academic staff so teaching and e-learning issues can be discussed and a sense of academic community can be developed. This is something that is seen as lacking even within the traditional campus environment, not just with regard to e-learning. We do not have any hard evidence on how students want to learn; they largely take what we offer them.

The reasons for encouraging more e-learning is not for economies of scale (in fact the economies may not exist or be negative), but rather to increase our catchment area, reach different target groups, re-focus our teaching methodologies as our learning materials will become more visible and transparent.

There will still be a need for a 'learning facilitator", but e-learning adds more

options to the 'toolbox'. Dealing with the emerging technology by allowing teachers to 'discard' technical features as they become superseded and 
encouraging them to be open to learning about future online systems and features should help overcome some resistance by teaching staff.

E-learning diffusion is taking place through the e-learning advisor role and through the use of embedded 'champions' of practice within various schools and faculties. The Academic Manager can also influence through the senior managers forum advising Deans of the e-learning strategy and direction. The Academic Manager and E-learning Advisor were not sure whether an ideal 'mix' or prescription for a blended learning environment approach could be defined for all programmes.

The issue of the 'pre-packaging' of an online course can be viewed positively as it disciplines academic staff to prepare professionally and adequately.

\subsection{THE EASTERN INSTITUTE OF TECHNOLOGY E-LEARNING STRATEGY}

The Eastern Institute of Technology has created an e-learning strategy report and this serves as a point of reference for the Academic Manager, the E-learning Advisor, senior managers, and generally for all staff. The e-learning strategy (2007-2009) sets its' vision as “E-learning can strengthen teaching and learning at EIT, and strengthen EIT as an institution.”

One of the premises of the EIT e-learning strategy is that individuals must change to take advantage of the opportunities now available through e-learning. E-learning in this EIT report is defined as "teaching and learning that takes advantage of all available resources, techniques and technologies”. One of the keys seen for successful e-learning is effective instructional design according to the strategy. The strategy outlined in the report aims to strengthen teaching and learning, integrate e-learning into overall academic efforts institute-wide. The authors believe that e-learning will strengthen EIT as an enterprise by creating the agility to respond to market demand for online programmes and to utilise sector resources in the form of grants and programmes. The strategy states that its success will be dependant on the participation of staff generally and on 
leadership from the management team. The e-learning advisor role will also play a key part working within EIT structures to communicate and implement the strategy.

The strategic report lists the key elements that require design: activities, teacherstudent communication, student-student communication, learning resources, assessments, feedback and remediation. The report also stipulates that belief is needed (by most staff presumably) that applied technology will not interfere with teaching and learning excellence. There are some similarities, in the need to overcome resistance, perhaps with the period in the 1980's when information technology was transforming the internal infrastructure of organisations and tertiary institutes.

The EIT e-learning strategy also spells out the terminology for all staff, ensuring that teachers with minimal IT experience are clear on what constitutes components of e-learning.

The EIT e-learning strategy report sought to explain to staff a typical 'translation' from traditional form examples to e-learning examples. This type of translation may seem obvious to many IT-literate and computing faculties but it is probably useful to clarify the specific goals and trends of online courses. 
Table 6.1

Translation of Traditional Teaching Processes

Teaching/Learning Processes

Online Learning Tools

lectures, presentations,

demonstrations

group discussion

assessments

teacher-student communication
Powerpoint and other media files, blogs, podcasts

chatrooms, discussion forums, wikis, e-mails

online quizzes and tests

e-mail, wikis, mobile technologies

The EIT e-learning strategy does not seek to stipulate a set of mandatory instructional methods but seeks to influence the attitude towards utilising elearning tools within staffs' professional development which is already committed to increase expertise in teaching and learning in general.

So it can be seen from this explanation and discussion of the EIT E-learning Strategic Report that the principles and aims contained within the report will exert an influence upon the levels of implementation of blended techniques and e-learning upon existing and new courses at EIT. The plan will also exert an influence on staff, staff training and guidance from managers and Deans with an accompanying effect on the types of blended learning environments that develop at EIT.

\subsubsection{Gradients of utilisation of the LMS by staff}

Examples of Moodle usage were cited by staff and various lecturers at EIT utilising the online e-learning software in diverse ways. Not only may they be different in depth of utilisation but the creative expressions within the online framework may also be reflective of the personal styles of individual lecturers. 
For example, some lecturers are still avoiding placing any course material on the LMS however this is becoming less likely due to most Faculties now requiring lecturers to display the course outline and skeleton lectures as a minimum requirement. A second group of lecturers includes those who are now placing the minimum material on the LMS such as course outline, welcome and some lecture notes while still delivering a 'bricks and mortar' course. An emerging third group of lecturers comprises those who are currently adding a good range of materials on the LMS (PowerPoint lectures, lab sheets, tutorials, course outline and weekly commentary). A fourth group of lecturers have now progressed beyond course material placement and are now experimenting with interactive quizzes, chat and discussion forums, wikis and other Web 2.0 technologies. Also there is some evidence that this fourth group are changing some of their timetabled teaching rooms to better complement their online activities. A final small group of academic staff are now directly involved with some emerging purely online courses where their entire teaching interface is through an online mechanism.

The third and fourth groups of academic staff are probably not acting under compulsion from their managers but rather are seeing the blended learning environment as an opportunity to improve their teaching, improve their student satisfaction, and create a richer learning environment overall for their students. Hennessey and Deaney (2004) confirm that teachers' confidence plays an important part in influencing their uptake of information technology and multimedia usage within their programmes. Tertiary teachers and lecturers will hold a wide range of pedagogical beliefs, IT skills and general confidence with new teaching techniques viewed as particularly influential (Mumtaz, 2000). Whether emerging IT and online learning management systems should be utilised across all tertiary sectors is longer an issue - IT, multimedia, online LMS, and Internet resources are here to stay but the effectiveness and diffusion of these enhancements and changes to the learning environment is still a debateable point of difference between institutions and between academic staff. Younger teachers were also more likely to try new information technology within their teaching environment and more likely to adopt new technology generally (Hennessy \& Deaney, 2004). 
Tertiary teachers and lecturers may therefore be placed on a gradient of mature utilisation of online e-learning environments. Some lecturers are taking advantage of e-learning training opportunities, are open to change and are confident enough of their fundamental professional teaching abilities that they are prepared to experiment (and perhaps risk failure in some sessions and elearning features). Dawes (2001) confirms this observation of how academic staff develop professional expertise in emerging technologies and how their motivation helps them to evolve from being potential users through the stages of 'participant', 'involved' and 'adept', through to 'integral users' ultimately.

\subsubsection{The disintermediation of the teaching and provision role}

This study has already mentioned the potential disintermediation of the teacher within the online e-learning or blended learning environment. Another developing area on the wider Internet arena is the growth of holistic and commercial content providers which may also disintermediate entire tertiary institutions. The use of Internet search engines and the phenomenal growth of user-edited dictionaries and resources modelled on Wikipedia has seen the rise of information and knowledge which is outside the direct control of the teacher or institute. The growth of certification courses provided by commercial companies with a higher level professional appearance and incorporating instructional design also generally surpasses the presentational quality of material provided by the average university or tertiary provider.

Huffaker (2003) warns that the integration of Internet-related assignments or multimedia into traditional curriculum is often not adequately considered. Academics generally are not fully considering how students are using the Internet outside of classes or campus. Students are frequently discovering for themselves how the Internet can be used for their unofficial and official learning without teacher guidance. 


\subsection{SUMMARY}

This chapter has presented and discussed the results from research questions, central to this study, that were asked to a wide range of staff at the Eastern Institute of Technology.

Academic staff were generally positive about the emerging presence of the online learning environment, and were also supportive of the concept of a balanced blended environment. The balanced blended environment was supported particularly by those staff who defended the pedagogical need for oncampus real world learning experiences by students.

Managerial and non-academic staff at EIT also expressed strong opinions on the need for progressing with online initiatives but reflected on some concerns with some academic staff who appeared somewhat resistant to the emerging online learning environment.

Interviews with key senior academic staff, who included the Academic Manager, the E-learning Advisor, and one Head of School, also were presented in this chapter. The E-learning strategy was also described and this helped put this study in context within the future aims of the institute.

Finally, some reflections were presented outlining some of the gradients of elearning and blended learning environments involvement by staff across EIT. The following chapter presents a synthesis of the results and findings of this entire study by addressing each of the research questions and reaches some conclusions stemming from this overall study. 


\section{CHAPTER 7}

\section{CONCLUSIONS}

"Effective teachers use e-learning to create new learning environments based on a blended learning approach” (NZ Ministry of Education, 2006, p. 12).

\subsection{INTRODUCTION}

This chapter synthesises the data and findings that were outlined in this study and draws some final conclusions and recommendations for tertiary institutes based on these findings, and finally proposes some ideas for further research. This study investigated the concept of an optimised learning environment within multiple adaptations of the 'classroom'. Conclusions are drawn from the student survey data and results, the student discussion and comments, and the teacher discussions and results.

Chapter 1 introduced the genesis of the concept of the ideal blended tertiary learning environment based on my ethnographical experience as a participant observer. Chapter 1 also presented an overview of the entire thesis and study including the general aim of the study.

Chapter 2 overviewed a range of literature pertaining to online e-learning environments, blended learning environments and other learning environment studies recently undertaken. The historic origin of the WEBLEI instrument was outlined along with some general learning environment historic development. Some of the issues surrounding the emerging technological trends and the convergence of the academic world and increasingly influential e-learning tools were discussed. 
The research questions were presented in Chapter 3 along with the main research instrument. Chapter 3 also outlined the rationale for the mixed methodology and the use of the WEBLEI instrument which were deemed suitable for the New Zealand tertiary environment.

Chapter 4 presented the reliability and validity of the adapted WEBLEI instrument and presented results highlighting student group experiences within the current online and traditional learning environments at the Eastern Institute of Technology. Differences in learning environment responses were examined in the light of student age, gender, level and programme types. Student responses to certain key questions relating to the tension between campus environments and online environments were also critically examined.

Chapter 5 presented data from the written comments from students that were recorded within the adapted WEBLEI instrument and grouped these comments into broad categories according to student preferences and experiences. This provided an opportunity to investigate possible reasons for key WEBLEI questions particularly pertaining to the student perception of the current state of blended learning environments at EIT.

Chapter 6 reported feedback and opinions from a range of teaching, managerial and support staff at the Eastern Institute of Technology regarding the current state of e-learning and recommended blended environment goals for EIT. These staff discussions were also brought into focus through an examination of the current e-learning strategy report of EIT.

The current study outlines the results from an adapted student-based WEBLEI survey instrument within a New Zealand institute of technology, combined with qualitative data from staff and students, with a view to recommending a direction for ideal blended environments at tertiary environments. The sample included 151 information technology certificate, diploma, and degree tertiary students at the Eastern Institute of Technology. The staff sample for the qualitative data collection included discussion comments from a range of tertiary academic and 
administrative staff. This study is unique in seeking to specifically recommend a framework for an idealised mix of online and traditional learning environments for future consideration at universities and institutes of technologies.

As Quinton (2006, p. 543) states: “The challenge will be to harness technological innovations in ways that will assist to deliver high quality learning outcomes relevant to the changing needs of learners”. Any proposed learning environment models for optimal blended learning environments will need to be flexible enough to cope with increasing technological changes that will continue to have an impact probably beyond web-based learning management systems.

This study attempted to achieve a holistic overview of the learning environment at a tertiary institute without narrowly focussing only on the technological and elearning elements available externally and being implemented at the case organisation. Web-based e-learning is still in its infancy and most of the tertiary sector is still largely physically based on the campus experience, however change is occurring at an increasing pace.

\subsection{MAIN FINDINGS OF THE STUDY}

Several research questions were proposed in this study and each one is addressed in this summary of findings.

\subsubsection{Research Question 1: Are modern tertiary students experiencing a sense of being in a positive, encouraging learning environment?}

The results in this study that were presented in Chapter 3 and 4 illustrate that the EIT-adapted WEBLEI is a valid and reliable instrument for use in the tertiary education sector in New Zealand. The results from the WEBLEI and the interviews indicated that tertiary students appreciated most elements of online learning that are currently made available to them. EIT students would appear to enjoy both online and traditional learning environments not wanting to exclude

either option. Students at EIT utilising the online learning systems indicate that 
they are not experiencing a dynamic online community while online, nor are they using the LMS for communicating with other students at a satisfactory level. These were the two lowest scores in the WEBLEI results. Although students are generally satisfied with the online system, if they had the personal freedom and availability themselves they would still prefer a traditional class rather than read an online lecture.

As in a traditional classroom setting, any student responses are probably influenced to some extent by the skill and personality of the lecturer involved in any particular course. One pleasing outcome from the WEBLEI quantitative data was that students rated the connection between the Moodle courses and the campus courses highly, indicating that EIT does have some correlations and synergies already happening in the early blended stages.

The discussion feedback from students at EIT does confirm that these tertiary students are experiencing a sense of being in a positive learning environment, both online and in the campus classroom. Female students are more likely to expect online systems to provide incentives and an environment conducive to interaction amongst students and with teaching staff. Older students appear to be less satisfied with current levels of online responsiveness at EIT, and this may imply a greater demand by older students for the online component to facilitate a high level of communication by all participants.

The qualitative results from the tertiary staff discussions are somewhat mixed with comments generally focussing on what the implications of a blended learning environment means for staff. Administrative and managerial staff appear to hold an opinion that we may be currently dissatisfying students by insisting on compulsory on-campus requirements such as orientation days and standard timetables.

The broad range of types of tertiary students enrolled at a typical institute such as the Eastern Institute of Technology makes it difficult to draw conclusions for all students. The majority of students enrolled at EIT are primarily on-campus 
students having access to Moodle, the online LMS, so most conclusions are based on this type of student. The majority of staff respondents appear to believe that a blended environment is viewed positively by most students; "blended is definitely the best of both worlds".

\subsubsection{Research Question 2: Has the recent addition of the LMS really enhanced the overall learning environment from the student's perspective?}

It would appear from the positive responses of students that generally students perceive the online material available on Moodle favourably. Students appear to easily utilise online material to augment their learning materials. As noted in Chapter 4 (WEBLEI results), statement 20 could be interpreted as, "Moodle is a reasonable substitute for an on-campus course” with a slightly positive response to this by students.

The three groups that emerged from the qualitative results from the WEBLEI; sole e-learning supporters, blended environment supporters, and traditional campus class supporters all agreed on the general benefits of the web-based learning management system at EIT, regardless of their expressed preference. In fact, there appears to now be a built in dependence and expectancy on the use of Moodle and the online environment regardless of the level of online or flexible delivery embedded in any particular course. Any standard campus-based student enrolled at EIT currently, now appears to have an expectation that there will be some learning support from a web-based system.

The discussions with students showed that the flexibility inherent in the webbased learning system has enhanced the learning environment for many part-time and students working full-time or with full-time family responsibilities. Flexibility appears to be one of the main reasons for satisfaction with many students, and these students would prefer classroom experiences but through necessity are satisfied with the online or flexible provision by EIT. 
The qualitative results from staff suggest that students are generally satisfied with the current blended environment at EIT, but staff caution that students still require pastoral and mentoring support to stay motivated where online learning has increased as a proportion of their overall course environment. Staff results also confirm the view that most students would still prefer to be immersed in classroom situations, but that by necessity they appreciate any flexible options.

As EIT is still in the early stages of e-learning and blended learning environment diffusion, there are still multiple gradients of e-learning in practice, ranging from a few fully online e-learning courses, the majority of traditional on-campus courses supplemented with Moodle, some flexible-delivery programmes supported by mixed media, and other early blended models. Within this range of blended diffusion, there are varying levels at which academic staff are deploying blended learning environments. This type of natural organic growth may be beneficial for students and helpful for staff, although may not be fast enough for some administrators with a strong e-learning agenda, based on their responses, or comprehensive enough for some students unable to commit to current campus requirements.

\subsubsection{Research Question 3: What elements help construct an ideal or optimal blended learning environment in a tertiary setting?}

The current learning management system (Moodle) and the current content appears to satisfy the majority of students based on the WEBLEI survey results, over a range of learning environment considerations. Therefore, the use of a LMS, such as Moodle, should be an essential requirement of any ideal blended environment. However, the extent to which the use of a system like Moodle should be deployed is still unclear from the quantitative results. Student results in this study tend to suggest that e-learning is viewed as supplementing rather than substituting classroom experiences, at least initially. To apply this student viewpoint may require a graduated scheme whereby, for example, the first year of a three year degree contains papers mainly campus-based with supplemental e-learning. In year two the blending could be expanded with some pure e- 
learning papers introduced, with other papers with less timetabled hours and more activity online. Finally, in the final year yet more emphasis could be placed on e-learning activity with perhaps the majority of papers purely online with a minority of papers on-campus supported by the LMS suiting the remaining practical ‘hands-on' papers.

Staff at EIT advocate the balanced use of campus facilities and the online systems, although some advise caution with rapid implementation of pure online courses in the current political climate. Every course should come under examination at EIT and conscious decisions made on the level and proportion of usage of Moodle, campus-based classes or meetings, physical learning materials (workbooks, CD's, and references), and channels of communication (email, discussion threads, call centre, personal face to face). Each new and existing course could be graded from one to four, according to the level of 'blending' deemed appropriate with one being the most traditional campus-based and four being a purely online course.

\subsubsection{Research Question 4: How can the best components of online e- learning be combined with the best components of the traditional 'bricks and mortar' classroom learning environments? Is there an ideal mix of the two types of environments?}

The qualitative data from tertiary staff did not support this concept of the idealised blended environment entirely. The main objection from staff appeared to be that every level, course and mix of students may require fine tuning of the 'mix', therefore one particular recommended blended mix may be too narrow to accommodate the diversity at the tertiary level.

The student quantitative data did appear to support a balanced range of online and campus-based environments although several clusters of preferences emerged here. A more detailed questionnaire would be needed to ascertain why some students had a strong preference for campus-based components in any course. 
There is some evidence that the blended learning environment is a transitional stage on the way towards a more fully online e-learning environment. As expressed by some staff, there is a fear that a blended model is only a transitional state in a progression towards distance-style full e-learning. If this is not an actual organisational goal then it may be beneficial for tertiary institutes to state this to staff and express a preference or at least a tolerance for a blended learning environment. It appears that some students and staff view the emerging online learning systems as something imposed on them with little consultation on levels of usage and content. There may be scope for EIT to consult staff and students at the school level before changes are made concerning the blended and online environments.

\subsubsection{Research Question 5: Does e-learning in some forms or implementations actually undermine or damage the 'real-world' learning environment?}

There appeared to be little evidence of negative effects of the advancement of online learning systems within the EIT environment from the data analysed in this study. There were concerns expressed by some staff, however these were more focussed on methods of implementation and workload issues rather than a prediction of negative impact on the campus courses and students. There was a strong reaction to this research question by a small number of managerial staff who perhaps perceived this question to be provocative or reflective of some academics who are resistance to change.

Academic staff expressed views on this question that they may be unable or unwilling to express to their Heads of Schools or Deans. This raises the issue that the responsibility for developing online e-learning or intentionally blended models of new or changing courses appears to be driven from centralised administration or special interest groups rather than from Deans or school academic leaders. 
One of the highest student scores on the Likert scale (4.29) resulted from the statement that the combination of online material and the classroom environment assisted learning. Students also indicated that they did not prefer online learning alone. This result agrees with another New Zealand study at Unitec (ITP), Auckland (Sherifdeen, 2007). So these two results indicate that students do not voluntarily wish to relinquish the campus classroom environment. Student results generally indicate that they hold a high value on traditional classes, real time interaction with their lecturer, and a sense of being part of a group of other students. Therefore, significant removal of compulsory campus activities may be viewed negatively by students.

Results from the student WEBLEI indicated that some students are relying on the online learning material when they choose not to attend classes. Staff results confirm that increasing numbers of students are playing 'pick and choose' on which classes to attend and this has an effect on the group dynamic within the campus classes where there has been an increase in absenteeism. This may be an early sign of a negative effect of online learning within the tertiary environment where teachers do not necessarily have the authority to force attendance unlike the secondary school environment. Some managerial staff believe this attendance effect is proof that those courses or components of such courses should be moved to an online environment as the attendance trends prove that the students can gain the necessary learning and content and still succeed in their assessment.

\subsubsection{Research Question 6: Are we simply forced by the trends and rise of Internet activity to 'jump on board' regardless of the cost to academic quality and sense of community?}

Evidence from the WEBLEI student data suggests that tertiary students engaged in all modes of delivery now have an expectation of some level of subject content support from online systems. It would be difficult to now envisage any full-time tertiary diploma or degree programme without an Internet-based LMS of some form supporting the course. This result supports the view that universities and 
tertiary institutes are now compelled to continue to provide online learning environments for their students, at least to some degree.

The qualitative data from staff and students also support the growth and evolution of virtual learning environments. However, managerial staff particularly, saw no correlation between increased e-learning and lower academic standards or lack of student community. Some administrative staff have a viewpoint that any course is simplistically delivering content, providing access, and then administering assessment. This view confirms Quinton's (2006) insight into the popular misconception by administrators that teaching is primarily about delivering content in a similar manner to channelling water through a pipe.

Some staff reflected on their positive experience with lower level certificate courses delivered flexibly and online, and believed that these courses were academically robust and working to the students' satisfaction. Some staff did agree that new forms of online 'community' would be crucial for success in the blended and online environment, particularly for Diploma and Degree programmes.

Staff results also provided evidence of other forms of blended learning environments which did not hinge primarily on Internet delivery but did use a non-traditional mixed environment including paper-workbooks, CD-ROM multimedia materials, informal campus-based computer rooms with assistants, and email/telephone support.

There was evidence from the staff results that infrastructure support is not necessarily planned or fully available at EIT to support newer forms of online or flexible programmes that have already been implemented. Students, and particularly students within the workforce, expect quick responses to technical issues and are not as tolerant of slower moving bureaucracy as the full-time oncampus students. More structured class sessions have been requested by students involved in online courses according to some staff at EIT. This confirms the preferences expressed by the WEBLEI students that even satisfied online students still have a strong desire for campus classroom experiences. 


\subsection{IMPLICATIONS OF THIS STUDY}

This study illustrated how embedded the use of the online learning environment is within the tertiary environment. The WEBLEI results reflect that tertiary students are familiar with most LMS features and would now have a low tolerance for a 'pure' classroom-only environment. The tertiary environment must evaluate and implement pertinent technologies continually to enhance and protect their students learning environment. However, the comments from students and staff indicate some warnings reflecting the need for caution in maintaining academic quality as online systems increase their influence. The value of academic programmes is evaluated by students as something more than delivery of content, absorption and then assessment. Students desire an experience and an immersion in some kind of learning environment during their process as a student. Assessment results are a narrow representation of the value of the experience as, say, a three-year IT degree student. A deliberate strategy for blended education delivery may be superior to a single focus strategy of adding e-learning scaffolding to every conceivable programme and course at EIT. A stated blended strategy may have a more inclusive effect on staff and students as all stakeholders can see the overall effect of new technologies and the impact within the context of the overall learning environment. Some caution may be needed using e-learning implementation as a means of radically re-constructing teaching and learning methodologies in an environment where current students do not appear dissatisfied.

It is also useful to set the results of this case study within the context of international and New Zealand developments in e-learning and flexible or blended learning environments. The influence of the New Zealand Flexible Learning initiative, the uptake of Wikieducator, and the international influences of utilising emerging technologies such as the Second Environment Advanced Learning project (Salmon, 2006) are all dynamically changing the overall learning environment in the tertiary sector. The blended learning environment is increasingly influenced by consortiums and groups of tertiary institutes who are working on initiatives beyond their individual campuses. 


\begin{tabular}{|c|c|c|c|}
\hline & $\begin{array}{l}\text { Student research } \\
\text { results }\end{array}$ & $\begin{array}{ll}\text { Staff } & \text { research } \\
\text { results } & \end{array}$ & $\begin{array}{l}\text { Blended } \\
\text { literature review }\end{array}$ \\
\hline Face to Face & $\begin{array}{l}\text { Classes retained } \\
\text { where possible. } \\
\text { Physical 'spaces' } \\
\text { reconfigured in } \\
\text { conjunction with } \\
\text { Blended mode. } \\
\text { Students require } \\
\text { interaction. }\end{array}$ & $\begin{array}{l}\text { Most teaching } \\
\text { staff } \\
\text { primarily engaged } \\
\text { in f2f. } \\
\text { Make changes to } \\
\text { face to face } \\
\text { classes. }\end{array}$ & $\begin{array}{l}\text { Retained as a } \\
\text { compulsory } \\
\text { 'backstop' and } \\
\text { minimum level in } \\
\text { Flexible Delivery }\end{array}$ \\
\hline E-learning & $\begin{array}{l}\text { Teaching } \\
\text { 'presence' still } \\
\text { required. } \\
\text { Training for } \\
\text { eLearners. } \\
\text { Tertiary Institutes } \\
\text { need to survey } \\
\text { their flexible } \\
\text { learners }\end{array}$ & $\begin{array}{l}\text { Staff } \\
\text { Development. } \\
\text { Aligned to wider } \\
\text { academic goals. } \\
\text { Ensure authentic } \\
\text { participation by } \\
\text { students. }\end{array}$ & \begin{tabular}{l}
\multicolumn{3}{l}{ Need to be able to } \\
question the \\
academic quality \\
of any given \\
elearning \\
programme.
\end{tabular} \\
\hline $\begin{array}{l}\text { Blended/Flexible } \\
\text { Learning }\end{array}$ & \begin{tabular}{lr} 
To fit around \\
work \& family \\
requirements - \\
\multicolumn{2}{l}{ Students are often } \\
online & by \\
necessity. \\
Do not exclude \\
f2f.
\end{tabular} & $\begin{array}{l}\text { Strive for a } \\
\text { balanced 'mix' } \\
\text { rather than strong } \\
\text { e-learning. }\end{array}$ & $\begin{array}{l}\text { Learners included } \\
\text { in a Community } \\
\text { of Practice as } \\
\text { professionals in- } \\
\text { training }\end{array}$ \\
\hline $\begin{array}{l}\text { Emerging } \\
\text { Technologies }\end{array}$ & $\begin{array}{l}\text { Use of PDA's, } \\
\text { mobile } \\
\text { technology. } \\
\text { IT Infrastructure } \\
\text { support needed. }\end{array}$ & $\begin{array}{l}\text { IT Services \& } \\
\text { Staff } \\
\text { Development } \\
\text { involvement in } \\
\text { strategic planning. }\end{array}$ & $\begin{array}{l}\text { Virtual Learning } \\
\text { Environment } \\
\text { emerging }\end{array}$ \\
\hline NZ Initiatives & $\begin{array}{l}\text { Sharing online } \\
\text { courses by } \\
\text { consortiums. } \\
\text { NZ students } \\
\text { prefer classroom } \\
\text { (Sherifdeen, } \\
2007 \text { ) }\end{array}$ & $\begin{array}{l}\text { Outline a desired } \\
\text { future state of an } \\
\text { institution in } \\
\text { terms of blended } \\
\text { 'balance'. }\end{array}$ & $\begin{array}{l}\text { Open Learning } \\
\text { Platforms. } \\
\text { Academic leaders } \\
\text { cognisant of NZ- } \\
\text { wide Flexible } \\
\text { Learning } \\
\text { initiatives. }\end{array}$ \\
\hline $\begin{array}{l}\text { International } \\
\text { examples }\end{array}$ & $\begin{array}{l}\text { Students benefit } \\
\text { from } \\
\text { providers in a } \\
\text { flexible } \\
\text { consortium }\end{array}$ & $\begin{array}{lr}\begin{array}{l}\text { Staff should } \\
\text { educated }\end{array} & \text { be } \\
\text { international } & \\
\text { initiatives } & \text { (not } \\
\text { just e-skills). } & \end{array}$ & $\begin{array}{l}\text { Academic leaders } \\
\text { cognisant of } \\
\text { International } \\
\text { Flexible Learning } \\
\text { initiatives. }\end{array}$ \\
\hline
\end{tabular}

Table 7.1. Elements of a desirable Blended/Flexible learning environment for the New Zealand ITP sector. 


\subsubsection{Optimal Blended learning environments}

Results from staff and students in this study suggest that an optimal level of blended learning, for tertiary institutes already possessing significant physical campus resources, should include an overall environment that is easily accessible and combines formal and informal learning on-campus and online with a focus on the learner in all modes.

It would appear from the student WEBLEI results, and the qualitative comments from staff and students that an optimal blended environment should include a 'teaching presence' ability, attendance and assessment of participation, online assessment submission, Internet features, and opportunities for student interaction.

Online academics and course managers should be active and experienced in real world applications of their subject matter. The blended environment should allow for the personality of the academic to demonstrate openness, flexibility and trust.

The EIT e-learning strategy includes a recommendation for teaching faculties and schools to analyse the audience, in terms of who the learners are, where geographically the students are located, and where they are going. This may prove problematic for lecturing staff as they often receive enrolments well into the third week of any given semester and only receive student names with no additional information.

Quinton (2006, p. 557) advises that there is "no single, correct medium for delivering eLearning, nor is there a set of formulaic specifications that dictates the kind of interaction most conducive to learning in all domains for all learners”. Instead tertiary academic staff should take responsibility for developing their own e-learning and technology skills to a level where they can respond flexibly and quickly to student demands and new opportunities within blended learning environments and emerging technologies. Seely-Brown (2007) discusses the concept of situated learning theory where students are situated in a simulated 
working environment, working alongside their teacher in a laboratory, studio or workplace setting. This modern version of the mentor-apprentice model is possible in the Internet age where we now have at our disposal tools and resources for engaging in productive inquiry and learning.

Developing new blended learning environments may have implications for the physical resources on campus. Classrooms and lecture theatres may need to be re-designed to accommodate different sized groups, less frequently occurring groups of students, students requiring resources in a similar way to academic or other staff, opportunities for students to work alongside staff providing mentoring opportunities. One example of this kind of changed environment is a large classroom which accommodates laboratory or computer workstation activities around the perimeter, discussion area tables, with the ability to accommodate informal lectures as well. This type of environment blends seamlessly with the online web-based environment and may even include campus-based navigation and exploration of web-based learning events.

The process of developing the online component requires academic staff to do more than just try to duplicate the classroom in an online format. Lecturers must transform instruction, which requires a total rethink of how to achieve learning objectives given the opportunities and restrictions of the online environment (Grandzol \& Grandzol, 2006).

Academic staff and administrators need to appreciate and discuss the relationship between the traditional classroom, the blended environment, and fully online tertiary learning environments in terms of achieving a sense of community. The blended environment rated the highest in terms of building a sense of community and lessening psychological distance between students (Rovai \& Jordan, 2004).

Characteristics of online students necessary for their success include interest in the material, self-motivation, self-directed learning, family support, and positive timely feedback. These characteristics are easier to produce in blended courses as the convenience of online content is available without the loss of face-to-face 
contact which is more able to nurture a sense of community in the students. The other advantage of balanced blended environments is that the variable technological skill of different students can be dealt with in the campus sessions, whatever these may be (Rovai \& Jordan, 2004).

In the same way, blended learning environments rate higher satisfaction than solely traditional class environments with students, as class discussions can occur in the physical classroom as well as within the online systems.

The blended concept of learning means thinking less about delivering instruction and more about producing learning, including more students through distance education technologies, and promoting a strong sense of community among learners. The idea behind blended learning is really a combination of these areas, and as the learning environment becomes more learning-centred, then the emphasis is placed on active learning through student group-work and social interaction alongside individual learning (Rovai \& Jordan, 2004). This convergence of online and traditional instruction is possibly one of the main trends in tertiary education today, and runs in parallel with the convergence of the constructivist methodology and the traditional teacher-led pedagogy.

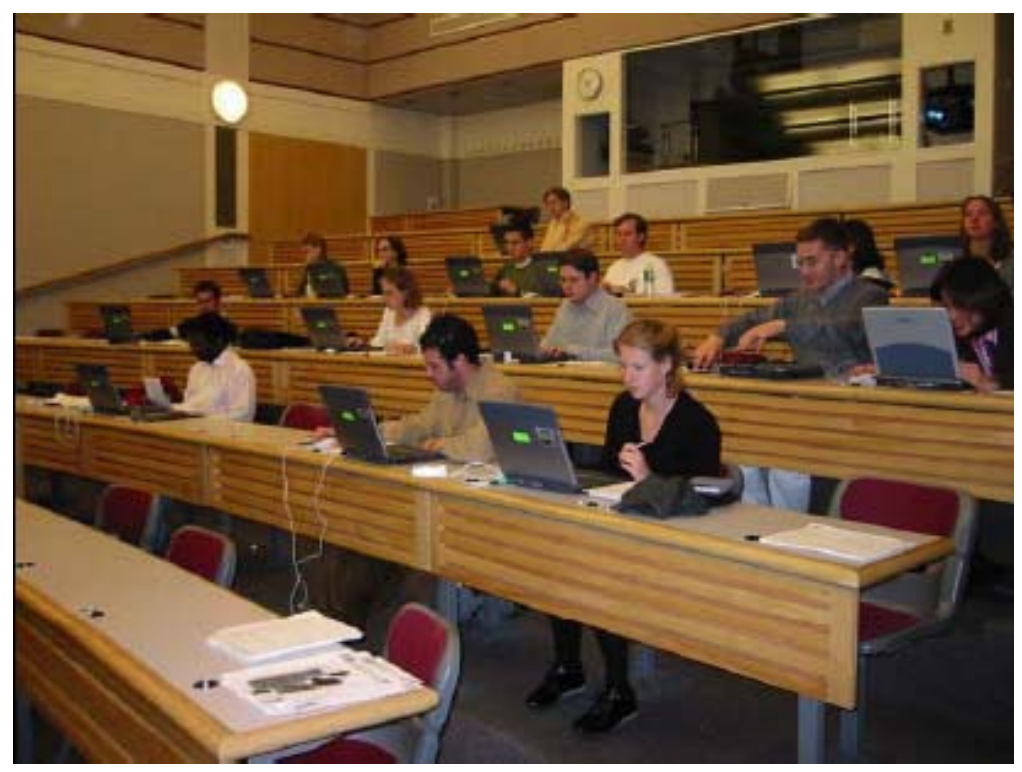

Figure 7.1. Blended learning on-campus - (Seely-Brown, 2007). 
Figure 7.1 shows a picture of a blended learning environment that is perhaps outside of our common understanding of online learning where we envisage students at home studying via the Internet. Here we see students with their own devices (computer notebooks) utilising campus infrastructure (computer network) working in a mixed class tutorial and still working on their own assignment, perhaps with Internet access and some student to student interaction. This figure illustrates that blended learning may still retain strong campus utilisation but in different ways from the traditional lecture, laboratory and tutorial.

\subsection{FUTURE PROSPECTS FOR THIS RESEARCH}

A similar study to this one could be undertaken across a number of tertiary institutes to add more depth and breadth to the findings of this study. A multiple case study may highlight some initiatives that tertiary institutes may be piloting and may help further establish an ideal blended learning environment. Investigating universities or tertiary institutes that are regarded as early adopters of e-learning and effective blended learning environments may highlight more starkly problems and opportunities for the future.

Another avenue of investigation could include investigating any negative effects of the advancement of the online and virtual learning environments in terms of any undermining of the physical campus and classroom provision. For every additional student enrolled in a flexible delivery programme, is there a reduction in the use of physical campus resources? This exploration could include comparing the resources and hours spent supporting an example class of online learners compared with a class of largely traditional learners. Some feedback from flexible-delivery lecturers suggests that workload can be substantially increased supporting groups of online learners in terms of email communication, updating of online resources and general class management - often repeating communication that normally can be broadcast just once in the traditional classroom. This type of investigation could include a cost-benefit analysis using return on investment models to allow tertiary institutes to evaluate the real cost 
effectiveness of choosing a purely online channel for a course compared to a mainly traditional programme. "Whilst there has been a relatively speedy uptake of the technologies, there has been little evaluation of the full impact of online learning on students, academics, institutional structures, policies and practices or teaching and learning” (Department of Education Science and Training, 2002, p. $52)$.

Future research opportunities would also include investigating emerging technologies and future virtual Internet environments. The social environment of secondlife.com and the social networking websites are likely to impact the online learning environment and by implication any blended environment that is built around the technological constructs. Future technologies that are beginning to influence learning environments include wireless campuses, flexible learning, learning objects, and different mixtures of technologies and campus resources.

Although valuable use may be made of the ideal blended learning environment over the foreseeable future, the blended mode may yet prove to be an interim stage as tertiary education moves increasingly to a fully online web-based dominated model. Picciano (2007) takes a look at the future of online learning, saying that higher education is entering a new stage of development that is being generated by the increasing use of blended learning techniques overall. "I think in another four or five years we are going to see another rapid deployment of distance learning as a lot of these people who are doing the blended stuff are going to move into a fully online environment" (Picciano, 2007, p.1).

Quality teaching is about finding the right balance between faceto-face communications, interaction via other media and individual work so that each learning experience is maximised. Flexible delivery of teaching is not intended to cut costs but to improve access and the quality of the learning experience for students.

(Department of Education Science and Training, 2002, p. 7) 
The literature review in Chapter 2 in this study examined the historic issues surrounding the integration of information technology generally within the tertiary campus. This historic diffusion of IT issues in the 1990s have been largely dealt with and absorbed into current practice at all tertiary institutes. Perhaps in the same way the issues surrounding the implementation of the blended and e-learning environments will also become normalised in the near future. The phenomenon of e-learning and blended learning in the tertiary sector and indeed all levels of education are likely to become so ubiquitous that the terminology and issues may become redundant as critical issues and we will face yet another new set of emerging technologies and industrial issues.

\subsection{SUMMARY AND CONCLUDING REMARKS}

This thesis provides an original study of learning environments within online paradigms and across traditional tertiary classroom situations and an evaluation of the ideal synthesis of the two environments.

The study identified associations between age, gender and year level and the perception of the usefulness of online learning environment features. This study has outlined the first use of the adapted WEBLEI instrument in a tertiary environment with the purpose of defining an ideal blended learning environment for tertiary students and for the tertiary environment generally.

As Wheeler (2004) predicts, and as this study has indicated, tertiary institutions such as EIT may be constrained to adapt and change their learning environments simply as a reaction to external factors and trends beyond its control. The influence of the typical tertiary institute or university is diminishing because it may not be adapting quickly enough to the fast-moving demands of the information society. At the same time, new tertiary organisations are growing in influence because they can offer flexible, "any time, any place" learning opportunities in a global economy. Offering flexible learning, particularly distance education, workplace training, online Internet-enabled learning, and oncampus flexible open learning is increasing and becoming more popular. These 
fresh approaches are poised to gain momentum over the foreseeable future as they are best suited to meet the needs of both students and employers. This viewpoint by Wheeler (2004) supports the findings of this study in proposing a blended learning environment strategy that seeks to adopt technology where appropriate, but also recommending collaboration of staff, diversification, investment in technology, and staff skills development in new educational practices. However, it is still unclear what the risks are for older existing tertiary institutes with a historic physical infrastructure to fully and heavily engage and compete in the online environment.

Incremental improvements to the overall learning environment with aims towards an optimal blended learning environment in a particular tertiary institute may be more successful than a single focus on implementing e-learning at every opportunity and using e-learning as leverage to reconstruct entire teaching methodologies and current practices. The use of the term 'blended learning environments’ may also be more readily understood and accepted by academic staff than the terms 'online' and 'e-learning' given the perceived threat that these terms represent to some staff according to the discussion feedback outlined in Chapter 5.

Replacing traditional campus-based courses and programmes at tertiary institutes and universities with pure online e-learning learning environments may be attempting to solve a non-existent problem. The tertiary sector in New Zealand has already suffered recently from adverse publicity surrounding 'non-attending' and non-traditional courses.

The concept of life-long learning has permeated across a wide cross-section of society today and this has been dramatically enabled by the Internet (SeelyBrown, 2007). Future tertiary blended learning environments may revolve around building virtual communities of practice where students can participate alongside practitioners and teaching staff rather than simply as a member of a classroom. The future blended student may become immersed in a social 
environment which is supported by both a physical and online presence, mentored by a professional practitioner/teacher.

Finally, this study has confirmed a number of useful findings that may benefit tertiary administrators and academic staff in planning and implementing blended, flexible and online learning systems, taking into account a broad range of influences and factors in the tertiary education sector.

Firstly in summary, this study has confirmed the adapted version of the WEBLEI for New Zealand blended learning environments as a valid and reliable instrument and may be useful as a research instrument in a range of similar studies.

Tertiary students have mainly positive experiences of the mixture of online and traditional classroom learning environments, however a strong affiliation with physical classroom experiences was recorded from this study regardless of their current mode of course. Female students appear to have a higher expectation of interaction within online learning systems. There was no significant difference in satisfaction between year levels in students experiencing a blended learning environment although the motivating reasons may be different. Tertiary students appeared to belong to three groups with regard to learning environment preferences: 1. Group preferring mainly online systems, 2. Group preferring a blended approach to learning, 3. Group preferring mainly classroom experiences.

Finally, tertiary staff were generally supportive of a blended learning environment approach to the implementation of flexible and online systems. Tertiary staff were aware of the external trends and influences of online and elearning and were generally supportive of the utilisation of emerging online technologies but staff did advise caution and inclusive planning for future success. Thus, for administrators, a learning and teaching strategy that embraced a flexible and blended approach may be more successful over an entire tertiary institute than a narrowly focussed e-learning strategy. 


\section{REFERENCES}

Anandam, K. (1998). A call for action. In K. Anandam (Ed.), Integrating technology on campus: Human sensibilities and technical possibilities (pp. 89-90). San Francisco: Jossey-Bass.

Atkins, C., \& Sampson, J. (2002, 6-8 June). Critical Appraisal Guidelines for Single Case Study Research. Retrieved 11 April, 2008, from http://is2.lse.ac.uk/asp/aspecis/20020011.pdf

Bach, S., Haynes, P., \& Smith, J. L. (2007). Online learning and teaching in higher education. Maidenhead: Open University Press.

Bain, D., McNaught, C., Mills, C., \& Leuckenhausen, G. (1998). Investigating classroom environments in Taiwan and Australia with multiple research methods. Learning Environments Research, 1, 163-180.

Bersin, J. (2004). The blended learning book: Best practices, proven methodologies, and lessons learned. San Francisco: Pfeiffer.

Brodsky, N. H. (1998). Learning from learners Internet style. Educom Review, 33(2), 14-16.

Calgary-University. (2007). Blended learning in a research University. Retrieved 21 September, 2007, from

http://www.commons.ucalgary.ca/documents/BlendedLearning_1.pdf

Cervone, D. P. (2002). Education as entertainment. Retrieved 23 June 2006, from http://www.math.union.edu/ dpvc/courses/advice/welcome.html

Chandra, V., \& Fisher, D. L. (2006). Assessing the effectiveness of a blended web-based learning environment in an Australian high school. In D. L. Fisher \& M. S. Khine (Eds.), Contemporary approaches to research on learning environments: Worldviews (pp. 461-478). Singapore: World Scientific Publishing.

Chang, V. (1999). Evaluating the effectiveness of online learning using a new web based learning instrument. Retrieved March, 2007, from http://www.waier.org.au/forums/1999/chang.html

Chang, V., \& Fisher, D. L. (1998). The validation and application of a new learning environment instrument to evaluate online learning in higher education. $\quad$ Retrieved 20 September, 2007, from http://www.aare.edu.au/01pap/cha01098.htm

Chang, V., \& Fisher, D. L. (2003). The validation and application of a new learning environment instrument for online learning in higher education. In M. S. Khine \& D. L. Fisher (Eds.), Technology rich learning 
environments: A future perspective (pp. 1-20). Singapore: World Scientific Publishing.

Chard, S. M. (2006). Evaluating the virtual learning environment. In D. L. Fisher \& M. S. Khine (Eds.), Contemporary approaches to research on learning environments: Worldviews (pp. 603-620). Singapore: World Scientific Publishing.

Clayton, J. (2003). Assessing and researching the online learning environment. In M. S. Khine \& D. Fisher (Eds.), Technology-rich learning environments: A future perspective (pp. 157-186). Singapore: World Scientific Publishing.

Collins, M. P., \& Berge, Z. L. (Eds.). (1995). Computer-mediated communication and the online classroom (Vol. 1-3). Cresskill, NJ: Hampton Press.

Cullen, M. (2007). Tertiary funding reforms: The next steps. Retrieved 9 April, 2008, from http://www.tec.govt.nz/upload/downloads/Minister-speech30April.pdf

Dawes, L. (2001). What stops teachers using new technology? In M. Leask (Ed.), Issues in teaching using ICT (pp. 61-79). London: Routledge.

de Freitas, S., \& Oliver, M. (2005). Does e-learning policy drive change in higher education?: A case study relating models of organisational change to elearning implementation. Journal of Higher Education Policy and Management, 27(1), 81-96.

Department of Education Science and Training. (2002). Higher education review process. Striving for quality: Learning, teaching and scholarship [Electronic Version]. DEST, 2007, 1-78 from http://www.backingaustraliasfuture.gov.au/publications/striving_for_quali ty/pdf/quality.pdf.

Deubel, P. (2003). Learning from reflections - Issues in building quality online courses. Online Journal of Distance Learning Administration, VI(III), 1-5.

Downes, S. (2006). E-learning 2.0. eLearn Magazine Retrieved 15 April, 2007, from http://www.elearnmag.org/subpage.cfm?section=articles\&article=29-1

Eastern Institute of Technology. (2007). Moodle at EIT. Retrieved 10 September, 2007, from http://eitonline.eit.ac.nz/

Ellis, A., \& Phelps, R. (2000). Staff development for online delivery: A collaborative, team based action learning model. Australian Journal of Educational Technology, 16(1), 26-44.

Falloon, G. (2006). "Learning digitally" - E-classrooms: Computers looking for a problem to solve? In D. L. Fisher \& M. L. Khine (Eds.), Contemporary 
approaches to research on learning environments: Worldviews (pp. 337368). Singapore: World Scientific Publishing.

Feldstein, M., \& Masson, P. (2006). Unbolting the chairs: Making learning management systems more flexible. Retrieved 22 March, 2007, from http://www.elearnmag.org/subpage.cfm?section=tutorials\&article=22-1

Fetaji, B. (2006). Experiences and issues in authoring e-learning content with solutions applied under the e-learning framework project. Retrieved 12 June, 2006, from http://www.iadis.org/Multi2006/Papers/17/S034_EL.pdf

FLINZ. (2006). Flexible learning in New Zealand. Retrieved 20 April, 2008, from http://www.flinz.ac.nz

Fraser, B. J., \& Tobin, K. (1991). Combining qualitative and quantitative methods in classroom environmental research. In B. J. Fraser \& K. G. Tobin (Eds.), Educational environments: Evaluation, antecedents and consequences (pp. 271-291). London: Pergamon Press.

Fraser, B. J. (1994). Research on classroom and school climate. In D. Gabel (Ed.), Handbook of research on science teaching and learning (pp. 493541). New York: MacMillan.

Fraser, B. J. (1998). Science learning environments: Assessment, effects and determinants. In B. J. Fraser \& K. G. Tobin (Eds.), International handbook of science education (pp. 527-564). Dordrecht, The Netherlands: Kluwer Academic Publishers.

Fraser, B. J. (2001). Twenty thousand hours: Editor's introduction. Learning Environments Research: An International Journal, 4, 1-5.

Fraser, B. J. (2002). Learning environments research: Yesterday, today and tomorrow. In S. C. Goh \& M. S. Khine (Eds.), Studies in educational learning environments: An international perspective (pp. 1-25). Singapore: World Scientific Publishing.

Fungaroli Sargent, C. (2000). Traditional degrees for non-traditional students: How to earn a top diploma from America's great colleges at any age. New York: Farrar, Straus \& Giroux.

Gansler, A. (2007). eLearners.com research debunks myths about online learning. Retrieved 6 September, 2007, from http://www.elearners.com/help/press/release-lead-survey.asp

Gardiner, W. L. (1989). Forecasting, planning, and the future of the information society. In P. Gourmain (Ed.), High technology workplaces: Integrating technology, management, and design for productive work environments (pp. 27-39). New York: Van Nostrand Reinhold. 
Gen-i. (2007). VoIP: Nortel and Microsoft offer business solution (Seminar Presentation). Napier: Gen-i New Zealand.

Goh, S. C., \& Fraser, B. J. (1998). Teacher interpersonal behaviour, classroom environment and student outcomes in primary mathematics in Singapore. In B. J. Fraser \& K. J. Tobin (Eds.), International handbook of science education (pp. 199-229). Dordrecht: Kluwer Academic Publishers.

Gould, J. W. (2003). Program planning of asynchronous on-line courses design complexities and ethics - Research. Acquisition Review Quarterly, Wntr(2003).

Grandzol, J. R., \& Grandzol, C. J. (2006). Best practices for online business education. The international review of research in open and distance, $7(1), 1-15$.

Hall, K. (2005). Science, globalization, and educational governance: The political rationalities of the new managerialism. International Journal of Global Legal Studies, 12(1), 153-182.

Hennessey, S., \& Deaney, R. (2004). Sustainability and evolution of ICTsupported classroom practice. Retrieved 21 September, 2007, from http://131.111.153.52/istl/SAE041.doc

Henriksen, J. (1998). Sources and information: Identifying and implementing technologies for higher education. In K. Anandam (Ed.), Integrating technology on campus: human sensibilities and technical possibilities (pp. 91-98). San Francisco: Jossey-Bass.

Huffaker, D. (2003). Reconnecting the classroom: E-learning pedagogy in US public high schools. Australian Journal of Educational Technology, 19(3), 356-370.

Hung, D., \& Tan, S. C. (2003). Design principles for web-based learning: Balancing individual and social perspectives in technology-rich learning environments. In M. S. Khine \& D. Fisher (Eds.), Technology-rich learning environments: A future perspective (pp. 385-406). Singapore: World Scientific Publishing.

Huang, S.-Y. L. (2006). Validation of an instrument for assessing psychosocial environments at colleges and universities in Taiwan. In M. S. Khine \& D.Fisher (Eds.), Contemporary approaches to research on learning environments: Worldviews (pp. 479-496). Singapore: World Scientific Publishing.

Jegede, O., Fraser, B. J., \& Fisher, D. (1998, April). Development, validation and use of a learning environment instrument for university distance education settings, Paper presented at Annual Meeting of the American Educational Research Association. San Diego. 
Jelassi, T., \& Enders, A. (2005). Strategies for e-business: Creating value through electronic and mobile commerce (First ed.). London: Prentice Hall.

Jonassen, D., Howland, J., Moore, J., \& Marra, R. M. (2003). Learning to solve problems with technology: A constructivist perspective. New Jersey: Prentice Hall.

Jorgensen, D. L. (1989). Participant observation: A methodology for human studies (Vol. 15). Newbury Park, CA: Sage.

Joyce, P. (2006). To sir, with grudge. Investigate, 6, 58-61.

Keller, H. (2000). Light in my darkness. Pennsylvania: Chrysalis Books.

Kerr, C. R., Fisher, D. L., Yaxley, B. G., \& Fraser, B. J. (2006). Studies of students' perceptions in science classrooms at the post-compulsory level. In D.Fisher \& M. S. Khine (Eds.), Contemporary approaches to research on learning environments: Worldviews (pp. 161-194). Singapore: World Scientific Publishing.

Kesner, M., Frailich, M., \& Hofstein, A. (2003). Implementing the Internet learning environment into the chemistry curriculum in high schools in Israel. In M. S. Khine \& D. Fisher (Eds.), Technology-rich learning environments: A future perspective (pp. 209-234). Singapore: World Scientific Publishing.

Khine, M. S. (2003). Creating a technology-rich constructivist learning environment in a classroom management module. In D. Fisher \& M. S. Khine (Eds.), Technology-rich learning environments: A future perspective (pp. 21-39). Singapore: World Scientific Publishing.

Kruse, K. (2004). Measuring the total cost of e-learning. Retrieved 2 October, 2007, from http://www.e-learningguru.com/articles/art5_2.htm

Lipponen, L., Lallimo, J., \& Lakkala, M. (2006). Designing infrastructures for learning with technology. In D. L. Fisher \& M. S. Khine (Eds.), Contemporary approaches to research on learning environments: Worldviews (pp. 449-460). Singapore: World Scientific Publishing.

Luke, A. (2003). Testimonial. In M. S. Khine \& D. Fisher (Eds.), Technologyrich learning environments: A future perspective (pp. 423). Singapore: World Scientific Publishing.

Mahara. (2008). Mahara: Open Source Portfolios. Retrieved 19 April, 2008, from http://www.mahara.org/

Maharey, S. (2007). 21st Century learning environments for all learners Retrieved 18 August, 2007, from 
http://www.minedu.govt.nz/web/downloadable/dl12063_v1/SteveMahare ySpeech.doc

McDonald, J., \& Postle, G. (1999). Teaching online: Challenge to a reinterpretation of traditional instructional models. Retrieved 23 June, 2006, from http://ausweb.scu.edu.au/aw99/papers/mcdonald/paper.htm

McDonald, J. (2002). Is "as good as face-to-face" as good as it gets? Journal of Asynchronous Learning Networks, 6(2), 10-23.

McSporran, M., \& King, C. (2005). Blended is better. Choosing educational delivery methods. Retrieved 16 April, 2008, from http://www.coda.ac.nz/cgi/viewcontent.cgi?article=1002\&context=unitec _scit_di

Moos, R. H. (1974). The social climate scales: An overview. Palo Alto, CA: Consulting Psychologists Press.

Moos, R. H.. (1979). Evaluating educational environments: Procedures, measures, findings and policy implications. San Francisco, CA: JosseyBass.

Moran, T. J., \& Payne, M. (1998). Humanizing the integration of technology. In K. Anandan (Ed.), Integrating technology on campus: Human sensibilities and technical possibilities (pp. 43-47). San Francisco: Jossey-Bass.

Muirhead, P. (2003). Technology and maritime education and training. In M. S. Khine \& D. Fisher (Eds.), Technology-rich learning environments: A future perspective (pp. 235-254). Singapore: World Scientific Publishing.

Mumtaz, S. (2000). Factors affecting teachers' use of information and communications technology: a review of the literature. Journal of Information Technology for Teacher Education, 9(3), 319-341.

Murray, H. A. (1938). Explorations in personality. New York: Oxford University Press.

Nash, S. S. (2007). Does our "e-celebrity" culture affect e-learning? . Retrieved 26 September, 2007, from http://elearnqueen.blogspot.com/

Newby, M., \& Fisher, D. (1997). An instrument for assessing the learning environment of a computer laboratory. Journal of Educational Computing Research 16(2), 179-197.

NMIT. (2007). NMIT gets a second 'life'. Retrieved August 2007, from http://www.nmit.ac.nz/portal/TabID_3549/NewsItemID_15100/Deskto pDefault.aspx 
Noble, D. F. (1998). Digital diploma mills - the automation of higher education. Retrieved 21 September, 2007, from http://www.firstmonday.org/issues/issue3_1/noble/

NZ Ministry of Education. (2006). Enabling the 21st century learner: An Elearning action plan for schools 2006 - 2010. Retrieved 21 October 2007, from http://www.digitalstrategy.govt.nz/upload/Main\%20Sections/Confidence/ Capability/itc-strategy.pdf

NZ Herald. (2007). Virtual world hires real economist. Retrieved 19 August, 2007, from http://www.nzherald.co.nz/section/3/story.cfm?c_id=3\&objectid=104582 84\&pnum=2

OECD. (2005). E-learning in Tertiary Education. Retrieved 23 June 2006, from http://www.oecd.org/dataoecd/55/25/35961132.pdf

Oblinger, D., \& Rush, S. (Eds.). (1998). The future compatible campus: Planning, designing, and implementing information technology in the academy. Bolton: Anker Publishing Company.

Otago Polytechnic Wikieducator. (2007). Otago's Education Resource Developments. $\quad$ Retrieved 20 April, 2008, from http://wikieducator.org/Otago_Polytechnic

Palloff, R., \& Pratt, K. (2001). Lessons from the cyber-space classroom: The realities of online teaching. San Francisco: Jossey-Bass.

Pascoe, R. (2007, 26 September). The Tamagotchi experience: Caring for the virtual student. Paper presented at the NZ Applied Business Education Conference, Otago, New Zealand.

Picciano, A. G. (2007). Blended learning environments. Retrieved 30 August, 2007, from http://www.edpath.com/RITfeaturePicciano.htm

Picciano, A. G. (2006). Blended learning: Implications for growth and access Journal of Asynchronous Learning Networks, 10(3), 1-4.

Quek, C. L., \& Wong, A. F. L. (2003). Evaluating e-learning environments in Singapore. In M. S. Kline \& D. Fisher (Eds.), Technology-rich learning environments: A future perspective (pp. 285-305). Singapore: World Scientific Publishing.

Quinton, S. (2006). A brief critique on the future of learning: Assessing the potential for research. In D. L. Fisher \& M. S. Khine (Eds.), Contemporary approaches to research on learning environments: Worldviews (pp. 543-578). Singapore: World Scientific Publishing.

Rickards, T. (2003). Technology-rich learning environments and the role of effective teaching. In M. S. Khine \& D. Fisher (Eds.), Technology-rich 
learning environments: A future perspective (pp. 115-132). Singapore: World Scientific Publishing.

Rovai, A. P., \& Jordan, H. M. (2004). Blended learning and sense of community: A comparitive analysis with traditional and fully online graduate courses. The International Review of Research in Open and Distance Learning, $5(2)$.

Salazar, I. (1988). The use of qualitative data as a supplement to quantitative analysis of objective survey items. Retrieved 31 August, 2007, from http://eric.ed.gov/ERICWebPortal/custom/portlets/recordDetails/detailmin i.jsp?_nfpb=true\&_\&ERICExtSearch_SearchValue_0=ED294896\&ERIC ExtSearch_SearchType_0=eric_accno\&accno=ED294896

Salmon, G. (2004). E-Moderating: The key to teaching and learning online (Second ed.): Routledge.

Salmon, G. (2007). A second guess at the future. Paper presented at the Eduserv Foundation Symposium, London. Retrieved 17 April, 2008, from http://www.le.ac.uk/beyonddistance/publications.html

Seely-Brown, J. (2007). New learning environments for the 21st century. Retrieved 14 September, 2007, from http://www.johnseelybrown.com/newlearning.pdf

Shapiro, M. (2006). The irascible professor. Retrieved 12 September, 2007, from http://irascibleprofessor.com/comments-03-15-06.htm

She, H. C., \& Fisher, D. (2003). Web-based e-learning environments in Taiwan: The impact of the online science flash program on students' learning. In M. S. Khine \& D. Fisher (Eds.), Technology-rich learning environments: A future perspective (pp. 343-365). Singapore: World Scientific Publishing.

Sherifdeen, S. A. S. (2007). Challenges faced by staff and students at tertiary level in a flexible learning environment: An institutional study. Masters Thesis. Retrieved 10 April, 2008, from http://www.coda.ac.nz/unitec_scit_di/3/

Sims, R., Dobbs, G., \& Hand, T. (2002). Enhancing quality in online learning: Scaffolding planning and design through proactive evaluation Distance Education, 23(2), 135-148.

Singh, H., \& Reed, C. (2001). A white paper: Achieving success with blended learning. Retrieved 4 September, 2007, from http://www.centra.com/download/whitepapers/blendedlearning.pdf

Squire, K. (2003). Video games in education. Journal of Intelligent Simulations and Gaming, 2(1), 49-62. 
Stacey, E., \& Rice, M. (2002). Evaluating an online learning environment. Australian Journal of Educational Technology, 18(3), 323-340.

Tartwijk, J. van, Wubbels, T., Brok, P. den, \& Jong, Y. (2003). Designing a websupported learning environment on communication in multicultural classrooms. In M. S. Khine \& D. Fisher (Eds.), Technology-rich learning environments: A future perspective (pp. 255-283). Singapore: World Scientific Publishing.

Tertiary Education Commission [TEC], 2007. Risk Profiling and Assessment. Retrieved 9 April, 2008, from http://www.tec.govt.nz/upload/downloads/tamu-risk-profilingassessment.doc

Thornburg, D. D. (2000). Redefining teaching in a disintermediated world. Retrieved 18 June, 2006, from http://www.tcpd.org/Thornburg/Handouts/disintermediation.html

Tobin, K. (1998). Qualitative perceptions of learning environments on the World Wide Web. In B. J. Fraser \& K. G. Tobin (Eds.), International Handbook of Science Education (pp. 139-162). Dordrecht: Kluwer Academic Publishers.

Tobin, K., \& Fraser, B. J. (1998). Qualitative and quantitative landscapes of classroom learning environments. In B. J. Fraser \& K. G. Tobin (Eds.), International Handbook of Science Education (pp. 623-640). Dordrecht: Kluwer Academic Publishers.

Torrisi-Steele, G. (2002). 'Technology for the sake of learning' - A planning approach for integrating new technologies in tertiary learning environments. Retrieved 10 August, 2007, from http://ausweb.scu.edu.au/aw02/papers/refereed/torrisi/index.html

Trinidad, S. (2003). Working with technology-rich learning environments: Strategies for success. In M. S. Khine \& D. Fisher (Eds.), Technologyrich learning environments: A future perspective (pp. 97-113). Singapore: World Scientific Publishing.

Udas, K., \& Brown, M. (2005). Technology and distance learning. Retrieved March, 2007, from http://www.govis.org.nz/conference2005/presentations/udas-brown.ppt

Van Petegem, P., \& Donche, V. (2006). Learning environment research in higher education: Assessing patterns of learning and teaching. In M. S. Khine \& D. Fisher (Eds.), Contemporary approaches to research on learning environments: Worldwide (pp. 93-124). Singapore: World Scientific Publishing.

Walberg, H. J. (1976). Psychology of learning environments: Behavioral, structural, or perceptual? Review of Research in Education, 4, 142-178. 
Waxman, H. C., \& Chang, H. L. (2006). Mixed method approaches for examining classroom learning environments for resilient and nonresilient students in urban elementary schools. In D. L. Fisher \& M. L. Khine (Eds.), Contemporary approaches to research on learning environments: Worldviews (pp. 195-220). Singapore: World Scientific Publishing.

Wheeler, S. (2004). Five smooth stones: Fighting for the survival of higher education Distance Learning, 3(1), 11-17.

Wheeler, S. (2006). Learner support needs in online problem based learning. Quarterly Review of Distance Education, 7(2), 175-184.

Wikipedia. (2007). e-learning. Retrieved 20 September, 2007, from http://en.wikipedia.org/wiki/E-learning

Wilson, D., \& Smilanich, E. (2005). The other blended learning. San Francisco: Pfeiffer.

Young, J. R. (2002). Hybrid teaching seeks to end the divide between traditional and online instruction [Electronic Version]. The Chronicle of Higher Education, A33. Retrieved March 2002 from http://chronicle.com/free/v48/i28/28a03301.htm.

Zandvliet, D. (2003). Learning environments in new contexts: Web-capable classrooms in Canada. In M. S. Khine \& D. Fisher (Eds.), Technologyrich learning environments: A future perspective (pp. 133-156). Singapore: World Scientific Publishing.

Zhu, E., \& McKnight, R. (2006). Principles of online design. Retrieved 27 September, 2007, from http://www.fgcu.edu/onlinedesign/Intro.html

Every reasonable effort has been made to acknowledge the owners of copyright material. I would be pleased to hear from any copyright owner who has been omitted or incorrectly acknowledged. 


\section{APPENDICES}


APPENDIX A.

Web-based Learning Environment Instrument (WEBLEI) 


\section{WEB-BASED LEARNING ENVIRONMENT INSTRUMENT}

\section{Directions for Respondents}

This questionnaire contains statements related to your learning in a web-based learning environment (Moodle at EIT). You will be asked how often each practice takes place. The term "Blended" refers to the mixture of on-campus classes and online Moodle resources.

There are no 'right' or 'wrong' answers. Your opinion is what is wanted.

Think about how well each statement describes what the web-based learning environment class is like for you.

Draw a circle around

$\begin{array}{lll}\mathbf{1} & \text { if the practice takes place } & \text { Never } \\ \mathbf{2} & \text { if the practice takes place } & \text { Seldom } \\ \mathbf{3} & \text { if the practice takes place } & \text { Sometimes } \\ \mathbf{4} & \text { if the practice takes place } & \text { Often } \\ \mathbf{5} & \text { if the practice takes place } & \text { Always }\end{array}$

Be sure to give an answer for all questions. If you change your mind about an answer, just cross it out and circle another.

Some statements in this questionnaire are fairly similar to other statements. Don't worry about this. Simply give your opinion about all statements. 


\section{WEB-BASED LEARNING ENVIRONMENT}

For each statement, please circle the number which best represents your answer.

\section{ACCESS}

$\begin{array}{ccccc}\begin{array}{c}\text { Alway } \\ \text { s } \\ 5\end{array} & \text { Often } & \begin{array}{c}\text { Sometim } \\ \text { es }\end{array} & \text { Seldom } & \text { Never } \\ 5 & 4 & 3 & 2 & 1 \\ 5 & 4 & 3 & 2 & 1 \\ 5 & & & & \\ 5 & 4 & 3 & 2 & 1 \\ 5 & 4 & 3 & 2 & 1 \\ 5 & 4 & 3 & 2 & 1 \\ 5 & 4 & 3 & 2 & 1 \\ 5 & 4 & 3 & 2 & 1 \\ & & & & \end{array}$

\section{INTERACTION}

9. I communicate with other students in this subject electronically (email, bulletin boards, chat line).

10. In this learning environment, I have to be selfdisciplined in order to learn.

11. I have the autonomy to ask my tutor what I do not understand.

12. I have the autonomy to ask other students what I do not understand.

13. Other students respond promptly to my queries.

14. I would find it difficult to study on this course without regular interaction with the Moodle resources.

15. I regularly interact with Moodle (at least twice a week).

$\begin{array}{ccccc}\begin{array}{c}\text { Alway } \\ \text { s }\end{array} & \text { Often } & \begin{array}{c}\text { Sometim } \\ \text { es }\end{array} & \text { Seldom } & \text { Never } \\ 5 & 4 & 3 & 2 & 1 \\ 5 & 4 & 3 & 2 & 1 \\ 5 & 4 & 3 & 2 & 1 \\ 5 & 4 & 3 & 2 & 1 \\ 5 & 4 & 3 & 2 & 1 \\ 5 & 4 & 3 & 2 & 1 \\ 5 & & & & \\ 5 & 4 & 3 & 2 & 1 \\ 5 & 4 & 3 & 2 & 1\end{array}$

16. I felt there was an "online community" with other students on the course. 


\section{WEB-BASED LEARNING ENVIRONMENT (CONT)}

\section{RESPONSE}

$\begin{array}{ccccc}\begin{array}{c}\text { Alway } \\ \text { s }\end{array} & \text { Often } & \begin{array}{c}\text { Sometim } \\ \text { es }\end{array} & \text { Seldom } & \text { Never } \\ 5 & 4 & 3 & 2 & 1 \\ 5 & 4 & 3 & 2 & 1 \\ 5 & 4 & 3 & 2 & 1 \\ 5 & 4 & 3 & 2 & 1 \\ 5 & 4 & 3 & 2 & 1 \\ 5 & 4 & 3 & 2 & 1 \\ 5 & 4 & 3 & 2 & 1 \\ 5 & 4 & 3 & 2 & 1 \\ & & & & \end{array}$

17. This mode of learning enables me to interact with other students and the tutor asynchronously (e.g. Forum \& email).

18. I felt a sense of satisfaction and achievement about this learning environment.

19. I enjoy learning in this environment (Moodle).

20. Moodle is no substitute for on-campus classes.

21 . It is easy to organise a group for a project.

22. It is easy to work collaboratively with other students involved in a group project.

23. The web-based learning environment held my interest throughout my course of study.

24. I felt a sense of boredom with the online material towards the end of my course of study.

\section{RESULTS}

$\begin{array}{ccccc}\begin{array}{c}\text { Alway } \\ \text { s }\end{array} & \text { Often } & \begin{array}{c}\text { Sometim } \\ \text { es }\end{array} & \text { Seldom } & \text { Never } \\ 5 & 4 & 3 & 2 & 1 \\ 5 & 4 & 3 & 2 & 1 \\ 5 & 4 & 3 & 2 & 1 \\ 5 & 4 & 3 & 2 & 1 \\ 5 & 4 & 3 & 2 & 1 \\ 5 & 4 & 3 & 2 & 1 \\ 5 & 4 & 3 & 2 & 1 \\ 5 & 4 & 3 & 2 & 1\end{array}$




\section{OPEN-ENDED COMMENTS}

Please write your responses in the space provided below. Your comments could provide an explanation of previous responses and/or additional information you may wish to provide.

1. Why are you studying in an on-line/blended mode?

2. What are the advantages of studying in an on-line/blended mode?

3. What are the disadvantages of studying in an on-line/blended mode?

4. Are they any suggestions to improve the delivery of your courses in an on-line/blended mode?

5. Do you prefer traditional classes and lectures with paper-based Workbooks and reference materials?

Please circle the following choices:

Gender: $\quad M \quad F \quad$ Age Group: $16-20 \quad 21-25 \quad 25-40 \quad 40+$

Faculty/School: IT Business

Year of study: Year1 Year2 Year3

Type of Programme: Degree Diploma Certificate 
APPENDIX B.

Staff Email Discussion Questions 
Hello to all staff @ EIT,

This is a request for some emailed comments from you regarding e-learning and blended learning. My name is David Skelton, IT Lecturer @ EIT, and I am currently completing a Doctorate in Science Education through Curtin University of Technology, Perth.

My thesis is looking at recommending an optimal 'mix' of traditional and online/flexible learning environments in the tertiary sector. I have completed an extensive survey of our EIT students regarding their experience of our online \& classroom environments.

I am now interested in your opinions, ideas \& experiences on what you see as the "ideal" learning environment @ EIT (or tertiary). The following are my formal research questions - but feel free to make any comment around this general area. I would be very interested in Non-teaching staff comments as well as lecturers etc.

Questions:

What elements help construct an ideal or optimal blended learning environment in a tertiary setting? How can the best components of online e-learning be combined with the best components of the traditional 'bricks and mortar' classroom learning environments? Is there an ideal mix of the two types of environments?

Does e-learning in some forms or implementations actually undermine or damage the 'real-world' learning environment? Are we simply forced by the trends and rise of Internet activity to 'jump on board' regardless of the cost to academic quality and sense of community?

Just email me your informal comments by return email. Your replies will be kept anonymous and confidential. All recorded data will be stored by Curtin University of Technology. My Supervisor is Darrell Fisher, [d.fisher@curtin.edu.au], Curtin University of Technology. I am happy to share my findings and work with any interested staff - my thesis will be available in the Twist Library in 2008.

Looking forward to your ideas \& experiences,

David

David Skelton, MIS

Senior Lecturer - Information Technology

Eastern Institute of Technology

P 974-8000 X 5457

dskelton@eit.ac.nz 
APPENDIX C.

The Eastern Institute of Technology e-learning strategy 


\section{Eastern Institute of Technology E-Learning Strategy}

\section{Executive Summary}

\section{E-learning can strengthen teaching and learning at EIT, and strengthen EIT as an institution. That is the vision, and the ultimate goal, of this strategy.}

The strategy defines e-learning and other common terms used in association with learning that uses technologies and communication tools. E-learning is defined as 'teaching and learning that takes advantage of all available resources, techniques and technologies’.

The key to successful e-learning is effective instructional design.

Successful e-learning requires a commitment to using technology to support (rather than interfere) with teaching and learning excellence. E-learning creates opportunities to be innovative in teaching, and to further personalise the learning experience.

Individuals and organisations must change to take advantage of the opportunities created by elearning. Consultation and participation in e-learning development and implementation is essential if its full potential is to be realised. This strategy, and the associated annual action plans, will steer discussion on teaching and learning at EIT. The strategy and plans will be reviewed regularly.

EIT’s vision for e-learning will be driven by the following missions:

A. E-learning will strengthen teaching and learning by:

1. being integrated into an holistic EIT Teaching and Learning Strategy

2. responding to learner needs

3. adapting to learning styles and preferences

4. adapting to a variety of instructional strategies and techniques

B. E-learning will strengthen EIT by:

1. responding to market desires for online programmes

2. making effective use of sector resources such as tools, programmes, grants

3. continually improving institutional ways of working together.

4. enabling staff to develop scholarship in teaching practices.

The success of this e-learning strategy depends on the participation of staff from a wide range of departments, and on leadership by Executive and Management group. The e-learning advisor plays a pivotal role and will work within existing EIT organisational structures to communicate and implement the strategy.

\section{E-learning can strengthen teaching and learning at EIT, and strengthen EIT as an institution. \\ That is the vision, and the ultimate goal, of this strategy.}




\section{INTRODUCTION}

The key components of this strategy are the vision and mission: the vision names our goals, and the mission describes how we will achieve those goals. All other sections support the vision and mission.

The brief history of e-learning arguably includes more failures than successes. In many cases, converting traditional classroom delivery to online delivery has been detrimental to teaching and learning. But failure is not inherent in the technologies E-learning solutions can strengthen teaching and learning.

The key to successful e-learning is design - including the design of:

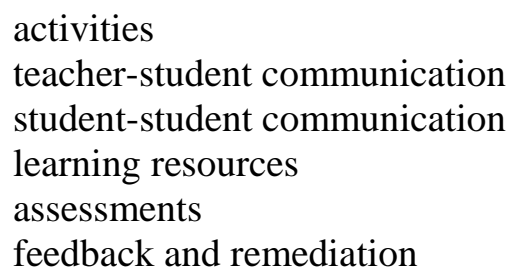

... and of all the other instructional design considerations that are part of the teaching and learning process. These issues are independent of technology, although technology - in the case of elearning - is used to facilitate and mediate. Success with e-learning requires a belief or commitment that using technology will not interfere with teaching and learning excellence. What we believe about teaching, learning and e-learning is self-fulfilling. Therefore, we must think carefully about what we believe.

\section{DEFINING OUR TERMS}

In order to clearly communicate our thoughts and intentions for e-learning, we must define the following commonly used terms.
E-learning
Flexible delivery
Blended learning
Web-enhanced learning
On-line learning
Social software
Distance learning
Correspondence learning

E-learning is teaching and learning that takes advantage of all available resources, techniques and technologies. The "e" typically stands for "electronic" or "internet-enabled" (as in eBusiness or eGovernment) but can also be "enhanced." E-learning is not confined to using computers and the internet, although those tools are the most popular. E-learning is an alternative to - or added to traditional classroom instruction, where students gather at a particular time and place for class sessions. E-learning differs from traditional classroom learning in one or two ways, depending on its implementation:

1) E-learning enables remote learning by using the internet and other media communication technologies (such as mobile technologies) to connect learners with learning materials, 
teachers, other learners and institutions. This is the telecommunications side of elearning.

and / or

2) E-learning uses computer and media communications technology (such as CDs and DVDs) to enhance learning experiences. It may use simulations, interactive multimedia, interactive case studies and online, scenario-based learning. This is the programmed instruction or computer-based learning side of e-learning.

Flexible delivery is a learner-centered approach to education that covers all learning modes, and provides increased choice to the learner (time, place, access, learning method, mode, tools, pace, institution and content).

Blended learning is the combination of instructional techniques and delivery formats, including classroom delivery and online activities. This last combination is also referred to as Web-enhanced learning.

Distance learning has been used for centuries. Learners do not physically attend the learning institution; an institution provides learning materials for the learner to study at home or at work. Modern distance learning solutions often use e-learning components.

Correspondence courses are a popular form of distance learning in which teachers and students use the traditional mail service to communicate. Students study print-based materials. E-learning replaces the mail service with the internet, and replaces print materials with digital learning resources. However, many online courses still include mailed print materials, CDs or DVDs as part of their resources.

Online learning describes the parts of the teaching and learning process that occur on a computer network - usually, the internet.

Social software refers to the communication capabilities of software, particularly those features that enable discussion, such as online forums and chat rooms.

The following table shows some online tools used to facilitate common teaching/learning processes:

Teaching/Learning Processes

lectures, presentations, demonstrations

group discussion

assessments

teacher-student communication

\section{Online Learning Tools}

$\longrightarrow$ PowerPoint and other media files, blogs, podcasts

$\rightarrow \quad$ chat rooms, discussion forums, wikis, e-mails

$\longrightarrow \quad$ on-line quizzes and tests

$\rightarrow \quad$ e-mail, wikis, mobile technologies 
Courses that use these online techniques, and where students do not meet together in classrooms, we will call Online Courses. However, such courses often include some face-to-face meetings (particularly at the start of the course) to enhance the social community of learning.

Given the kinds of learning described above, the range of delivery modes can be shown on a continuum.

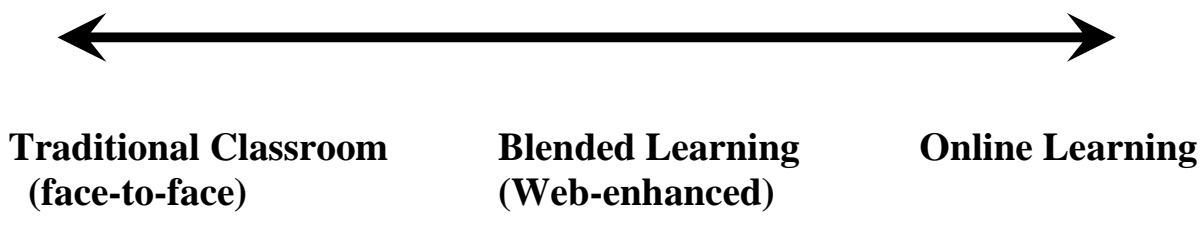

\section{VISION}

Our vision is for EIT to become an outstanding example of how e-learning can:

1) strengthen teaching and learning, and

2) strengthen EIT as a learning institution.

\section{MISSIONS}

We will achieve this vision by driving the following missions:

A. E-learning will strengthen teaching and learning by:

1. being integrated into an holistic EIT Teaching and Learning Strategy

2. responding to learner needs

3. adapting to learning styles and preferences

4. adapting to varieties of instructional strategies and techniques

B. E-learning will strengthen EIT by:

1. responding to market desires for online programmes

2. making effective use of sector resources such as tools, programmes, grants.

3. continually improving institutional ways of working together.

4. enabling staff to develop scholarship in teaching practices.

Each of these items will be described in the following section.

\section{A1. E-Learning in Relation to E.I.T.'s Teaching and Learning Strategy.}

How would we know that E.I.T. has a sound and effective E-learning Strategy (or a Teaching and Learning Strategy)?

1. Intention Course developers and tutors/lecturers can describe the rationale for teaching and learning activities in the classroom and online. Learner

'We are able to needs, instructional strategies, assessment strategies and other factors 


\begin{tabular}{|l|l|}
\hline $\begin{array}{l}\text { explain why we } \\
\text { did what we } \\
\text { did'. }\end{array}$ & $\begin{array}{l}\text { are used to explain activities, the learning outcomes, and the teaching } \\
\text { and learning environment. While they are not necessarily the best } \\
\text { possible choices, they are considered choices. }\end{array}$ \\
\hline $\begin{array}{l}\text { 2. Attitude. } \\
\text { 'We are } \\
\text { learning } \\
\text { continually.' }\end{array}$ & $\begin{array}{l}\text { The strategy is not a set of mandatory instructional strategies: it is the } \\
\text { attitude EIT expects toward the art and science of teaching and } \\
\text { learning. For example, all staff are expected to continually increase } \\
\text { their expertise in teaching and learning. This expectation is separate } \\
\text { from their need to keep up to date with subject content. }\end{array}$ \\
\hline $\begin{array}{l}\text { 3. } \begin{array}{l}\text { Documentation } \\
\text { and } \\
\text { Demonstration. }\end{array} \\
\begin{array}{l}\text { 'We are able } \\
\text { to measure } \\
\text { improvements } \\
\text { in our teaching } \\
\text { and learning } \\
\text { practices.' }\end{array}\end{array}$ & $\begin{array}{l}\text { 'records' of staff achievements in relation to the strategy. E-portfolios } \\
\text { and reflective journals, for example, can capture intent and attitude, } \\
\text { serve multiple purposes, including fostering critical reflection and, } \\
\text { making a teaching and learning strategy actionable and demonstrable. }\end{array}$ \\
\hline
\end{tabular}

\section{A2. Responsive to Learner Needs}

This section describes elements of an audience analysis. These factors should be considered when designing learning solutions.

\begin{tabular}{|l|l|}
\hline $\begin{array}{l}\text { WHO are } \\
\text { the } \\
\text { learners? }\end{array}$ & $\begin{array}{l}\text { Learners vary greatly in their educational backgrounds and experiences, } \\
\text { and these influence their response to educational environments. Cultural } \\
\text { backgrounds can also affect teaching and learning, as shown by recent } \\
\text { studies with Maori and Pacific learners. We can afford the shortcomings of } \\
\text { a "one size fits all” approach, or a fully individualised approach. Our } \\
\text { strategy needs to enable us to balance and respond to these factors. }\end{array}$ \\
\hline $\begin{array}{l}\text { WHERE } \\
\text { are the } \\
\text { learners? }\end{array}$ & $\begin{array}{l}\text { EIT students are geographically distributed. They live and work in a } \\
\text { variety of places can study at different times of the day. Many EIT } \\
\text { students study part time because they are already in the workplace, and } \\
\text { their lifestyle influences the design and delivery of the teaching/learning } \\
\text { process. }\end{array}$ \\
\hline $\begin{array}{l}\text { WHERE } \\
\text { are our } \\
\text { learners } \\
\text { going? }\end{array}$ & $\begin{array}{l}\text { EIT's mission includes preparing learners for the workplace. Workplaces } \\
\text { often require teamwork, and self-directed, independent learning. Modern } \\
\text { workers need to solve problems quickly and accurately. Our teaching and } \\
\text { learning strategy must prepare such workers. It goes beyond teaching them } \\
\text { 'content' and suggests activity-based learning strategies. }\end{array}$ \\
\hline
\end{tabular}

Note: There will be always be some tension between the innovative use of technology to enhance the learning process, and the need to be cost effective in course development and delivery. 
Sample Learner Profiles 2007-2010

- A teenager, technophile, constantly online, has been using a computer all their life, although in a limited fashion and with bad habits.

- A 24-year-old, with limited computer skills and bad study experiences, who wants to upskill from a menial job.

- A parent, with continuing childcare responsibility, who is returning to the workforce.

- A 45-year-old who wants to change their career, and is learning about computers.

- A Māori learner who is technically literate with mobile phones and MP3 players, but less familiar with computers.

- A rural student without broadband internet connectivity.

- An international student who faces challenges with both language and culture.

- A student who might be taking a fully online programme.

- A student with disabilities (developmental, learning)

- An older student (50s-60s), with limited computer skills, wanting to upskill because of 'younger' competition in their workplace.

- A teenager pressured by family to continue education, with low interest and motivational levels.

\section{A3. Adaptable to Learning Styles and Preferences}

Although there is little evidence assessing learning styles translates into particular, improved teaching processes, it is sensible to provide instruction in ways that satisfy multiple preferences. For example, a lecture captured in both text and audio provides a valuable choice for many learners - not because they will learn more, but because most students will have a preference for one format. There are numerous learning styles models available. Here are some examples.

\begin{tabular}{|c|c|}
\hline \multicolumn{2}{|c|}{ Learning Styles Models } \\
\hline $\begin{array}{c}\frac{\text { VISUAL }}{\text { AUDITORY }} \\
\text { KINESTHETIC / TACTILE }\end{array}$ & $\begin{array}{l}\text { ACTIVE AND REFLECTIVE } \\
\text { SENSING AND INTUITIVE } \\
\text { VISUAL AND VERBAL } \\
\text { SEQUENTIAL AND GLOBAL }\end{array}$ \\
\hline $\begin{array}{l}\text { CONCRETE AND ABSTRACT PERCEIVERS } \\
\text { ACTIVE AND REFLECTIVE PROCESSORS }\end{array}$ & $\frac{\text { MYERS BRIGGS TYPE INDICATOR }}{\text { (MBTI) }}$ \\
\hline OWARD GARDNER'S MULTIP & INTELLIGENCE MODEL \\
\hline
\end{tabular}

These, and other models, can guide the production and sequence of instructional resources.

\section{A4. Adaptable to Varied Instructional Strategies and Techniques}

There are many instructional strategies available to teachers and instructional designers. Selection of strategies for given teaching/learning situations should be considered independently of any available technology. For example, if problem-based learning is the best approach for a given subject and audience, then the availability of technology - or the need to deliver online - should not alter the strategy. Moving a course online is never an excuse to reduce interactivity and active, learner-centred instruction. 
Our strategy does not promote particular instructional strategies. Teaching staff should be regularly exposed to the breadth of available strategies as part of their ongoing professional development. Teachers should also be encouraged to explore and experiment with various techniques. Technology provides extra choices to complement existing teaching strategies.

Are there fundamental principles? Given the breadth of research and opinion, it is difficult to agree on specific principles for strong teaching and learning. The following principle is provided as a starting point for discussion.

\begin{tabular}{|l|l|}
\hline $\begin{array}{l}\text { Key } \\
\text { Principle }\end{array}$ & $\begin{array}{l}\text { Learning takes place when a learner interacts with their } \\
\text { environment (including people, places, objects and learning } \\
\text { resources) and receives meaningful feedback in response to their } \\
\text { interaction. }\end{array}$ \\
\hline
\end{tabular}

Sound learning should therefore be activity-based. The activity is immediately followed by a coaching-style interaction that includes feedback and remediation.

This premise is often watered down into lectures (in place of genuine activity) and assessments (in place of genuine feedback and remediation).

According to this principle, telling or showing the learner something is not a learning event. However, if the learner re-phrases or summarises what was said - and the presenter then confirms or corrects the learner's understanding - then a learning event has occurred.

The original telling/showing doesn't denote learning: the learner's action followed by feedback enables learning to happen.

\section{B1. Responsive to market desires for online programming}

A process has not been determined for assessing market desire for particular programmes and courses. One of the activities within the eCapability project is a marketing discussion forum during which outside consultants and EIT staff will meet to discuss this issue, share best practice and draft procedures for EIT.

\section{B2. Leading in the use of sector resources such as tools, programmes, grants}

Numerous projects and resources related to e-learning across the tertiary sector have been developed through the TEC-funded e-Learning Collaborative Development Fund (and others). Our e-learning strategy will take appropriate advantage of these. Through our involvement with the TANZ, eLearnz, and ITPNZ we plan to use existing resources as a starting point when developing new courses.

\section{B3. Continually improving collaborative activities}

Effective support of learners requires changes to ways of doing things. EIT's strategy includes evaluation of existing processes and roles to effectively support learners, and changing identified processes to recognise the importance and interconnection of all EIT's components. Support services will find ways to work more closely with faculties to enhance the learning process. 
Externally, collaborative partnerships will be more important, and networks such as TANZ will be used to develop networks of flexible provision.

\section{B4. Enabling staff to develop scholarship in teaching practices}

Staff will develop new roles and skills and may change from being expert resource providers and lecturers to being learning facilitators. Roles such as web designers, multi-media and educational designers, online facilitators, LMS administrator, and Moodle trainer will be introduced.

By reflecting on and using different technologies and activities to support learners, staff will further develop scholarship in teaching practices.

Students will also have different roles as they learn to communicate with different media. The move into e-learning requires all at EIT to respond to the changing environment.

\section{KEY WORKING RELATIONSHIPS/PARTNERSHIPS}

The success of this E-learning Strategy depends on a wide range of organisational departments, sections, and staff. The following list describes these roles.

- E-learning advisor: The arrival of the new e-learning advisor (ELA) is an appropriate time to define the responsibilities that relate to management of the learning management system (Moodle) and related activities. These include:

Creating new blank courses

Adding/editing students and tutors

Posting general announcements

Developing protocols for naming courses, continuing access by students, copying cf creating new courses, archiving, and privacy issues

Upgrading Moodle

- Innovation in Teaching and Learning Group: Coordinates this e-learning strategy with EIT’s emerging Teaching and Learning Strategy. Coordinates the teaching/learning strategies covered in e-learning professional development activities.

- IT Services: Coordinates and negotiates technological issues such as software and infrastructure needs, storage capacity, and bandwidth issues. Manages and maintains servers for Moodle and other e-learning initiatives. EIT needs a secure network, but teaching and support staff will want to use advanced social software and other technologies.. There is a tension between these two institutional needs. EIT needs a communication channel to discuss and resolve such issues in a way (and timeframe) that suits both the institution and its learners.

- Education Team: Provides discussion and feedback on e-learning policy and procedure development.

- Library: Coordinates information literacy issues for students and copyright issues for staff (among other issues to be determined). Train students to use Moodle. Staff designing an online course must discuss their resources in detail with their Library Liaison person and the e-Learning Advisor early in the design process. This will help to ensure that courses have 
the best resources available and that they meet copyright and quality standards. - The Impact Report template will be updated to include these steps.

- Staff Education and Development: Advises on staff training needs for e-learning delivery, facilitation, and incorporating e-learning into qualification requirements for the Certificate in Adult Learning. Every EIT tutor/lecturer must have the e-learning skills that they expect of their learners.

- Marketing: Coordinates the role of e-learning in marketing outreach, and measures market demand for e-learning.

- Registry, Enrolment. Coordinates online enrolments and certification processing.

- Schools/Faculties: Coordinates staff training needs and partnership in communications to teaching staff.

- Outside Consultants: Partners in programme development and staff capability.

\section{E-LEARNING TECHNOLOGIES}

\begin{tabular}{|c|c|}
\hline A. Where we are; what we have & B. Future possibilities \\
\hline \multicolumn{2}{|l|}{ Synchronous techniques (real-time) } \\
\hline $\begin{array}{l}\text { - Campus telephone system (not } \\
\text { currently used instructionally) }\end{array}$ & - Mobile phones \\
\hline - Chat Rooms (within Moodle) & $\begin{array}{l}\text { - VoIP (voice over IP / internet } \\
\text { telephony) }\end{array}$ \\
\hline - Blogs, wikis & - Video Conferencing \\
\hline \multicolumn{2}{|l|}{$\begin{array}{l}\text { Asynchronous techniques (non-real- } \\
\text { time) }\end{array}$} \\
\hline • Voice-mail & $\begin{array}{l}\text { - Creating pod-casts, other audio } \\
\text { files, and video }\end{array}$ \\
\hline - E-mail & $\begin{array}{l}\text { - Recording synchronous events } \\
\text { for asynchronous playback }\end{array}$ \\
\hline \multicolumn{2}{|l|}{ - Discussion Forums (within Moodle) } \\
\hline \multicolumn{2}{|l|}{ Interactive modules (within Moodle) } \\
\hline $\begin{array}{l}\text { - Lessons and assignments (as called } \\
\text { in Moodle ) }\end{array}$ & $\bullet$ \\
\hline - Quizzes, tests & $\bullet$ \\
\hline - Questionnaires, surveys & $\bullet$ \\
\hline$\bullet$ & $\bullet$ \\
\hline \multicolumn{2}{|l|}{ Other tools } \\
\hline $\begin{array}{l}\text { - Scenario-based e-learning tool } \\
\text { (PBLi project) }\end{array}$ & \\
\hline
\end{tabular}




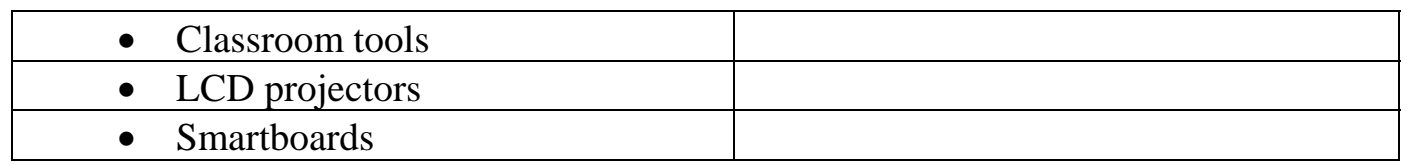

\section{COMMUNICATION (SHARING AND REINFORCING THE STRATEGY AND RELATED IDEAS)}

The e-learning advisor will work with the Director, Academic and Student Services, and other Executive members to determine the best approach for:

A. Communicating the e-learning vision, mission, strategy

B. Publicising and creating professional development opportunities

C. Showcasing examples of best practice

D. Monitoring trends in technologies and providing information on these to staff to take up as appropriate.

\section{Financial Planning ANd Resources}

The budget outlined below supports building competencies and capabilities to design, develop, and deploy best practice e-learning services and materials. A basic set of tools is proposed, along with a small but dedicated physical space. Technology requirements will be discussed with appropriate budget owners (such as Academic Section, IT Services, Faculty, and Human Resources) and a business case will be built for the purchases.

\begin{tabular}{|c|c|c|}
\hline & Description & Budget \\
\hline $\begin{array}{l}\text { Dedicated } \\
\text { Space/Studio }\end{array}$ & $\begin{array}{l}\text { To support audio-visual recording, e.g. } \\
\text { Narration } \\
\text { Audio lectures } \\
\text { Talking-head clips } \\
\text { Dedicated space, about } 16 \mathrm{~m}^{2} \text {, windowless interior } \\
\text { room }\end{array}$ & \\
\hline $\begin{array}{l}\text { Dedicated } \\
\text { Equipment }\end{array}$ & $\begin{array}{l}\text { Development level workstation } \\
\text { Large hard drive and memory, fast processor } \\
\text { CD/DVD burners } \\
\text { Firewire port for video capture } \\
\text { Cross-platform functionality (PC and Mac) } \\
\text { Multiple monitors }\end{array}$ & $\$ 10,000$ \\
\hline E-learning tools & $\begin{array}{l}\text { Equiv. of Adobe Creative Suite } \\
\text { Equiv. of Macromedia Suite }\end{array}$ & $\$ 5,000$ \\
\hline \multirow[t]{2}{*}{ Misc. Equipment } & $\begin{array}{l}\text { High-consumer-level mini-DV video camera } \\
\text { High quality digital (still) camera }\end{array}$ & $\$ 3,000$ \\
\hline & $\begin{array}{l}\text { Microphones (2) } \\
\text { Headphones (2) } \\
\text { cables and adapters } \\
\text { Green screen } \\
\text { Small light kit }\end{array}$ & $\$ 2,000$ \\
\hline
\end{tabular}




\section{RISK MANAGEMENT}

\begin{tabular}{|c|c|}
\hline Area of Risk & Managing Risk \\
\hline $\begin{array}{l}\text { Insufficient technical } \\
\text { literacy of students }\end{array}$ & $\begin{array}{l}\text { - Tutors identify such students as early as possible. } \\
\text { - Provide sound orientation for all students - both on-campus (for students } \\
\text { who can attend an orientation programme) and online } \\
\text { - develop user-friendly instructions for distance students to log-in to the LMS } \\
\text { - Provide technical help-line (either help-desk or tutorial) particularly in the } \\
\text { first } 4 \text { weeks of course. Provide support such as additional classes, coaching } \\
\text { and other assistance on computer skills, including telephone support. To be } \\
\text { determined: who, where, when, how. } \\
\text { - Provide tutors with the capability and confidence in the LMS to give basic } \\
\text { support themselves. }\end{array}$ \\
\hline $\begin{array}{l}\text { Technology } \\
\text { unavailable to students } \\
\text { eg - broadband } \\
\text { availability to students }\end{array}$ & $\begin{array}{l}\text { Specific software and technological specifications must be clear in the pre- } \\
\text { enrolment information. } \\
\text { Tutors and development teams should not create/deploy resources that require } \\
\text { specific technology (such as broadband) unless other arrangements for delivery } \\
\text { are also made, (for example, mailing CDs or DVDs). } \\
\text { Resources can be optional enhancements to learning rather than essential } \\
\text { components. }\end{array}$ \\
\hline $\begin{array}{l}\text { Support staff } \\
\text { adaptation to growth in } \\
\text { e-learning }\end{array}$ & $\begin{array}{l}\text { Each support service must determine the impact of e-learning (particularly on- } \\
\text { line learning) on their service delivery and draft a plan for response. } \\
\text { Monitor trends in Impact Reports for new and changed courses and } \\
\text { programmes. }\end{array}$ \\
\hline
\end{tabular}

\section{KEY ACTIVITIES AND INITIATIVES FOR 2007-9}

Because an e-learning strategy must remain alive and up to date, this section focuses on activities planned for the next year (2007-08). Our 2007-2009 e-learning plan should be revised annually.

In this section, we describe the following activities:
A. The eCapability Project
B. Maximising Staff Capability
C. Course/Programme Development Assistance
D. Staff Readiness for Online Delivery
E. Developing and Maintaining Policies and Procedures

\section{A. The eCapability Project}

E.I.T. is a direct participant in this project, which is managed by ITPNZ. The purpose of the project is to increase the institution's e-learning capabilities by:

1. Facilitating an analysis to benchmark current capabilities 
2. Facilitating professional development activities to build capabilities in agreed areas by using external consultants.

3. Completing a follow-up benchmarking exercise to determine the increase in capability

Professional development activities include project funding for 20 consultant days. Most of these days will be used to facilitate discussions on key topics. These topics are detailed in Appendix A.

Events in 2007 may include presentations, round-table forums, workshops or working sessions on the following topics:

Build learning design capability of wine and viticulture degree lecturers through group and 1:1 sessions.

Online teaching and facilitation including synchronous and virtual classroom tools; and integrating chat in courses

Advanced e-learning techniques including mobile learning, digital storytelling, audio technologies

M-learning (mobile)

Marketing issues

E-learning and campus physical design (podcast)

Games and virtual worlds in education

Develop and gain approval for institute e-learning processes and practices.

\section{B. Maximising Academic Staff Capability}

As well as the eCapability project efforts, e-learning capability development will include the following delivery modes and methods:

1. Rotating topics workshops

2. Coaching and mentoring as needed

3. E-learning orientation for new teaching staff

4. Moodle skills for on-line learning

1. Rotating topics workshops. The professional development calendar for 2007 ( $1^{\text {st }}$ semester) includes the following:

Open / drop-in Moodle and e-learning sessions

Come by and work on your course site or projects with help close by. First and third

Fridays of each month.

\section{Advanced Moodle workshops}

We will cover techniques that are often placed in the "too hard" basket, including wikis, lessons, quiz formats and other techniques. E-mail the e-learning advisor ahead of time to propose specific topics.

\section{Moodle for administration staff}

Have you been tagged to manage Moodle pages? This session will cover a wide range of features and techniques. Bring your questions and challenges.

2. Informal coaching and mentoring. The e-learning advisor will provide help-desk style assistance to staff as needed. If necessary, projects will be prioritised in consultation with the Executive. 
3. E-Learning orientation for new teaching staff. Human Resources notify the e-learning advisor by email when new staff members join EIT. The e-learning advisor then sends an e-mail of introduction to the new staff, advising that the e-learning advisor can assist them, and inviting them to meet to assess immediate needs.

\section{Course/Programme Development Assistance}

A development process for converting courses in the Bachelor of Wine and Bachelor of Viticulture from traditional and correspondence delivery to online delivery was started in early 2007. The process includes fortnightly design workshops facilitated by the e-learning office. The first five courses for the online programme will be ready for delivery in 2008.

These workshops focus on redesigning classroom activities and assignments into the strongest form of active learning that we can collectively design. They include specific techniques of feedback and remediation.

The design process includes the following steps:

1) Specify the relevant learning outcomes (Objectives)

2) Describe how to assess these outcomes (Assessments)

3) Determine the activities that will allow learners to demonstrate their knowledge or competencies related to these outcomes (Activities)

4) Provide clear expectations and instructions that will guide learners through the unit of work, link and explain resources, and fill gaps that are not covered by resources elsewhere (Topics and Themes)

5) Determine the most appropriate technical methods for providing feedback and remediation to the learner. (Interaction between Tutor and Learner)

6) Implement the above decisions in ways that are consistent with established standards and best practice (these to be determined during the early design workshops)

The OTARA model, in the following chart, may be used to facilitate this process:

\begin{tabular}{|l|l|l|l|l|}
\hline $\begin{array}{l}\text { Learning / } \\
\text { Performance } \\
\text { Outcomes and } \\
\text { objectives }\end{array}$ & $\begin{array}{l}\text { Topics of } \\
\text { study }\end{array}$ & $\begin{array}{l}\text { Activities: } \\
\text { techniques } \\
\text { to support } \\
\text { active } \\
\text { learning }\end{array}$ & $\begin{array}{l}\text { Resources to } \\
\text { enable students to } \\
\text { achieve learning } \\
\text { outcomes: } \\
\text { techniques to } \\
\text { access information } \\
\text { to achieve the } \\
\text { outcomes }\end{array}$ & $\begin{array}{l}\text { Assessment: } \\
\text { techniques to } \\
\text { provide feedback } \\
\text { and remediation }\end{array}$ \\
\hline
\end{tabular}

\section{Staff Readiness for Online Delivery}

D1. Tutors. As new courses and programmes are developed for online delivery, the teaching staff, heads of school and the e-learning advisor will collaboratively assess the readiness of teaching staff to deliver online learning. The outline below shows the skill set for this assessment. Staff development will be provided as needed.

Staff release time to learn new skills and design and develop new and updated courses needs to be addressed practically by all involved. Reality dictates the outcomes... even if release time is 
available, the Heads of School and individual staff need to make sure that time is not consumed by other activities. Staff need to know how much time is available before they can have constructive discussions with the e-learning advisor to assess which of the following strategies and developments are manageable. One option is that an extended plan is used where parts of a course, and activities, are introduced over several semesters. Programme Coordinators can assist in drawing up a list of priorities for development so the whole development plan is achievable.

\begin{tabular}{l} 
Assessment of Staff Readiness for Online Delivery \\
\begin{tabular}{|l|l|}
\hline Teaching and Learning & $\begin{array}{l}\text { Pedagogical comparison: traditional vs. online } \\
\text { Online }\end{array}$ \\
& $\begin{array}{l}\text { Translating traditional teaching skills to online skills } \\
\text { Discussions of theory, best-practice, biases }\end{array}$ \\
\hline $\begin{array}{l}\text { Facilitation Skills and } \\
\text { Techniques for Online } \\
\text { Tutors }\end{array}$ & $\begin{array}{l}\text { Nurturing participation } \\
\text { Communications plans } \\
\text { Fostering self-directed, independent learning } \\
\text { Providing feedback and remediation }\end{array}$ \\
\hline $\begin{array}{l}\text { Designing Activities, } \\
\text { Assignments and }\end{array}$ & Collaboration and group work \\
Courses & Synchronous and asynchronous activities \\
& Considering all media types \\
\hline Moodle: & Practice simulations \\
\hline
\end{tabular} \\
\hline
\end{tabular}

D2. Support Staff. Support services across the institution will need to adapt to the increase in online learning students as this will affect the services they provide for these students. Learning Services, Enrolments, IT Services, Marketing, Disability Services, Library, and the Bookshop, for example, need to determine the impact on their service delivery and devise a plan to respond. The Impact Report template for new and revised courses must be amended to include the effect of online students on support services.

\section{E. Develop and Maintain Policies and Procedures}

A change in delivery mode is considered a significant change and must meet TEC rules before funding will be approved. In 2007 policies and procedures will be developed, using those specified in this section as a starting point. These policies will align with the approval for major changes to courses and programmes, and with the approval for new programmes. The eLearning Guidelines and work from TANZ partners will be used to support this process.

It is proposed that procedures are developed to cover any change in delivery mode that moves away from the classroom. The procedures may be divided into those courses for which the delivery method primarily uses traditional techniques, and those for which the primary delivery is online.

Proposed Procedures for online learning design and development

\begin{tabular}{|l|l|}
\hline Stage & Requirement \\
\hline 1. Idea & $\begin{array}{l}\text { Initial consultation with e-learning advisor } \\
\text { Discussion and evaluation of staff readiness for online tutoring } \\
\end{array}$ \\
& $\begin{array}{l}\text { Discussion and evaluation of online activities and learner-centered } \\
\text { pedagogy }\end{array}$ \\
\hline
\end{tabular}




\begin{tabular}{|l|l|}
\hline & \multicolumn{1}{|c|}{$\begin{array}{c}\text { Identify the planning requirements; step through planning documents } \\
\text { and checklists; agree required steps and deadlines }\end{array}$} \\
\hline 2. Planning & $\begin{array}{l}\text { E-learning advisor assists as needed during planning. } \\
\text { Staff member meets with e-learning advisor and library liaison to discuss } \\
\text { current and potential resources }\end{array}$ \\
\hline 3. Implementation & $\begin{array}{l}\text { Goal: } 3 \text { weeks before start of delivery: } \\
\text { 1. Evaluate the planning achievements } \\
\text { 2. Evaluate staff readiness } \\
\text { 3. Evaluate online components readiness }\end{array}$ \\
\hline 4. Evaluation & Agree changes as required \\
\hline
\end{tabular}

Planning Documents. The CPIT checklists will be incorporated into EIT guidelines for eLearning. An additional step will be added to ensure the online techniques to be used to support particular learning and assessments are clear. The OTARA model described in ' $\mathrm{C}$ ' above (or an equivalent planning tool) will be used to support this.

'Techniques' should refer to specific features such as:

Forums

E-mail

Chats

Glossaries

Quizzes

Wikis

Journals

Video conference

Media files (eg audio, video, Flash, problem-based scenarios...) 